Review

\title{
Diversity of peptidic and proteinaceous toxins from social Hymenoptera venoms
}

\author{
José Roberto Aparecido dos Santos-Pinto a , Amilcar Perez-Riverol a, \\ Alexis Musacchio Lasa ${ }^{\mathrm{b}}$, Mario Sergio Palma ${ }^{\mathrm{a}}{ }^{*}$ \\ a Social Insect Study Center, Biology Department, Biosciences Institute of Rio Claro, São Paulo State University, Rio Claro, SP, 13500, Brazil \\ b Center for Genetic Engineering and Biotechnology, Biomedical Research Division, System Biology Department, Ave. 31, e/158 and 190, P.O. Box 6162, \\ Cubanacan, Playa, Havana 10600, Cuba
}

\section{A R T I C L E I N F O}

\section{Article history:}

Received 27 February 2018

Received in revised form

24 April 2018

Accepted 25 April 2018

Available online 30 April 2018

\section{Keywords:}

Hymenoptera

Venomic

Peptides

Proteins

Toxins

Allergens

\begin{abstract}
A B S T R A C T
Among venomous animals, Hymenoptera have been suggested as a rich source of natural toxins. Due to their broad ecological diversity, venom from Hymenoptera insects (bees, wasps and ants) have evolved differentially thus widening the types and biological functions of their components. To date, insect toxinology analysis have scarcely uncovered the complex composition of bee, wasp and ant venoms which include low molecular weight compounds, highly abundant peptides and proteins, including several allergens. In Hymenoptera, these complex mixtures of toxins represent a potent arsenal of biological weapons that are used for self-defense, to repel intruders and to capture prey. Consequently, Hymenoptera venom components have a broad range of pharmacological targets and have been extensively studied, as promising sources of new drugs and biopesticides. In addition, the identification and molecular characterization of Hymenoptera venom allergens have allowed for the rational design of component-resolved diagnosis of allergy, finally improving the outcome of venom immunotherapy (VIT). Until recently, a limited number of Hymenoptera venoms had been unveiled due to the technical limitations of the approaches used to date. Nevertheless, the application of novel techniques with high dynamic range has significantly increased the number of identified peptidic and proteinaceous toxins. Considering this, the present review summarizes the current knowledge about the most representative Hymenoptera venom peptides and proteins which are under study for a better understanding of the insect-caused envenoming process and the development of new drugs and biopesticides.
\end{abstract}

(C) 2018 Elsevier Ltd. All rights reserved.

\section{Contents}

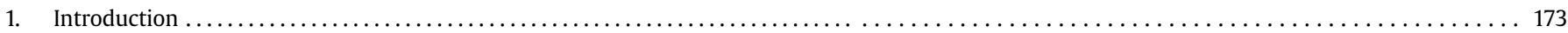

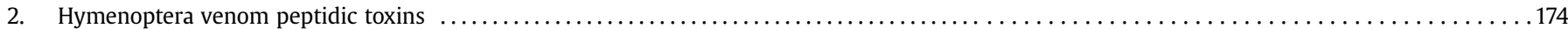

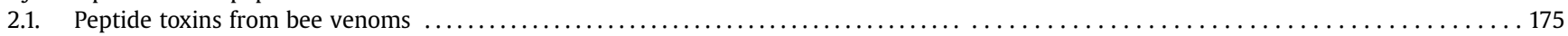

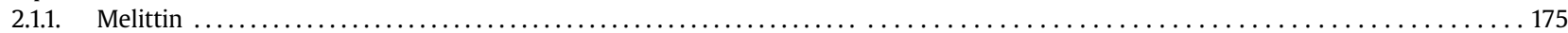

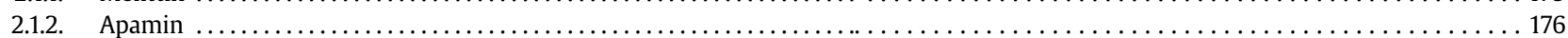

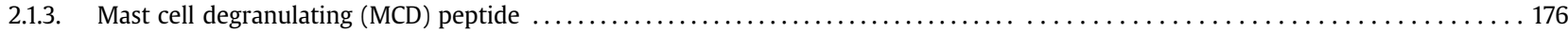

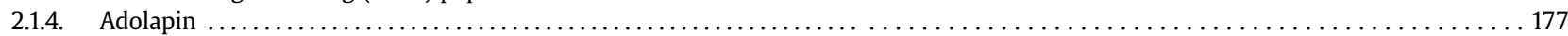

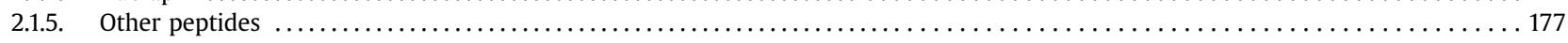

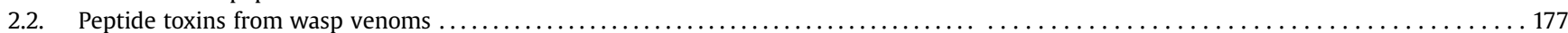

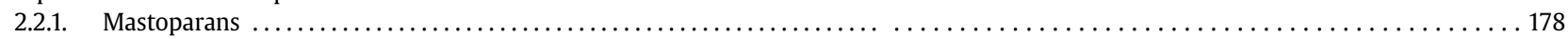

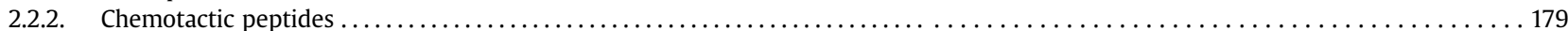

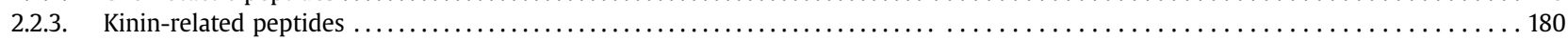

* Corresponding author. CEIS-IBRC - UNESP, Av. 24 A, 1515, 13506-900, Rio Claro, SP, Brazil.

E-mail address: mspalma@rc.unesp.br (M.S. Palma). 


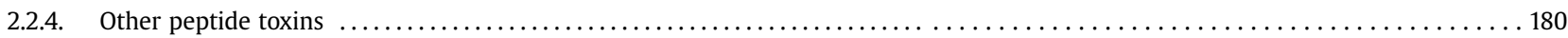

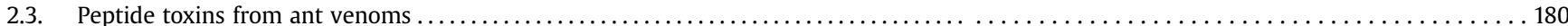

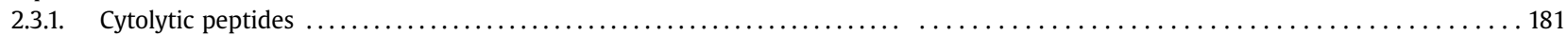

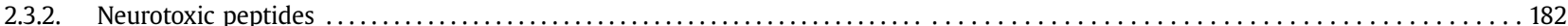

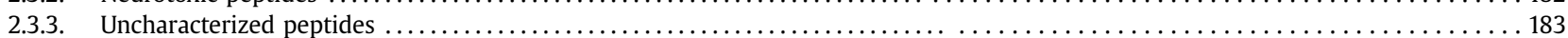

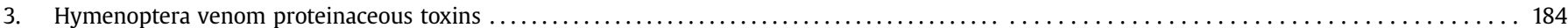

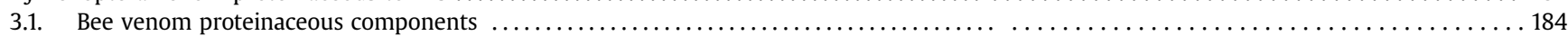

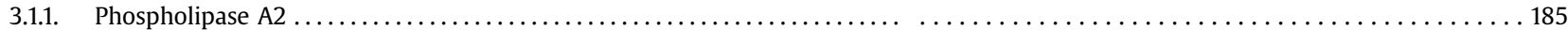

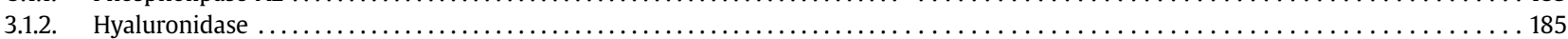

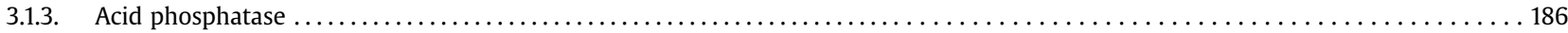

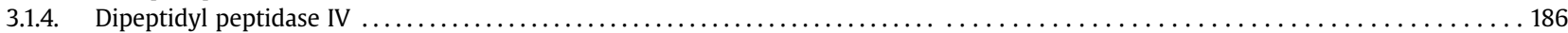

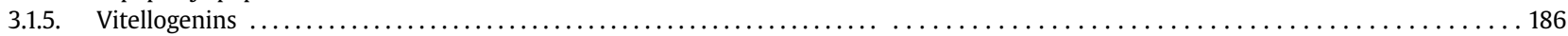

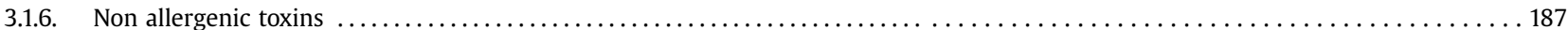

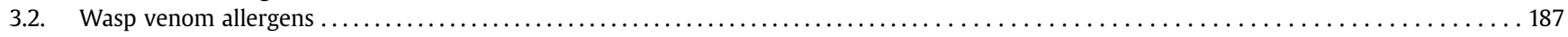

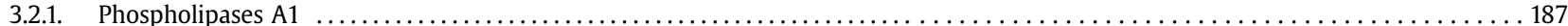

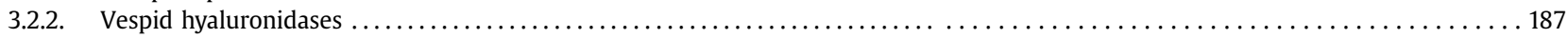

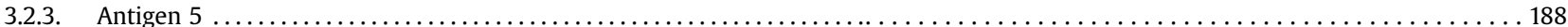

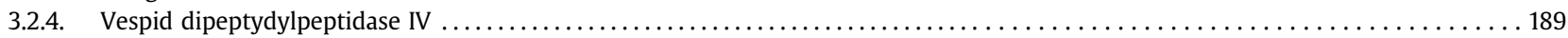

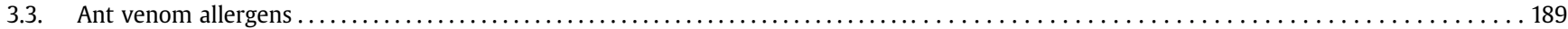

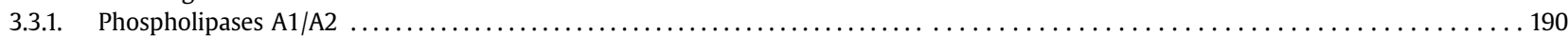

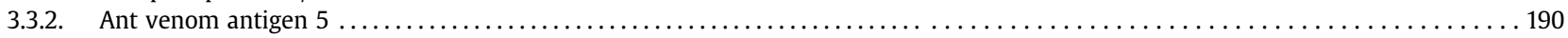

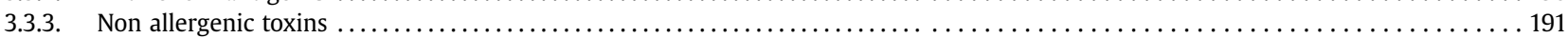

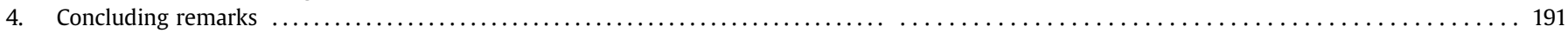

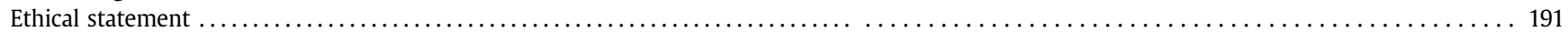

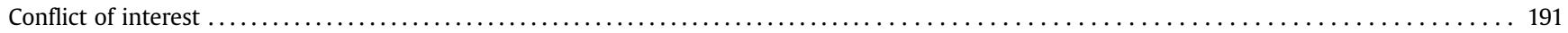

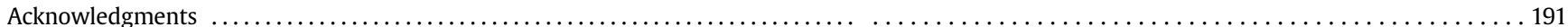

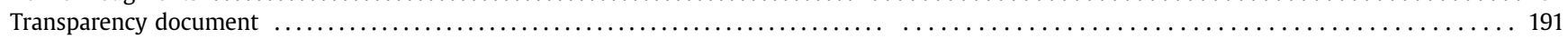

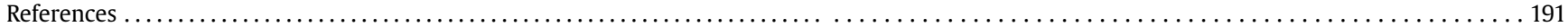

\begin{tabular}{|llll|}
\hline \multicolumn{2}{|l|}{ Abbreviations: } & PWV & paper wasp venom \\
& & PW & paper wasp \\
MCD & mast cell degranulating & VIT & venom immunotherapy \\
CNS & central nervous system & HVA & Hymenoptera venom allergy \\
NMR & nuclear magnetic resonance & CRD & component-resolved diagnosis \\
PMNLs & polymorphonuclear leukocytes & SIgE & specific immunoglobulin E \\
3-D & three-dimensional structure & PDB & Protein Data Bank \\
PLA1 & phospholipase A1 & DSSP & Define Secondary Structure of Proteins \\
PLA2 & phospholipase A2 & CD & circular dichroism \\
DPPIV & dipeptydylpeptidase IV & ICK & inhibitor cystine knot structural motif \\
HBV & honeybee venom & CCDs & Cross-reactive Carbohydrate Determinants \\
YJV & yellow jacket venom & VEGF & Vascular endothelial growth factor \\
\end{tabular}

\section{Introduction}

Social Hymenoptera is one of the most diverse group of venomous animals encompassing insects that can sting such as bees (Apoidea), wasps (Vespoidea) and ants (Scolioidea). Members of social Hymenoptera often organize their colonies in a complex social hierarchy. Venoms of these insects are natural chemical weapons evolved to be used for defense, predation and against pathogenic microorganisms (Palma, 2013). They comprise several bioactive components including low molecular weight compounds, highly abundant peptides, and allergenic proteins (Müller, 2011). These molecules may act as toxins, hormones, antibiotics, and defensins, interacting with different pharmacological targets and causing pain, inflammation, changes in blood pressure, tachycardia/ bradycardia, cardiac arrhythmia, and neurotoxicity, among other toxic effects (Dias et al., 2015; Palma, 2013).

While low molecular weight compounds and peptides from social insect venoms are often involved in limited toxic reactions, allergenic proteins cause local and/or systemic hypersensitive reactions including life-threatening anaphylaxis (Arcuri et al., 2016; Bilò, 2011; Palma, 2013; Perez-Riverol et al., 2017). According to epidemiological studies, $56-94 \%$ of the human population have been stung by a social Hymenoptera once in their lifetime with systemic reactions occurring in $0.3-7.5 \%$ of the victims (Antonicelli et al., 2002). Insect stings represent one of the three major causes of anaphylaxis accounting for up to $27 \%$ of the cases worldwide and for the $20 \%$ of the anaphylaxis-related fatalities (Bilò, 2011; Oropeza et al., 2017). Unraveling the molecular composition of Hymenoptera venoms is a mandatory prerequisite for the development of improved diagnosis tools of allergy and therapeutic interventions which reduce the impact of insect-caused envenomation in human health (Ollert and Blank, 2015).

In addition to their clinical relevance, social Hymenoptera have gained attention as a potential source of novel bioactive compounds (Perez-Riverol et al., 2017; Touchard et al., 2016a). From the perspective of molecular toxinology, the scientific interest in 
deciphering molecular composition of social Hymenoptera venom has increased due to the vast taxonomical and ecological diversity of these insects as well as the broad range of pathophysiological symptoms experienced by the victims during the envenoming process (Bouzid et al., 2013; Fitzgerald and Flood, 2006). Similar to other animal venoms, the structural and functional characterization of the insect venom components could result in rational design of antitoxins (Calvete and Lomonte, 2015) as well as novel biopharmaceuticals and biopesticides (Perez-Riverol et al., 2017; Touchard et al., 2014a).

Most of the currently characterized bioactive compounds from social Hymenoptera venoms were identified using traditional proteomic methods. For decades, several factors such as the limitation of the experimental techniques, the low amount of venom that can be extracted from each individual and the heterogeneity in the levels of venom components, have hindered the identification of novel social Hymenoptera toxins. In particular, the use low resolution approaches prevented the identification of a broad range of low abundant venom components. However, recent advances in venom toxinology based on the use of biomolecule databases, bioinformatic tools and several -omics- approaches as well as the application of high resolution techniques had helped to unravel the hidden toxin arsenal from these insects (Calvete et al., 2014; PerezRiverol et al., 2015; Van Vaerenbergh et al., 2014) (Fig. 1).

Peptides and proteins from Hymenoptera are the most abundant types of bioactives compounds currently identified in insect venoms. For instance, in honeybee, peptides and the allergen phospholipase A2 account for up to $70 \%$ and $12 \%$ of the venom dry weight, respectively of HBV (Jakob et al., 2017; King et al., 1976). Due to their high structural and functional diversity these toxins target a wide range of cellular molecules and physiological processes. Consequently, peptides from social Hymenoptera are under investigation as potential candidates for development of antimicrobial (Tonk et al., 2016a), anti-inflammatory (Lee and Bae, 2016a) and anti-tumor (Leite et al., 2015; Wang et al., 2008) drugs. Meanwhile, allergenic toxins currently identified, has allowed the development of systems for component-resolved diagnosis (CRD) of allergy, thus improving the efficacy and reliability of the VIT (Ollert and Blank, 2015; Perez-Riverol et al., 2015).

In the last decade, the combined use of traditional methods and in-depth analysis on insect venomics had remarkably increased the number of peptide and proteinaceous toxins identified. This review will summarize the available data of the most representative and thoroughly characterized venom peptides and proteins from social Hymenoptera. Although their venoms share general features in the overall composition, such as the presence of short and linear polycationic peptides and homologue allergenic proteins, several families and even species-specific toxins have been recently reported (Touchard et al., 2016a; Van Vaerenbergh et al., 2015). A vast number of studies and reviews related to the systemic action of the crude venoms, as well clinical aspects of social Hymenoptera sting accidents are available (Golden, 2007, 2017; Przybilla and Ruëff, 2010). Thus, here we will mainly focus on the venom molecular composition, the data related to structural and functional characteristics of individual components, and their putative pathophysiological role in the envenoming process. The novel toxins identified in the social Hymenoptera venom using -in depth-analyses that are under molecular characterization, will also be detailed here.

\section{Hymenoptera venom peptidic toxins}

Peptidic components from social Hymenoptera venoms have been described with a molecular weight range of 600-7000 Da, and together comprise up to $70 \%$ of the dried weight of Hymenoptera venoms. It has been demonstrated that most of these peptides have polycationic amphipathic components, presenting a
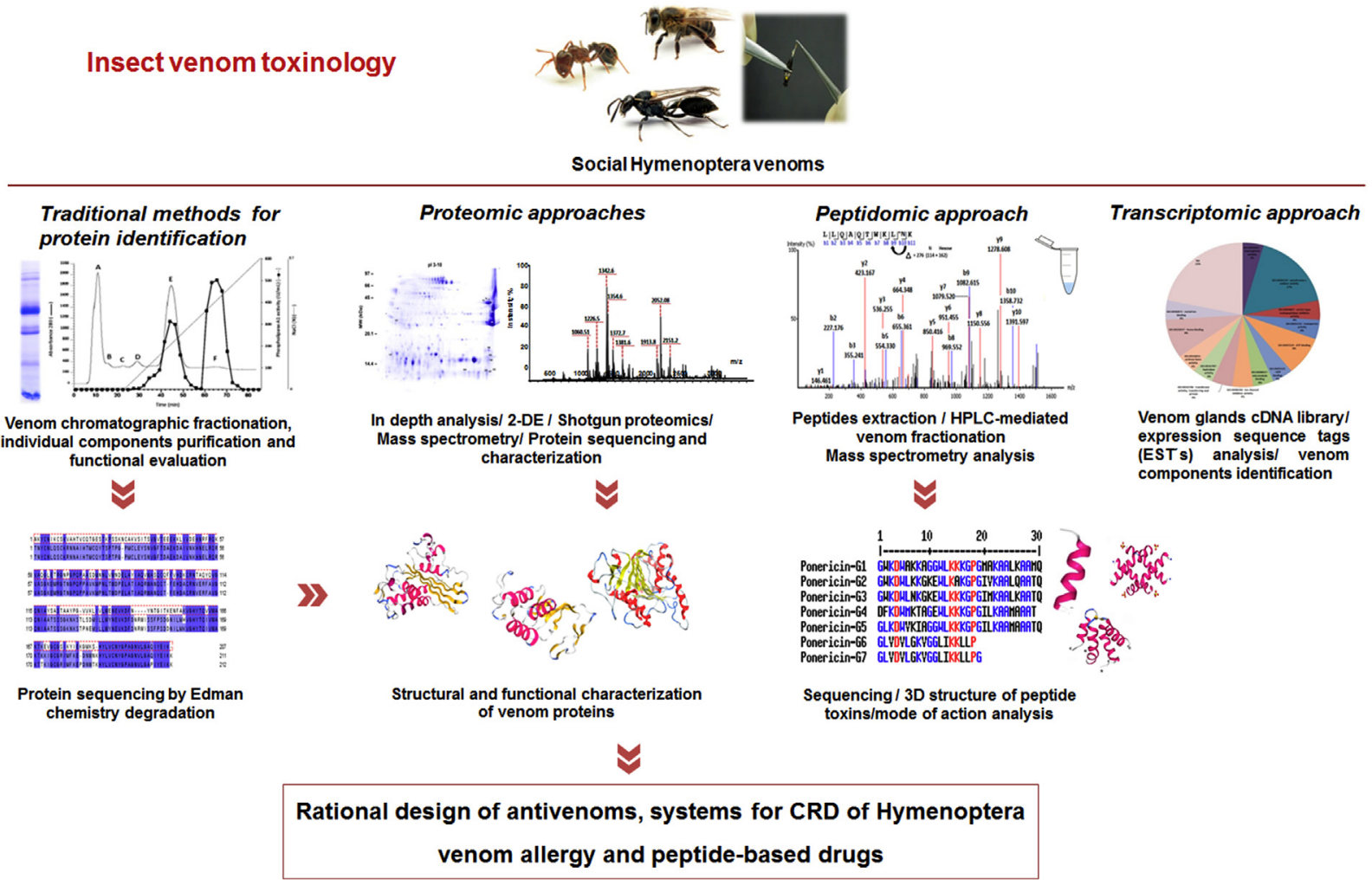

Fig. 1. Overview of the workflow used for the venomic analysis of Hymenoptera - bees, wasps and ants. 
high content of $\alpha$-helices in their secondary structures, and generally account for cell lysis, hemolysis, antibiosis, mast cell degranulation, chemotaxis of polymorphonuclear leukocytes (PMNL), smooth muscle contraction and sometimes promote the delivery of cellular activators/mediators (De Souza and Palma, 2009). The identification of peptides in these venoms is important for characterizing the pharmacological symptoms observed during the envenoming process (Dias et al., 2015).

Hymenoptera venoms have been shown as very complex samples and their chemical diversity of peptides is still not well understood. These venoms have many unknown and not very abundant molecules, which have not yet been identified, not only because of the low abundance of each individual peptide in these venoms, but also because of the limitations of the research approaches used when these studies were carried out. For years, venomic peptides studies were based on low-resolution chromatographic methods, which were able to detect only the most abundant peptide toxins (Escoubas et al., 2008a,b). Therefore, efforts have been conducted to develop new strategies to identify and characterize peptidome profiling on a large-scale in venomic research. Venom profiling is a basic approach to global venom exploration by mass spectrometry, and the recent advances in mass spectrometry techniques, using peptidomic and peptide de novo sequencing approaches, are beginning to reveal the complex composition of Hymenoptera venoms.

Several studies describe these approaches, with or without chromatographic separation, to produce a global peptidome profiling of the venoms (Calvete et al., 2007; Davis et al., 2009; Dias et al., 2015; Escoubas et al., 2008a,b; Baptista-Saidemberg et al., 2011; Jia et al., 2006). The combination of high-resolution liquid chromatograph systems with modern mass spectrometers has enabled a better understanding of the composition of Hymenoptera venoms, detecting and sequencing tiny amounts of peptides (Dias et al., 2015; jia et al., 2006).

Despite the biochemical diversity of peptide present in social Hymenoptera venoms, in this section we will highlight the current knowledge related to the best characterized peptidic toxins from bee, wasp and ant venoms. The structural features and putative biological roles from these toxins will be also detailed. Molecular and functional characterization of insect peptides have resulted in the description of novel molecular mechanisms of action and paved the way for the development of new peptide-based drugs and biopesticides.

\subsection{Peptide toxins from bee venoms}

Honeybee (Apis mellifera) venom is complex and among its chemical constituents are unique biologically active peptides such as melittin, apamin, mast cell degranulating (MCD) peptide, adolapin and other peptides. Some of these peptides present a detergent-like action on plasma membranes, causing cell lysis, while others are neurotoxins. In general, bee venom peptides are likely to act on the nervous system in both the periphery and the central nervous system (CNS) as ion channel modulators, leading to various biological, pharmacological and toxicological activities (Chen and Lariviere, 2010). A number of recent studies regarding the beneficial effects of bee venom have been reported, such as radioprotection (Gajski and Garaj-Vrhovac, 2009), anti-mutagenic effect (Varanda et al., 1999), anti-nociception (Baek et al., 2006; Yoon et al., 2015), anti-cancer (Hu et al., 2006; Huh et al., 2010; Moon et al., 2006) and anti-inflammatory effect (Kim et al., 2013; Lee and Bae, 2016b; Park et al., 2014). In the present review, the current knowledge of these peptides will be summarized and presented in individual sections.

\subsubsection{Melittin}

Melittin was separated and purified as the major component of bee venom, constituting approximately $50-60 \%$ of whole dry venom (Chen et al., 2016). This amphiphilic peptide has a linear structure and consists of 26 amino acid residues (Table 1 ), mostly with hydrophobic or at least uncharged side chains, except for the C-terminal region; and it adopts a cylindrical amphiphilic $\alpha$-helical shape which is hinged in the center (De Souza and Palma, 2009). The structure of melittin isolated from Apis mellifera venom was resolved by X-ray crystallography and deposited in the Protein Data Bank (PDB) under accession number (2MLT) (Fig. 2A). This structure indicated that residues 1 to 10 and residues 13 to 26 form $\alpha$-helixes aligned about $120^{\circ}$ to each other, while the proline residue in position 14 was suggested to be the cause of a bend in the middle of the rod structure; thus, a single polypeptide chain has the conformation of a bent alpha-helical cylinder as shown in Fig. 2A (De Souza and Palma, 2009). Due to its surfactant properties melittin is considered a direct hemolytic factor, acting synergistically with phospholipase $\mathrm{A}_{2}$, activating this enzyme (Banks and Shipolini, 1986). In high doses, melittin may cause itching, inflammation, and local pain, and has been described as the major pain-producing substance of bee venom (Raghuraman and Chattopadhyay, 2007).

Many studies report that melittin has various biological, pharmacological and toxicological effects including strong surface activity on cell lipid membranes, hemolyzing activity, antibacterial and antifungal activities (Gauldie et al., 1976; Habermann, 1972; Lariviere and Melzack, 1996) and antitumor properties (Liu et al., 2008; Oršolić et al., 2003). It was reported that melittin inhibits

Table 1

Peptide toxins identified in the venoms of honeybee (Apis mellifera) and bumblebee (Megabombus pennsylvanicus).

\begin{tabular}{|c|c|c|c|}
\hline Bee species & Peptides & Amino acid sequences & References \\
\hline \multirow[t]{3}{*}{ Apis mellifera } & Melittin & GIGAVLKVLTTGLPALISWIKRKRQQ-NH & Habermann, 1972 \\
\hline & Apamin & CNCKAPETALCARRCQQH-NH & Hugues et al., 1982 \\
\hline & Mast cell degranulating (MCD) peptide & IKCNCKRHVIK PHICRKICGKN- $\mathrm{NH}_{2}$ & Jasani et al., 1979 \\
\hline \multirow[t]{5}{*}{ Megabombus pennsylvanicus } & Bombolitin I & IKITTMLAKLGKVLAHV- $\mathrm{NH}_{2}$ & Argiolas and Pisano, 1985 \\
\hline & Bombolitin II & SKITDILAKLGKVLAHV- $\mathrm{NH}_{2}$ & Argiolas and Pisano, 1985 \\
\hline & Bombolitin III & IKIMDILAKLGKVLAHV- $\mathrm{NH}_{2}$ & Argiolas and Pisano, 1985 \\
\hline & Bombolitin IV & INIKDILAKLVKVLGHV- $\mathrm{NH}_{2}$ & Argiolas and Pisano, 1985 \\
\hline & Bombolitin V & INVLGILGLLGKALSHL- $\mathrm{NH}_{2}$ & Argiolas and Pisano, 1985 \\
\hline
\end{tabular}


A
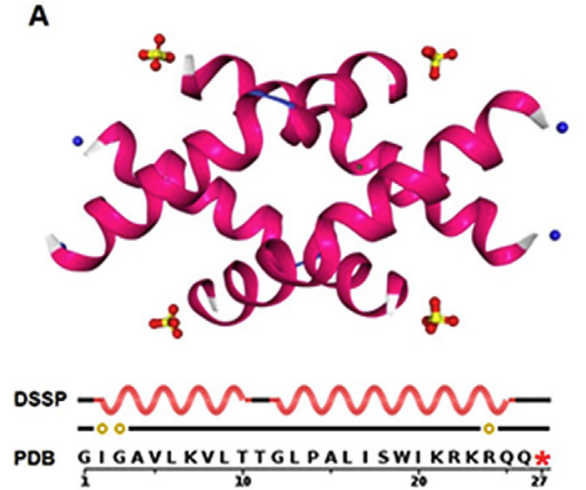

DSSP legend

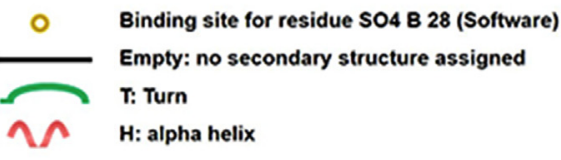

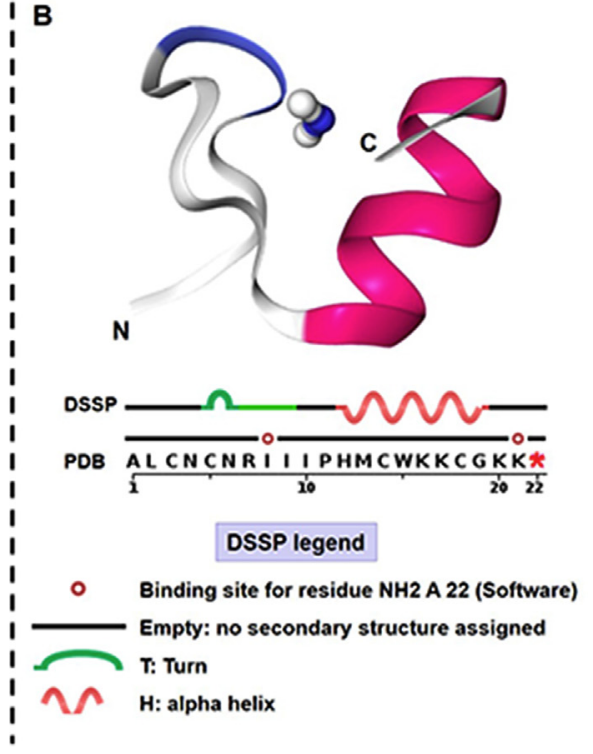

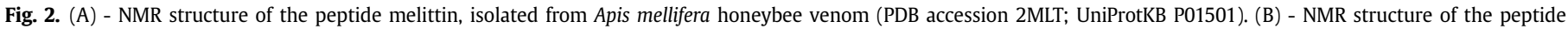
tertiapin, isolated from Apis mellifera venom (PDB accession 1TER; UniProtKB P56587). DSSP Secondary Structure (Kabsch and Sander, 1983) legend.

tumor cell growth and induces apoptosis, thereby indicating a potential application of this peptide as an alternative or complementary medication for human cancer treatment (Gajski and GarajVrhovac, 2013; Moreno and Giralt, 2015; Rady et al., 2017).

Melittin showed an antibacterial effectiveness against both Gram positive and Gram negative bacterial strains; and a significant inhibitory activity was reported against Staphylococcus aureus strains (Choi et al., 2015; Fratini et al., 2017; Issam et al., 2015). Besides that, melittin is also known as a natural poreforming peptide that can insert itself across the phospholipid bilayer, and interactions between biomembrane and proteins can be studied using this biological activity (Chen et al., 2007; Matsuzaki et al., 1997; Smith et al., 1994); and although the molecular and cellular mechanisms underlying the nociceptive and anti-nociceptive effects of melittin are not clearly defined, some studies have demonstrated that melittin can cause neural plastic changes along pain-signaling pathways by activation and sensitization of nociceptor cells (Hao et al., 2008; Yu et al., 2009; Chen et al., 2006; Li and Chen, 2004; Lu et al., 2008).

Melittin has been described as the most studied and known bee venom peptide; however its development for clinical applications remains mainly in preclinical phases; some patents and promising studies have focused on bacterial and viral infections, immunologic adjuvants, rheumatoid arthritis, cancer and endosomolytic properties for drug delivery (Lee and Bae, 2016a; Moreno and Giralt, 2015).

\subsubsection{Apamin}

Apamin is another important neurotoxic peptide with 18 amino acids residues (Table 1) comprising 2-3\% of dry bee venom (Chen and Lariviere, 2010). The CD spectroscopy study of apamin in solution is consistent with a peptide presenting an $\alpha$-helix with a high degree of stability over a wide range of $\mathrm{pH}$ values (Banks and Shipolini, 1986); and this stability is a consequence of the rigidity imposed by two disulfide bridges, while the stability in solution is not only due to the two disulfide bridges, but also due to at least seven intra chain hydrogen bonds (De Souza and Palma, 2009). It was reported that apamin selectively blocks the small conductance of $\mathrm{Ca}^{2+}$ dependent $\mathrm{K}^{+}$channels (SK channels) expressed in the central nervous system (CNS). According to Habermann (1984), this type of channel plays a crucial role in repetitive activities in neurons, blocking many hyperpolarising-inhibitory effects, including alpha-adrenergic, cholinergic, purinergic, and neurotensin-induced relaxations (Habermann, 1984; Lazdunski, 1983). If compared to other arthropod neurotoxins, apamin has the ability to cross the blood brain barrier and acts in neurons where the SK channels are extensively expressed, and control the firing frequency of neurons (Gati et al., 2012).

Studies have shown that apamin has a neuroprotective effect (Alvarez-Fischer et al., 2013), leading to memory and learning improvement by decreasing the calcium sensibility in SK channels, and it also presents neurorestorative activity in Parkinson's disease in conjunction with symptomatic and neuroprotective activity (Hartmann et al., 2016). In the Romero-Curiel et al. (2011) study, working with Alzheimer's disease it was suggested that apamin may act in the regulation of glutamatergic excitability because it causes modulation in the small conductance calcium-activated $\mathrm{K}^{+}$ channels (SK channels). In addition, in the investigations by Levin et al. (2010), it was suggested that post-hypoxic hyperexcitability in the hippocampal CA1 pyramidal neurons is inhibited in vitro by apamin (Levin et al., 2010). Due to these results, apamin is used nowadays in the method for early diagnosis of Alzheimer's disease (Jiménez-Vargas et al., 2017).

\subsubsection{Mast cell degranulating (MCD) peptide}

The mast cell degranulating (MCD) peptide is a cationic peptide with 22 amino acid residues (Table 1) that comprises 2-3\% of dry bee venom (Banks et al., 1990). The MCD peptide secondary structure was studied by $\mathrm{CD}$ and ${ }^{1} \mathrm{H}$ NMR (Habermann, 1972; Wemmer and Kallembach, 1982), which indicated a close resemblance to $\alpha$-helical peptides from positions 13 to 19. It is stable over the $\mathrm{pH}$ range $2-8$, stabilized by two disulfide bridges and six intrachain hydrogen bonds, which form a 28 -atom ring structure, also observed in apamin (Banks and Shipolini, 1986; Dotimas et al., 1987).

This peptide has been described as a potent anti-inflammatory agent, but, at low concentration it is a strong mediator of mast cell degranulation and histamine release from mast cells (Ziai et al., 
1990). Biological and pharmacological actions in the central nervous system (CNS), have demonstrated that MCD peptide has specific binding sites in the hippocampus, resulting in the production of long-term potentiation (LTP), in the distinct area from where LTP is evoked by conditioning electrical stimulation. These molecular and cellular mechanisms in the hippocampus are not clear, however some reports have demonstrated that it has selective binding sites and effects on voltage-dependent potassium channels (Chen and Lariviere, 2010).

\subsubsection{Adolapin}

Adolapin is a basic peptide with 103 amino acid residues in its sequence; it constitutes $1 \%$ of dry bee venom, and it was shown to have anti-nociceptive, anti-inflammatory and antipyretic effects (Koburova et al., 1984, 1985; Shkenderov and Koburova, 1982). Adolapin can inhibit prostaglandin. It has a potent analgesic effect and anti-inflammatory effect on rats, blocking prostaglandin synthesis via inhibition of cyclooxygenase activity. Besides that, it was also found that adolapin inhibits the activity of phospholipase A2 in bee venom; it increases the cyclic guanosine monophosphate (cGMP) level in both the rat spleen and brain and decreases the cyclic adenosine monophosphate (c-AMP) level in rat spleen. Similar to other non-steroid analgesics, adolapin has an antipyretic effect (Koburova et al., 1985).

\subsubsection{Other peptides}

In bee venom there are many other peptides that have been well characterized; however, many of them are not found in all venom samples; besides that, their presence must vary with the strain or subspecies of Apis mellifera. Some of these peptides are secapin, tertiapin, melittin F, procamin and cardiopep (Moreno and Giralt, 2015).

Secapin comprises only $0.5 \%$ of dry bee venom (Gauldie et al., 1976). This peptide has been isolated from the venom of various subspecies, such as Scapin from European A. mellifera (Vlasak and Kreil, 1984), Scapin-1 from Chinese Apis mellifera (Meng et al., 2012), and Scapin-2 from the Africanized honeybee (Moreno and Giralt, 2015); all these peptides present 25 amino acid residues and share a similar secondary structure, with a single disulfide bridge and high proline content (de Souza et al., 2009). In Mourelle et al. (2014) studies, it was demonstrated that secapin-2 can induce leukotriene-mediated hyperalgesia and edema (Mourelle et al. 2014).

Tertiapin is a very minor component of bee venom, comprising $<0.1 \%$ of the dry weight. It is a presynaptic neurotoxin of 21 amino acids (Gauldie et al., 1978; Jin and Lu, 1998), containing two disulfide bridge and a C-terminal residue in an amidated form. In the Xu and Nelson (1993) study using NMR, the 3D structure of the peptide tertiapin isolated from A. mellifera venom was determined (Fig. 2B). It has been proposed that Tertiapin has both $\alpha$-helical and $\beta$-sheet tendencies along the length of its sequence, raising the question of which conformational state the molecule is likely to be in. Considering the positions of both disulfide bridges as well as its $C D$ spectrum which has no indication of a $\beta$-sheet occurrence, the structure of tertiapin is probably analogous to that of the MCD peptide (Banks and Shipolini, 1986). This peptide blocks certain types of inwardly rectifying potassium channels. Potassium channel blockers can become the alternative nondopaminergic treatment of neurodegenerative diseases (Kitamura et al., 2000). There are a series of studies showing that tertiapin is a high affinity inhibitor for inward-rectifier $\mathrm{K}^{+}$channels (Felix et al., 2006; Jin and Lu, 1999; Kanjhan et al., 2005; Ramu et al., 2008). In addition, tertiapin is not particularly toxic in intravenous injections, it degranulates mast cells with low potency, and has been compared pharmacologically to prostaglandins under the same conditions
(De Souza and Palma, 2009).

The peptide melittin $\mathrm{F}$ was described containing 19 amino acid residues and it resembles a fragment of melittin, from which it differs in that the first seven residues of the $\mathrm{N}$-terminus are absent (Gauldie et al., 1978). Another peptide, procamine, was described as a series of smaller peptides, which possess 5 amino acid residues; these peptides have been isolated from Canadian honeybee venom, but not from the European honeybees. Like secapin and tertiapin, these molecules have low toxicity toward mammals (De Souza and Palma, 2009; Kwon et al., 2002). Meanwhile, cardiopep peptide is isolated from whole bee venom that shows beta adrenergic and anti-arrhythmic effects (Vick et al., 1974).

Besides the bee venom peptides mentioned above, there are also some peptide toxins that have been isolated from bumblebee venoms, such as bombolitins and bumblebee mast cell degranulating (MCD) peptide. Bombolitins are the most abundant component of bumblebee venom and shares structural and biological properties with melittin, a component of honeybee venom (Choo et al., 2010). They are represented by five structurally related heptadecapeptides rich in hydrophobic amino acids that were initially isolated from bumblebee Megabombus pennsylvanicus venom. Bombolitin -I, -II, -III, -IV and -V have been isolated, which are structurally and functionally very similar comprising 17 amino acid residues (Table 1) (Argiolas and Pisano, 1985). Studies have demonstrated that like melittin, bombolitin exhibits lytic properties toward erythrocytes and liposomes, and enhances phospholipase A2 activity. In addition, conformational studies have demonstrated that bombolitins fold into an amphipathic $\alpha$-helical conformation in lipophilic environments (Argiolas and Pisano, 1985; Peggion et al., 1997; Schievano et al., 2003). These peptides have been isolated also from bumblebee Bombus lapidaries venom (Favreau et al., 2006) and from Bombus ignitus venom. Bombolitin showed high antibacterial activity against two Gram-positive and two Gram-negative bacteria (Choo et al., 2010). In addition, this peptide displayed antifungal activity against the plant pathogenic fungi Fulvia fulva and Alternaria radicina.

Another peptide toxin that has been isolated from bumblebee venoms is the bumblebee mast cell degranulating (MCD) peptide. It is a 28-amino acid peptide isolated and characterized from bumblebee Megabombus pennsylvanicus venom. This peptide has the ability to degranulate rat peritoneal mast cells, and it resembles the bee venom MCD peptide; it is not lytic and releases histamine at low doses (Argiolas et al., 1985).

\subsection{Peptide toxins from wasp venoms}

Wasp venoms contain a large amount of peptides with a molecular weight range of $1.4-7 \mathrm{kDa}$, comprising up to $70 \%$ of the dried venoms (De Souza and Palma, 2009; Palma, 2013). Most of these peptides are linear, polycationic and amphipathic molecules. The identification and pharmacological characterization of the peptides in venoms are important steps in understanding the symptoms observed during the envenoming process. In social wasp venoms, peptide toxins are generally classified into families according to the type of biological activities they exhibit: (i) mastoparans, which cause mast cells degranulation; (ii) chemotactic peptides, which promote chemotaxis of polymorphonucleated leukocytes; (iii) kinin-related peptides (wasp kinins), which are known to cause pain; and (iv) other peptides toxins (Arcuri et al., 2016; Baptista-Saidemberg et al., 2011; de Graaf et al., 2009; Dohtsu et al., 1993; Lee et al., 2016a,b). Many peptides, which make up a considerable portion in solitary wasp venom, are not exactly categorized in the well-defined groups of social wasp venom peptides, as mentioned above. Thus, the present review presents and summarizes the current knowledge of known social wasp venom 
peptide toxins and their functional roles, into those four different groups, and will provide further details on solitary wasp venom peptides in a separate section.

\subsubsection{Mastoparans}

The mastoparans represent the most abundant class of peptides in venoms from both solitary and social wasps (Lee et al., 2016a,b). They are membrane-active polycationic molecules of 12-14 amino acid residues; and most mastoparans are tetradecapeptides containing from two to four $\mathrm{K}$ residues at positions $4 / 5$ and/or 11/12 and an amide C-terminal residue (dos Santos Cabrera et al., 2009). The positioning of $\mathrm{K}$ residues at these sites can contribute to flanking and maintaining stable helical chains as well as a more homogeneous hydrophobic surface for these molecules in an amphipathic structure; and this surface could contribute to the lytic activity of these peptides (de Souza et al., 2011; de Souza and Palma, 2008). In addition, the mastoparans also have antimicrobial activity and the potential to cause cytolytic action in animal cells (Dos Santos Cabrera et al., 2008); and it has been reported by Puri and Roche (2008) that these peptides play important roles in allergy and inflammation because they activate exocytosis and granule fusion with the plasma membrane, with the consequent releasing of histamine, proteases, lipid mediators and cytokines (Puri and Roche, 2008).

Several studies have demonstrated that mastoparans can act on mast cells through two different mechanisms: (i) binding to specific sites of the $\mathrm{G}_{\alpha}$-subunit of heterotrimeric $\mathrm{G}$-protein receptors, stimulating the guanine nucleotide exchange and leading to a cascade of events, including an increase in the intracellular levels of $\mathrm{Ca}^{+2}$ ions, which in turn activates a downstream cascade that results in exocytosis; and (ii) binding to specific proteins in endosomal membranes, which activates a $\mathrm{Ca}^{+2}$ - independent FceRI-mediated exocytosis pathway (Chahdi et al., 2004; Delazari dos Santos et al., 2012; Miles et al., 2004; Moreno and Giralt, 2015). Thus, mastoparans have been characterized as multifunctional toxins that are involved at different levels to produce pain, oedema and inflammation (Dias et al., 2015).

Many studies have shown the presence of mastoparans in different wasp species as shown in the summarized Table 2 In Hori et al. (2001) and Todokoro et al. (2006) studies using NMR, the 3D structures of mastoparans isolated from Vespula lewisii and Vespa xanthoptera venoms were determined, respectively (Fig. 3A-B) (Hori et al., 2001; Todokoro et al., 2006). In helical conformations, as shown in Fig. $3 \mathrm{~A}-\mathrm{B}$, mastoparans generally form amphipathic wheels, in which all lysine residues are located on the same side of the helix with the hydrophobic amino acid residues positionated in the opposite side of wheel.

Despite these studies, the chemical diversity of peptides from wasp venom is still not well understood. The levels and diversity of biological activities described for mastoparan peptides identified in this venom demonstrates that these peptides are key players during the envenoming process. Mastoparans induce histamine secretion from mast cells, oedema formation that causes pain and a remarkable physiological discomfort in predators. The detection and molecular characterization of this group of peptides partially explains several symptoms experienced by victims after a $P$. paulista sting, for example. In the $P$. paulista wasp venom six mastoparans peptides were identified such as Polybia-MP I, Polybia-MP II, Polybia-MP III, Polybia-MP IV, Polybia-MP V and Polybia-MP VI (Dias et al., 2015).

Polybia-MP I has been described as a typical mastoparan tetradecapeptide of 1654.09 Da that presents mast cell degranulation,

Table 2

Mastoparan peptides identified in the venoms of different wasp species.

\begin{tabular}{|c|c|c|c|}
\hline Wasp species & Peptides & Amino acid sequences & References \\
\hline \multirow[t]{2}{*}{ Agelaia pallipes } & Agelaia-MP I & INWLKLGKAIIDAL-NH ${ }_{2}$ & Baptista-Saidemberg et al. (2011) \\
\hline & Agelaia-MP II & INWKAILQRIKKML- $\mathrm{NH}_{2}$ & Baptista-Saidemberg et al. (2011) \\
\hline \multirow[t]{6}{*}{ Polybia paulista } & Polybia-MP I & IDWKKLLDAAKQIL-NH ${ }_{2}$ & de Souza et al. (2009) \\
\hline & Polybia-MP II & INWLKLGKMVIDAL-NH ${ }_{2}$ & de Souza et al. (2009) \\
\hline & Polybia-MP III & IDWLKLGKMVMDVL-NH ${ }_{2}$ & De Souza et al. (2005) \\
\hline & Polybia-MP IV & IDWLKLRVISVIDL-NH ${ }_{2}$ & Dias et al. (2015) \\
\hline & Polybia-MP V & INWHDIAIKNIDAL-NH ${ }_{2}$ & Dias et al. (2015) \\
\hline & Polybia-MP VI & IDWLKLGKMVM-OH & Dias et al. (2015) \\
\hline Parapolibia indica & Parapolybia-MP & INWKKMAATALKMI-NH ${ }_{2}$ & Nakajima (1986) \\
\hline Protonectarina syllveirae & Protonectarin-MP & INWKALLDAAKKVL-NH ${ }_{2}$ & Dohtsu et al. (1993) \\
\hline \multirow[t]{3}{*}{ Protopolybia exígua } & Protopolybia-MP I & INWLKLGKVSAIL-NH ${ }_{2}$ & Mendes et al. (2005) \\
\hline & Protopolybia-MP II & INWKAIIEAAKQAL-NH ${ }_{2}$ & Mendes et al. (2005) \\
\hline & Protopolybia-MP III & INWLKLGKAVIDAL-NH ${ }_{2}$ & Mendes et al. (2005) \\
\hline Vespa crabro & Mastoparan-C & INWKALLAVAKKIL- $\mathrm{NH}_{2}$ & Nakajima (1986) \\
\hline Vespula lewisii & Mastoparan & INLKALAALAKKIL-NH 2 & Hirai et al. (1979) \\
\hline \multirow[t]{3}{*}{ Vespa orientalis } & HR-I & INLKALAALVKKVL-NH ${ }_{2}$ & Nakajima (1986) \\
\hline & HR-II & FLPLILGKLVKGLL-NH ${ }_{2}$ & Nakajima (1986) \\
\hline & Mastoparan-II & INLKALLAVAKKIL-NH ${ }_{2}$ & Nakajima (1986) \\
\hline Vespa xanthoptera & Mastoparan-X & INWKGIAAMAKKLL-NH ${ }_{2}$ & Nakajima (1986) \\
\hline
\end{tabular}




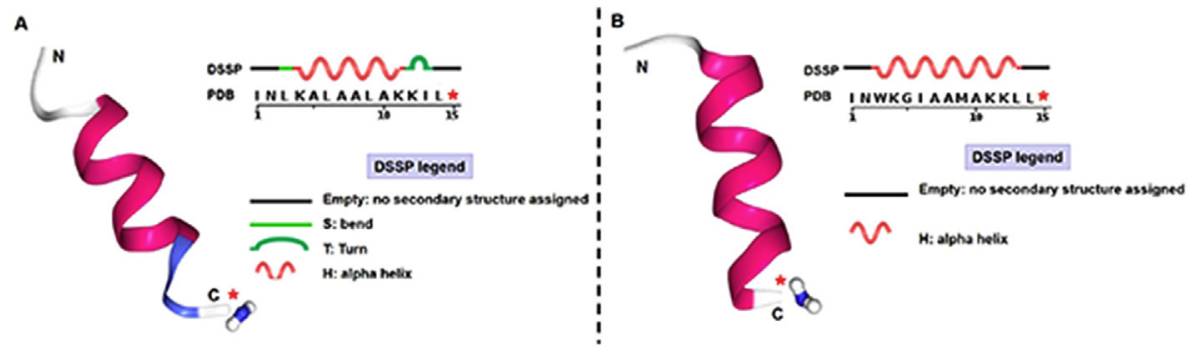

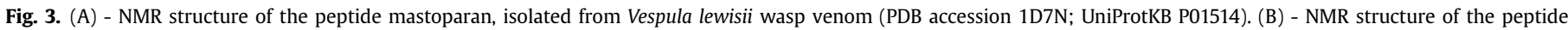

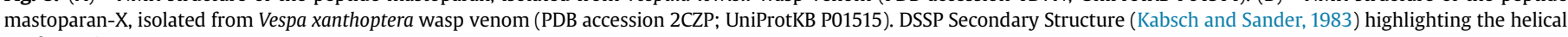
conformation.

chemotaxis to PMNLs, and has showed significant and highly selective antimicrobial activity against Gram-positive and/or negative bacteria (de Souza et al., 2009; Dias et al., 2015). According to Mendes et al. (2005) the differential interaction of this venom toxin with bacterial and red blood cells suggests it is related to the peptide structure and cell membrane composition. Thus, these findings pointed to Polybia-MP-I as an interesting candidate for the development of a potentially highly selective and effective antibiotic compound (Mendes et al., 2005). In addition, antimicrobial peptides have shown to present cytotoxic activity against diverse cancer cell lines (Tonk et al., 2016b); and the Polybia-MP I mastoparan showed highly selective cytotoxic and antiproliferative activity against prostate and bladder cancer cells, and leukemic cell lines (Leite et al., 2015; Wang et al., 2009, 2008).

\subsubsection{Chemotactic peptides}

The second most important group of peptides in venoms from both solitary and social wasps are chemotactic peptides, which generally are trideca-polycationic peptides with primary sequences resembling the mastoparans in regards to the richness of hydrophobic amino acid residues and the amidation of the C-terminal residue (Nakajima, 1986). These peptides cause massive recruitment in polymorphonuclear leukocytes (PMNLs), inducing them to deliver large amounts of oxygen peroxide around the site of wasp stings. The resulting hyperoxidative environment induces local inflammatory responses, cell death and pain (Palma, 2013). The chemotactic peptides do not cause pain directly, but play an important role enhancing the inflammatory effect caused by wasp stingings. A novel type of chemotactic peptide was recently reported in which the acetylation of the $\mathrm{N}$-terminal residue seems to play part in the modulation of PMNL attraction (Ribeiro et al., 2004).

Studies have demonstrated that the social wasp venoms generally contain two different types of chemotactic peptides. The first is the classical deca- and dodecapeptides, which contain a single $\mathrm{K}$ residue between positions 8 and 10 of the peptide chain and can induce chemotaxis in leukocytes (Baptista-Saidemberg et al., 2010; Dias et al., 2015; Mendes et al., 2005), while the second type consists of small chemotactic peptides (from tetra-to octapeptides) that act in modulating the chemo attraction of leukocytes. According to Monoi et al. (2004) studies, this second type also inhibit catecholamine secretion by non-competitively blocking specific acetylcholine receptors, but without affecting the catecholamine release that is caused in the presence of high concentrations of potassium ions (Monoi et al., 2004). These peptides appear to be natural proteolytic products of serineproteinases on chemotactic peptides.

Table 3 summarizes the chemotactic peptides identified in the venoms of different wasp species. In the Polybia paulista wasp venom studies (de Souza et al., 2004; Dias et al., 2015) Polybia-CP, Polybia-CP 2, and Polybia-CP 3 were identified, which are representative of the first type of chemotactic components, whereas Protonectin (1-6) identified in Protonectarina sylveirae wasp venom (Dohtsu et al., 1993) is a representative of the second type. In addition to the chemotaxis of PMNLs, these peptides also presented mast cell degranulation activity, hypernociception, and oedema

Table 3

Chemotactic peptides identified in the venoms of different wasp species.

\begin{tabular}{|c|c|c|c|}
\hline Wasp species & Peptides & Amino acid sequences & References \\
\hline Agelaia pallipes & Protonectin (1-6) & ILGTIL-NH 2 & Baptista-Saidemberg et al. (2010) \\
\hline \multirow[t]{4}{*}{ Polybia paulista } & Polybia-CP & ILGTILGLLKGL-NH ${ }_{2}$ & Mendes et al. (2004) \\
\hline & Polybia-CP 2 & ILGTILGLKIL-OH & Dias et al. (2015) \\
\hline & Polybia-CP 3 & ILGTILGTFKSL-NH ${ }_{2}$ & Dias et al. (2015) \\
\hline & Polybia-Protonectin & ILGTILGLLKSL-NH ${ }_{2}$ & Mendes et al. (2004) \\
\hline \multirow[t]{3}{*}{ Protonectarina sylveirae } & Protonectarin & IAWKALLDAAKKVL-NH ${ }_{2}$ & Dohtsu et al. (1993) \\
\hline & Protonectin $(1-6)$ & ILGTIL-OH & Mendes et al. (2004) \\
\hline & Protonectin & ILGTILGLLKGL-NH $_{2}$ & Dohtsu et al. (1993) \\
\hline Vespula lewisii & VesCP-L & FLPIIAKLVSGLL-NH 2 & Nakajima (1986) \\
\hline Vespa crabro & Cabrolina & FLPLILAKIVTAL-NH 2 & Nakajima (1986) \\
\hline Vespa mandarina & VesCP-M & FLPIIGKLLSGLL-NH ${ }_{2}$ & Nakajima (1986) \\
\hline
\end{tabular}


formation, which corroborate the multifunctional nature of the toxins (Dias et al., 2015). Polybia-CP (de Souza et al., 2009) showed different levels of activity against Gram-positive and/or Gramnegative bacteria; as well as antifungal and fungicidal activity against different species of Candida. Protonectin was reported also in Agelaia pallipes (Mendes et al., 2005), and in Polistes rothneyi iwatai (Polistes-Protonectin) (Murata et al., 2009) wasp venoms. It is remarkable that this peptide is the only one of this group that presents the C-terminal residue in its free acidic form; the other peptides contain amides at this position (Table 3). As may be noted in the peptide sequences shown in Table 3, there is an interesting structural feature of this group of toxins - the chemotactic peptides isolated from social wasp venoms that are endemic to the Neotropical regions ( $P$. paulista and $P$. sylveirae) contain a highly conserved sequence ILGTIL. According to Dias et al. (2015), this motif may be considered a molecular signature of this group. Meanwhile, wasp species that are endemic to the northern hemisphere (Vepula lewisii, Vespa mandarinia, and Vespa crabro) have the motif FLP at the N-terminal region as their molecular signature (Dias et al., 2015).

Until now, the action mechanism of chemotactic peptides from wasp venoms remains unknown, but, it has been postulated that chemoattraction of leukocytes induced by these toxins is mediated by the interaction with G-protein coupled receptors (GPCRs) in the cell membrane. Thus, the direct interaction between GPCRs and the chemotactic peptides activates a molecular event cascade resulting in cell migration to the sting site and promoting a potent proinflammatory response (Li et al., 2015; Mendes et al., 2005).

\subsubsection{Kinin-related peptides}

Wasp kinins represent a third group of peptides biologically important among the wasp toxins. Kinins are polypeptides presenting from 9 to 18 amino-acid residues, containing internally a bradykinin-like sequence (Piek, 1991). The bradykinin-like sequence may be either bradykinin, $\mathrm{Hyp}^{3}$-bradykinin or $\mathrm{Thr}^{6}$-bradykinin. Sometimes there is also an elongation of the $\mathrm{N}$-terminal region from the original bradykinin C-terminal portion (Nakajima, 1986). The kinins from hymenopteran venoms are structurally similar to the mammalian pain-producing nonapeptide bradykinin (BK) (Bhoola et al., 1992; Gobbo et al., 1992; Piek et al., 1983; Yasuhara et al., 1987).

The function of kinin-related peptides in wasp venoms is still not clearly understood. The bradykinin-like peptide was found in wasp venoms as the first neurotoxic and pain-producing peptide (Schachter and Thain, 1954), and have been described as neurotoxic components of wasp and ant venoms, causing in the insect central nervous system (CNS) a presynaptic block of the cholinergic transmission by means of an irreversible depletion, probably caused by a non-competitive inhibition of choline uptake (Piek, 1991). Besides this, wasp kinins cause hypertension in mammals, hypotension in chickens, bronchoconstriction in rodents, and the contraction of a series of isolated smooth muscle preparations, and the relaxation of the rat duodenum (Piek, 1991). Gobbo et al. (1995) isolated and synthesized two bradykinin-like peptides, the Vespakinin-A from Vespa analis, Vespakinin-T from Vespa tropica and some cyclic analogs (Gobbo et al., 1995). Zhou et al. (2006) reported the purification, characterization, and cDNA cloning of bradykinin-like peptide, the vespakinin from Vespa magnifica. Recently, a group of wasp kinins was identified in $P$. paulista venom (Dias et al., 2015). The authors reported the presence of Thr ${ }^{6}$-Bradykinin, RA-Thr ${ }^{6}$-Bradykinin and RA-Thr ${ }^{6}$-Bradykinin-DT. In this study an uncommon type of wasp kinin was described because the peptide RA-Thr6-Bradykinin-DT contains both the dipeptide RA attached to the N-terminal residue of Thr6-Bradykinin, and the dipeptide DT attached to the $\mathrm{C}$-terminal residue of this peptide. This wasp kinin type was previously reported in Megascolia flavifrons solitary wasp venom (Piek et al., 1987a, 1987b), named as megascoliakinin (Thr6-BK-Lys-Ala), as well as in the Vespa analis (Nakajima, 1986).

Most of the kinin-related peptides in animal venoms have longer peptide chains and their actions are longer-lasting than BK (Piek, 1991). Thr ${ }^{6}$-Bradykinin is a neurotoxic component that has already been reported in the venom of solitary wasps $M$. flavifrons and Colpa interrupta (Piek et al., 1987a, 1987b). According to literature, almost all social wasp venoms may have kinin or kinin-like activities, while among solitary wasps, Cyphononyx dorsalis (Pompilidae) and several Scoliidae wasps have Thr6-bradykinin in their venom; and bradykinin was found only in the Megacampsomeris prismatica (Scoliidae) venom (Konno et al., 2002). Since one of the major pharmacological effects of kinins is pain sensation in vertebrates, the ubiquitous distribution of kinins in social wasp venoms suggests that kinins may be used as toxins for defense against mammals and/or birds, which are predators of social wasp colonies, causing physical discomfort in the envenomed vertebrate predators (Dias et al., 2015; Lee et al., 2016a,b).

\subsubsection{Other peptide toxins}

Currently, a novel class of peptides presenting an intramolecular disulfide bridge has been reported in social wasp venom. These peptides present different profiles of inflammatory activities. A novel peptide named Paulistine with an unusual structure among the peptide toxins from social wasps was recently isolated from Polybia paulista venom (Arcuri et al., 2016; Gomes et al., 2014). This peptide presents 21 amino acid residues in its sequence, with a single intramolecular disulfide bridge as reported before for some honeybee venom peptides, such as Apamine, Tertiapine, and MCDPeptide, which possess four cysteine residues forming two intramolecular disulfide bridges (Banks and Shipolini, 1986). A peptide similar to Paulistine named Sylverin was previously reported in Protonectarina sylveirae wasp venom (Dohtsu et al., 1993). However, the structure and biological activities of this peptide were never investigated. A Sylverin-like peptide was also isolated from Agelaia pallipes pallipes wasp venom (Costa, 1997). These peptides contain from 21 to 25 amino acid residues in their primary sequences and present a single disulfide bridge. They are potent mast cell degranulators without any known hemolytic activity.

Another peptide described in wasp venom and is not exactly categorized in kinin, mastoparan, or chemotactic peptides is Crabrolin. This polycationic peptide was isolated from Vespa crabro venom and has 13-amino acid residues, presenting a helical conformation (Krishnakumari and Nagaraj, 1997). It was demonstrated that this peptide produces potent hemolytic and antibacterial activity; however, it is a weak mast cell degranulator, with less than $20 \%$ of mastoparan activity. In the investigation of structure-function of this peptide and it's analogs, it was also demonstrated that although helical conformation is necessary for hemolytic activity, it is not a prerequisite for antibacterial activity. Appropriately positioned, charged and hydrophobic residues and overall hydrophobicity appear to determine antimicrobial activity (Argiolas et al., 1985).

\subsection{Peptide toxins from ant venoms}

Ant venoms are known to be rich in alkaloids, however peptide identification in ant venoms are becoming more common, but yet remain understudied. Although ant venoms remain very much unexplored, recent studies have shown that venoms of the ants, belonging to the subfamilies Paraponerinae, Ponerinae, Amblyoponinae, Dorylinae, Myrmeciinae, Myrmicinae, Pseudomyrmecinae and Ectatomminae, are also rich in peptides, similar to other animal 
venoms (Cologna et al., 2013; Touchard et al., 2015). Recent advances in mass spectrometry techniques have begun to reveal the true complexity of ant venom peptide composition. In the few venoms explored up to now, most toxins appear to occur as small, polycationic linear peptides, with antibacterial properties and insecticidal activity. Ant venoms contain a range of homodimeric and heterodimeric peptides with one or two interchain disulfide bonds possessing pore-forming action, allergenic and paralytic activities; and it seems to have only a small number of monomeric disulfide-linked peptides (Aili et al., 2014; Touchard et al., 2016a). To date, only 75 venom peptides have been completely sequenced (Aili et al., 2014). These peptides have been classified according to their structure, but considering their biological functions, they can be grouped into cytolytic, neurotoxic and uncharacterized peptides. Thus, the present review presents and summarizes the current knowledge of known ant venom peptide toxins and their functional roles, into those three different groups.

\subsubsection{Cytolytic peptides}

Proteomic studies on ant venoms have so far revealed the prevalence of small, polycationic linear peptides (devoid of disulfide bonds) with molecular masses below $5 \mathrm{kDa}$ (around 35 residues) (Cologna et al., 2013; Rifflet et al., 2012; Touchard et al., 2015, 2014b). Many of these peptides are cytolytic and have insecticidal activity, haemolytic and/or antimicrobial properties. Included in this group are ponericins from the ant Neoponera goeldii (Schmidt and Shattuck, 2014), dinoponeratoxins from the ant Dinoponera australis (Johnson et al., 2010), pilosulins from the ant Myrmecia pilosula (Zelezetsky et al., 2005), and bicarinalins from the ant Tetramorium bicarinatum (Rifflet et al., 2012).

The ponericins are a group of 27 peptides described from Pachycondyla sp (renamed Neoponera spp.) ant venom that have been classified into three different families, based on their sequence homology - "G", "W" and "L" (Aili et al., 2014). According to Orivel et al. (2001) ponericins present haemolysis activity, antibacterial activity against both Gram-positive and Gramnegative bacteria, as well as insecticidal action (Orivel et al., 2001). The authors suggest that the ponericins may adopt an amphipathic alpha-helical structure in polar environments, such as cell membranes. Thus in ant colonies, ponericins peptides exhibit a defensive role against microbial pathogens arising from prey introduction (Orivel et al., 2001). Other peptides similar to ponericins were also sequenced from Neoponera apicalis and Neoponera inversa ant venoms (Touchard et al., 2016a), showing a strong homology to the "G", "W" and "L" ponericin family. Recently, Pluzhnikov et al. (2014) isolated three novel antimicrobial linear peptides (molecular weight $3 \mathrm{kDa}$ ), with homology to ponericin W5 peptides from Ectatomma brunneum ant venom (Pluzhnikov et al., 2014). These peptides showed antimicrobial and cytolytic activities at low micromolar concentrations.

Additional homologous toxins to ponericins, dinoponeratoxins, were also identified in Dinoponera australis and D. quadriceps ant venoms (Aili et al., 2014; Cologna et al., 2013; Johnson et al., 2010). In the Johnson et al. (2010) study, using peptidomic approach over 75 proteinaceous components with numerous small mass peptides, 429-3214 Da, were identified in the D. australis venom. The six most abundant peptides were de novo sequenced and named dinoponeratoxins. The two largest and most abundant peptides, $3105 \mathrm{Da}$ and $3177 \mathrm{Da}$, have a $92.9 \%$ identity with the ponericin G2 peptide sequence, while the most hydrophobic peptide, presenting molecular mass of $1837 \mathrm{Da}$, is amidated at the C-terminus, and shares homology with poneratoxin, a neurotoxic peptide found in the bullet ant Paraponera clavata. We will comment on this peptide later in this review. Several novel peptides known as Dq toxins are similar to dinoponeratoxin peptides, recently isolated from D. quadriceps ant venom (Cologna et al., 2013). Aili et al. (2014), proposed to separate the currently identified dinoponeratoxins into six groups based on their structural and functional features (Aili et al., 2014).

Another group of peptides identified in ant venoms are pilosulins (1, 2, 3, 4 and 5), described as the main venom allergens of Myrmecia pilosula (Wanandy et al., 2015). These peptides exhibit hemolytic, cytolytic, hypotensive and antimicrobial activities. Pilosulin 1 is a long linear peptide with 56 amino acid residue and molecular weight $6052 \mathrm{Da}$. Studies have reported that pilosulin 1 had a more potent cytotoxic activity compared to honeybee venom derived mellitin (Wiese et al., 2007; Wu et al., 1998; Davies et al., 2004; Zelezetsky et al., 2005). A chemically synthesized pilosulin 1 showed potent and broad spectrum antimicrobial activity against a number of Gram-positive and Gram-negative bacteria, as well as against Candida albicans (Zelezetsky et al., 2005). According to authors, pilosulin 1 have the ability to assume an amphipathic, alpha-helical conformation that permits their incorporation, and subsequent microbial cell membranes lysis. The 3-D structure of Pilosulin 1, determined by NMR was recently deposited in the Protein Data Bank (PDB: 5X3L), as shown in Fig. 4.

Pilosulin 2 shares $62 \%$ structural homology with pilosulin 1, and is also associated with cytotoxic activity (Donovan and Baldo, 1997; Wanandy et al., 2015). Studies have demonstrated that pilosulin 2 has no haemolytic activity towards red blood cells up to a tested concentration of $80 \mathrm{mM}$ (Wu et al., 1998), however, pilosulin 2 demonstrated a hypotensive effect when it was administered to laboratory rats via its tail veins (Donovan and Baldo, 1997). Pilosulins 3, 4, and 5 are a group of homo and heterodimeric peptides.

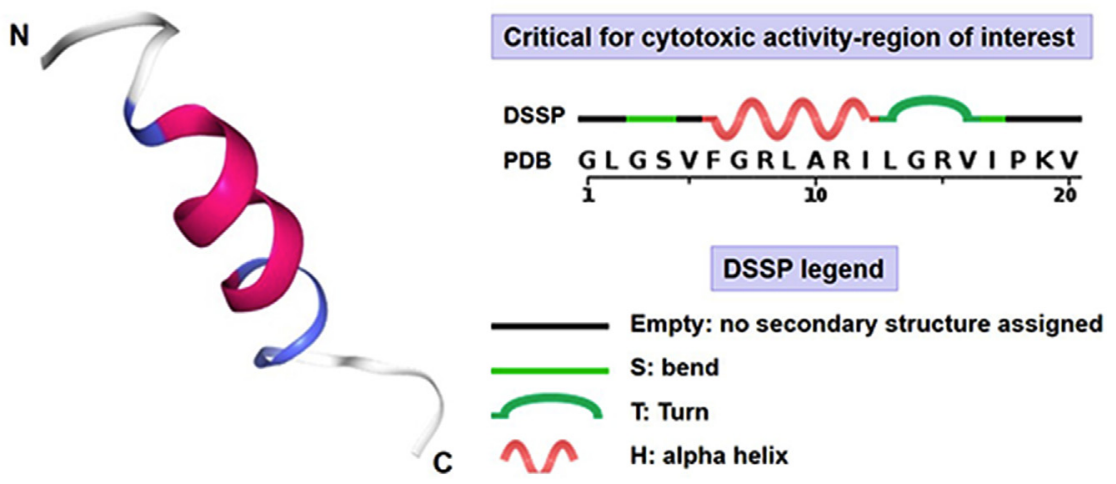

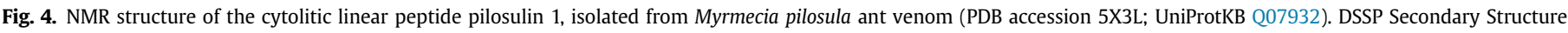
(Kabsch and Sander, 1983) highlighting the sequence of cytotoxic activity-region of interest. 
These peptides have an unknown biological function, although they possess some antimicrobial activity; they are classified as allergens (Inagaki et al., 2004). Pilosulin 3 has antimicrobial, membranedisrupting, and nociceptive activities. Also known as $\Delta$-myrtoxinMp1a in accordance with the rational nomenclature of peptide toxins (King et al., 2008), is considered the most abundant component of $M$. pilosula venom. This peptide is an antiparallel heterodimer comprising 49-residues linked by two interchain disulfide bonds (Dekan et al., 2017). In addition, Mp1a displayed broad-spectrum antimicrobial activity, with the highest potency against Gram-negative Acinetobacter baumannii (Dekan et al., 2017). Recently, Kazuma et al. (2017) identified six pilosulin-like peptides, including intact pilosulin-like peptide 1 and truncated pilosulin-like peptides 2 and 3, by transcriptomic and peptidomic analysis in Odontomachus monticola ant venom (Kazuma et al., 2017).

Two novel antimicrobial peptides, bicarinalins, have been characterized as the most abundant peptides from Tetramorium bicarinatum ant venom (Téné et al., 2016). These antimicrobial peptides are active against Staphylococcus aureus and S. xylosus. The bicarinalin 1 and 2 (P17) amino acid sequences have been determined by de novo sequencing using mass spectrometry and by Edman degradation chemistry; and interestingly, these peptides show very low homology with any known peptide toxins (Rifflet et al., 2012; Téné et al., 2016). Similar to melittin, pilosulin and defensing, bicarinalin showed potent and broad antibacterial activity, but weak haemolytic effect. The analysis of Tetramorium bicarinatum venom gland transcriptome revealed the presence of allergenic/cytotoxic peptides, with homology to pilosulins 1, 3 and 5 , and paralytic peptide toxins, which contribute to $70 \%$ of the total EST cDNAs (Bouzid et al., 2013). Recently, Guzman et al. (2017) showed that bicarinalin peptide has anti-Helicobacter pylori properties. According to the authors, the peptide showed an antibacterial activity similar to known activity from four antibiotics currently used in therapies against this pathogen and can be considered as a candidate to develop novel drugs. In addition, Benmoussa et al. (2017) demonstrated that the bicarinalin 2 (P17) promotes antifungal activities of macrophages through the induction of C-type lectin receptors dependent on LTB4-mediated PPAR $\gamma$ activation (Benmoussa et al., 2017). The authors state that this activation is associated to an inflammatory profile characterized by reactive oxygen species (ROS), interleukin (IL)-1 $\beta$, and TNF- $\alpha$ release; and identify P17 as an original activator of the fungicidal response of macrophages that acts upstream PPAR $\gamma /$ CLRs axis and offer new immunomodulatory therapeutic perspectives in the field of infectious diseases.

It is believed that the cytolytic peptides identified in ant venoms are multifunctional components. In venoms of spiders and scorpions, these peptides can act as membrane-disrupting agents, facilitating the diffusion of other neurotoxins through cell barriers to reach their molecular targets (Kuhn-Nentwig, 2003). Most of the ants seem to have developed venoms made up of highly cytolytic peptides, which may have a direct toxic effect on prey (Cologna et al., 2013; Orivel et al., 2001), although insecticidal activity is generally moderate compared to neurotoxins (King and Hardy, 2013), acting synergistically against different cell types, causing membrane rupture and consequently killing prey (Touchard et al., 2016a). In addition, these peptides may exhibit some antimicrobial activity, which would be a way for the ant to perform asepsis of captured prey before taking it into the colony. Another action would be pre-digestion of the prey, since the cytolytic activity combined with an enzymatic action would aid in the degradation of prey cell membranes, as occurs with spider venoms (Orivel et al., 2001). Peptides that have membrane-perturbing properties have been extensively investigated for many years in order to find in these peptides promising candidates for the future development of novel antimicrobial, insecticidal and anti-cancer drugs (Kuhn-Nentwig, 2003).

\subsubsection{Neurotoxic peptides}

Neurotoxic peptides are widely expressed in animal venoms to aid in the rapid immobilization of prey. These neurotoxins act on several molecular targets, mainly ion channels, with varied selectivity, specificity and efficiency. Many ant venoms have been described as having paralytic effects on arthropods, these venoms possibly also contain neurotoxins that induce paralysis (Orivel et al., 2001). However, few studies have been carried out to investigate the neurotoxic properties present in ant venoms; to date, only three neurotoxic peptides were described in ant venoms: poneratoxin from Paraponera clavata (Piek et al., 1991), ectatomins from Ectatomma tuberculatum (Arseniev et al., 1994) and more recently, poneritoxin from Anochetus emarginatus (Touchard et al., 2016a).

Poneratoxin is a 25-residue peptide with an average mass of 2756.4 Da (Piek et al., 1991). This molecule is a major component of $P$. clavata venom which has been investigated as a candidate for the development of bioinsecticides (Hendrich et al., 2002; Szolajska et al., 2004). This peptide have no apparent homology to other known peptides, and was able to modulate the sodium channel voltage $\left(\mathrm{Na}^{+}\right)$in both vertebrates and invertebrates, blocking synaptic transmission in insects CNS (Piek et al., 1991). In the Szolajska et al. (2004) study, the 3-D NMR structure of poneratoxin was determined and revealed a ' $\mathrm{V}$ '-shaped peptide with two $\alpha$-helices connected by a $\beta$-turn, as showed in Fig. $5 \mathrm{~A}$. According to the authors, the poneratoxin has a potential toxin-induced interconversion between a fast and a slow conducting state of the $\mathrm{Na}_{\mathrm{v}}$ channel. Due to its high efficacy, this peptide can be used as a model for the rational development of novel bioinsecticides using a recombinant poneratoxin-producing baculovirus (Szolajska et al., 2004). More recently, Johnson et al. (2017) identified three new isoforms of poneratoxin with average masses of $2814.4 \mathrm{Da}$ (glyceryl-PoTx; the presumed precursor of PoTx with an additional glycine residue at position 26), 2814.4 Da (A23E PoTx), and 2783.5 Da (D22N A23V PoTx) from Paraponera clavata venom collected from different geographical locations.

Ectatomin Et-1, a potent neurotoxic peptide was isolated from the ant venom Ectatomma tuberculatum, which was considered at the time, the most potent neurotoxic peptide isolated from ant venoms (Pluzhnikov et al., 1994). This peptide was shown to be a calcium channel blocker $\left(\mathrm{Ca}^{2+}\right)$, besides acting as a cytotoxic peptide in the formation of pores in vertebrate and invertebrate cells (Arseniev et al., 1994; Pluzhnikov et al., 1999). A homologue toxin, ectatomin Et-2 was further isolated from the ant venom (Pluzhnikov et al., 2014) Et-1 appears to account for the major toxic effect from Ectatomma tuberculatum venom, causing toxic effects in both mammals and insects (Pluzhnikov et al., 1999). These peptides are highly basic heterodimeric complexes and comprise two highly homologous amphiphilic polypeptide chains linked together by one inter-chain disulfide bond (Arseniev et al., 1994). According to King and Hardy (2013), disulfide bonds provide venom peptides resistant to a number of different proteases and environmental extreme conditions resulting in stable peptide toxins (Herzig and King, 2015). The 3-D structure of Et-1 was determined and revealed that each ectatomin chain comprises two anti-parallel $\alpha$ helices linked by a hinge region of four amino acid residues and a disulfide bridge (Nolde et al., 1995), as shown in Fig. 5B. Another investigation by Pluzhnikov et al. (2000) revealed two other ectatomins (Eq-1 and Eq-2) isolated from Ectatomma brunneum venom; these novel peptides are also dimeric and linked by one interchain 


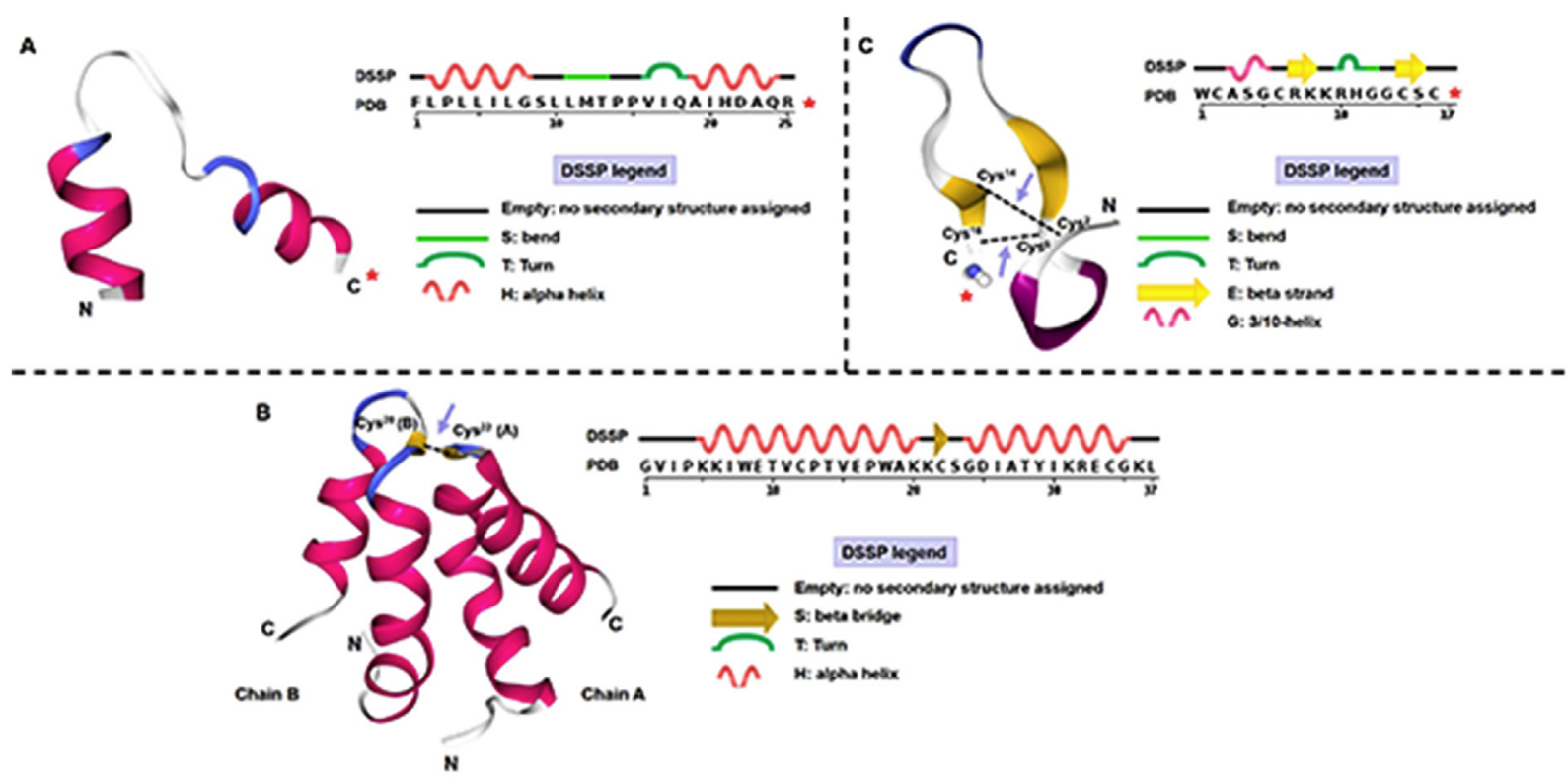

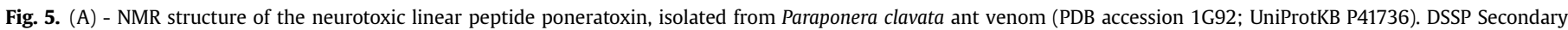

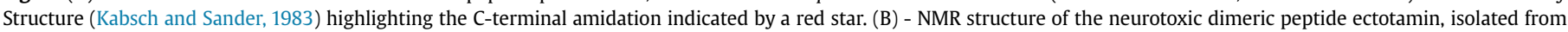

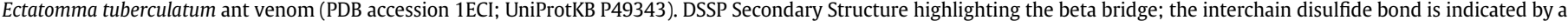

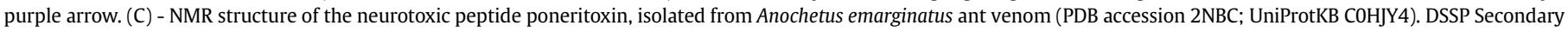

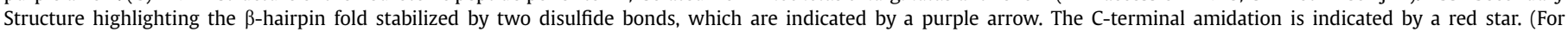
interpretation of the references to colour in this figure legend, the reader is referred to the Web version of this article.)

disulfide bond. Meanwhile, they lack the intra-chain disulfide bond present in Et-1 and -2 (Pluzhnikov et al., 2000).

A third neurotoxic peptide, poneritoxin Ae1a was recently characterized from Anochetus emarginatus venom (Touchard et al., 2016b). In this investigation, a novel family of neurotoxic disulfide-rich peptides ( 7 peptides) were isolated and sequenced, and none of these peptides are homologous to known venom peptides from ants or other venomous animals. The 3D structure of synthetic Ae1a revealed a unique $\beta$-hairpin fold stabilized by two disulfide bonds, as shown in Fig. 5C. Animal venom peptides are often structured by multiple disulfide bonds and therefore exhibit a wide variety of folds. Synthetic Ae1a reversibly paralyzed blowflies and inhibited human L-type voltage-gated calcium channels $\left(\mathrm{Ca}_{\mathrm{V}} 1\right)$. According to the authors, Anochetus ant venoms are a rich source of novel ion channel modulating peptides, some of which might be useful leads for the development of biopesticides.

Considering all Hymenoptera peptide toxins mentioned above, it is possible to propose a general mechanism for envenoming pathogenesis caused by the peptide components from the venoms of bee, wasp and ant (Palma, 2013). Fig. 6 summarizes the general contribution of the peptide toxins to the envenoming caused by the social Hymenoptera.

\subsubsection{Uncharacterized peptides}

In this group includes uncharacterized peptides that have no complete sequence, or known structure and/or biological functions/activity such as: myrmexins from Pseudomyrmex triplarinus venom (Pan and Hink, 2000) and ICK-like peptides from Dinoponera

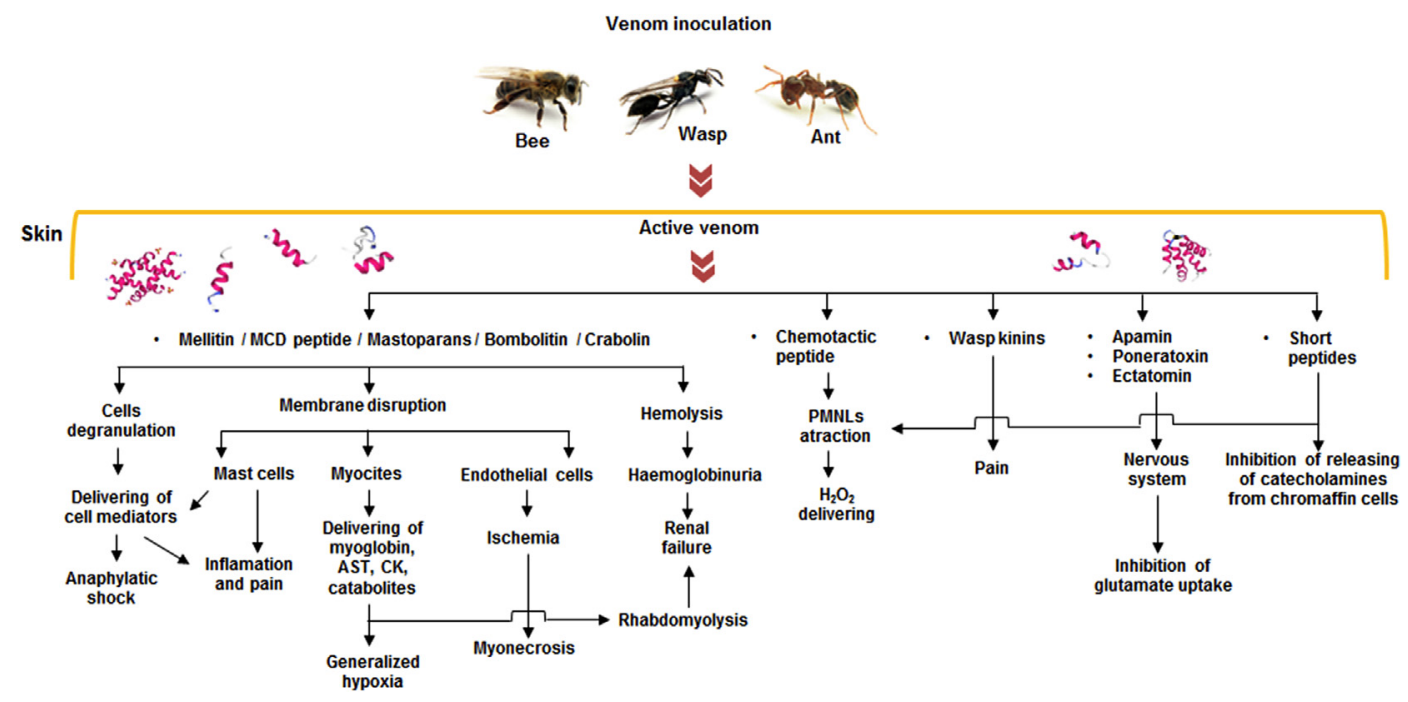

Fig. 6. General mechanism of envenoming proposed for the peptide toxins from social Hymenoptera venoms - bees, wasps and ants - (modified from Palma, 2013). 
quadriceps venom (Torres et al., 2014) and from Strumigenys kumadori venom (Inagaki et al., 2008).

The myrmexins, whose biological functions remain unknown, are a group of six heterodimeric peptides isolated from Pseudomyrmex triplarinus ant venom (Pan and Hink, 2000). Homo and heterodimeric peptides were also reported in Pseudomyrmex penetrator venoms (Touchard et al., 2014b) and Tetraponera sp (Touchard et al., 2015), although their amino acid sequences and biological activities also remain uncharacterized. Myrmexin-like peptides were identified also in three other Pseudomyrmex ant species (Touchard et al., 2014b). The authors demonstrated that Pseudomyrmex termitarius venom is composed of 87 linear peptides, while both Pseudomyrmex gracilis and Pseudomyrmex penetrator venoms (23 and 26 peptides, respectively) possess peptides with disulfide bonds. Furthermore, Pseudomyrmex penetrator venom contains three hetero- and homodimeric peptides consisting of two short peptidic chains linked together by two interchain disulfide bonds. The large number of peptides in Pseudomyrmex termitarius venom is likely related to the large diversity of potential prey plus the antibacterial peptides required for nesting in the ground. Although they are not yet sequenced, these myrmexins may represent a new class of toxins in Pseudomyrmex sp. ant venoms.

The ICK-like peptides, normally, have been reported from other arthropod venoms. The inhibitor cystine knot (ICK) structural motif is an evolutionary conserved structure that has been found in plants, fungi, and in many venomous animals such as spiders, scorpions, cone snails, insects and sea anemones (Aili et al., 2014; Barbault et al., 2003; Bloch and Cohen, 2014; Gilly et al., 2011; Rodríguez et al., 2014; Zhu et al., 2003). In ant venom only two types of this structural motif are currently known: Strumigenys kumadori venom possesses ICK-like peptides (named SKTXs), which are postulated to modulate $\mathrm{Na}_{\mathrm{V}}$ channels of Drosophila, however, this study remains unpublished and sequences of these peptides are still unknown (Aili et al., 2014; Inagaki et al., 2008). Recently, the transcriptome analysis of Dinoponera quadriceps venom glands, confirmed the presence of peptides similar to ICK, with unknown biological activity (Torres et al., 2014). Commonly, such peptides consist of single chain molecules with molecular weight ranging from 3 to $10 \mathrm{kDa}$, rich in cysteine residues, forming disulfide bonds. This ICK-like peptide is described as a minor component in Dinoponera quadriceps venom, but shows a VI/VII cysteine framework (-C-C-CC-C-C-) consistent with other ICK toxins (Aili et al., 2014; Torres et al., 2014) reported in spider and cone snail venoms, normally exhibiting neurotoxic properties (Craik et al., 2001; Herzig and King, 2015).

\section{Hymenoptera venom proteinaceous toxins}

As noted, insect venoms are mixtures of bioactive compounds that have been optimized during evolution to be used against colony predators and preys (Palma, 2013). Small compounds and peptides mainly mediate local reactions causing discomfort in the victims. Meanwhile, proteinaceous components are involved in direct tissue damage or in the induction of systemic hypersensitive reactions including anaphylaxis (Jakob et al., 2017). Due to the low amount of venom often injected in the victim, life threatening cases caused by insect stings are often related to allergens rather than to the direct toxic activity of other venom components. Consequently, most currently characterized proteins from social Hymenoptera venoms are allergenic toxins (Spillner et al., 2014).

For decades the venom composition of stinging insects remained obscure, partially due to the limitations of the approaches used to elucidate their toxin arsenal (de Graaf et al., 2009; Perez-Riverol et al., 2017). However, the application of novel techniques with high dynamic range and sensitivity in venomic analyses have allowed the identification of several never described insect toxins (Aili et al., 2017; Barkan et al., 2017; dos Santos et al., 2010; Peiren et al., 2005; Van Vaerenbergh et al., 2015, 2014). The biological data obtained from these analyses has significantly uncovered the molecular composition of Hymenoptera venoms thus increasing our understanding of the pathophysiological processes triggered by the insect sting (de Graaf et al., 2009; Perez-Riverol et al., 2017; Spillner et al., 2014).

Hymenoptera allergens represent the most thoroughly studied proteinaceous toxins from bee, ant and wasp venoms. So far, up to 75 venom proteins from 31 Hymenoptera species have been officially annotated as allergens (www.allergen.org, accessed in February 2018) (Jakob et al., 2017). From this group of molecules, the predominant allergens phospholipase A1, -A2, hyaluronidases and antigen 5 are the most characterized. However, several less abundant allergens such as DPPIV (Blank et al., 2010; Schiener et al., 2018), vitellogenins (Blank et al., 2013b), serine protease (Georgieva et al., 2010), serine protease inhibitors (Michel et al., 2012), MRJPs (major royal jelly proteins) (Blank et al., 2012), icarapin (Blank et al., 2011a,b) have been recently described as clinically relevant. As most of the published data related to Hymenoptera venom allergenic proteins is related to predominant allergens, these molecules will represent the main focus of the section. Nonetheless, information related to other novel allergens as well as the new biological data regarding novel proteinaceous toxins and provided by -in depth-analyses of Hymenoptera venoms will be also described here.

\subsection{Bee venom proteinaceous components}

Despite being the most largely explored venom from social Hymenoptera, only $30 \mathrm{HBV}$ components had been described until recently. These compounds were identified mainly by using classical proteomic approaches (Hoffman et al., 1976). Furthermore, for decades most of the studies for elucidation HBV composition was aimed at the characterization of the abundant and clinically relevant allergenic proteins (Hoffman et al., 1977; Hoffman, 1977). Consequently, limited information related to none allergenic proteins was available at the time. The use of high resolution proteomic techniques in HBV composition studies allowed overcoming this panorama (de Graaf et al., 2009; Peiren et al., 2005; Van Vaerenbergh et al., 2015). A shotgun proteome analysis of A. mellifera venom resulted in the identification of 83 novel compounds, including 33 putative toxins (Van Vaerenbergh et al., 2014). Similarly, an in-depth proteomic analysis of Bombus terrestris allowed the identification of 52 venom components never described in bumblebees (Van Vaerenbergh et al., 2015). Some of these compounds represent unique venom toxins with no homologue in HBV. Recently, the proteome from venoms of five other species of bumblebees also revealed the presence of several species-specific toxins (Barkan et al., 2017).

The venom of $A$. mellifera contains different types of allergenic toxins (Api m 1 - Api m 12) officially annotated in the list of Hymenoptera venom allergens (Jakob et al., 2017). While HBV major allergens such as phospholipase A2 (Api m 1), hyaluronidase (Api m 2 ) and acid phosphatase (Api m 3 ) were identified in early studies of venom composition, several allergens were described recently (Blank et al., 2013b, 2012; 2010; Frick et al., 2016; Georgieva et al., 2010). The identification of these novel allergenic compounds represents a milestone for the success of molecular diagnosis of allergy. For instance, classical allergens such as Api $\mathrm{m} 1$ has shown low sensitivity during diagnosis of allergic patients (Korošec et al., 2011). The identification of additional allergens often underrepresented in crude venoms and their inclusion on panels for CRD has drastically improved the identification of culprit venom and 
consequently the outcome of the IT in HBV-sensitized patients (Köhler et al., 2014). Currently, venom allergens represent the most extensively characterized proteinaceous toxins in HBV.

\subsubsection{Phospholipase A2}

Mature phospholipase A2 from $\mathrm{HBV}$ (Api m 1) is a $16-18 \mathrm{kDa}$ protein of 134 amino acids which accounts for up to $12 \%$ of the venom's dry weight (d.w.) (Jakob et al., 2017). The primary sequence contains eight cysteine residues involved in the formation of four disulfide bonds and one N-glycosylated residue (Asn13) (Hoffman, 2006; Shipolini et al., 1974). Unlike snake PLA2 from elapid (Class IA) and viper (Class IIA/IIB) venoms, Api $m 1$ belongs to Group III of bee/lizard/scorpion, secretory and $\mathrm{Ca}^{2+}$-dependent venom PLA2s (Hoffman, 2006; Shen et al., 2010). The enzyme hydrolyzes the $s n-2$ ester linkage of glycerophospholipids releasing free fatty acids and lysophospholipids (Dennis et al., 2011), as illustrated in Fig. 7.

During envenoming HBV PLA2 activity causes membrane disruption and necrotic cell death (Lee and Bae, 2016b). Interestingly, it has been suggested that melittin cooperates with the activation of apid PLA2 in a mechanism involving substrate replenishment on the enzyme-containing vesicles (Cajal and Jain, 1997). Finally, a catalytic activity-independent ligand role which mediates neurotoxicity has been described for this bee venom toxins (Nicolas et al., 1997). The 3-D structure (Fig. 8A) of the protein was solved using X-ray crystallography showing an overall architecture typical from Group III of PLA2s (Scott et al., 1990). PLA2 is the most predominant allergen in HBV with up to 74-95\% of sensitized patients showing IgE reactivity to this allergenic protein (Köhler et al., 2014). Despite PLA2s being present in some wasp venoms (De Oliveira and Palma, 1998), these types of insect toxins have been described as allergen exclusively in bees. Furthermore, vespid PLA1s and HBV PLA2 showed no primary sequence or 3-D identity overall preventing the incidence of peptide-based crossreactivity. Along with vespid antigen 5 and phospholipases A1 (PLA1s), Api $\mathrm{m} 1$ represents the most widely used allergen in molecular diagnosis (Müller et al., 2012).

In addition to Api m 1, apian PLA2s from other species such as Bombus ignitus (Bom i 1) and A. cerana (Api c 1) had been described, cloned and expressed as recombinant proteins (Shen et al., 2010; Xin et al., 2009). The primary sequence of Api m 1 share high levels of identity with Api c 1 (95\%) and limited similarity with Bom i 1 (53\%). Both enzymes showed conserved cysteine and residues corresponding to bee PLA2s catalytic and $\mathrm{Ca}^{2+}$ binding sites (Xin et al., 2009). Interestingly, an in vitro analysis of biological activity showed that Bom i 1 localized at cell membrane and cytoplasm and induces apoptosis in Sf9 cells.

\subsubsection{Hyaluronidase}

Hyaluronidase from HBV (Api m 2) is a $45 \mathrm{kDa}$ glycosylated protein composed of 350 amino acids (Marković-Housley et al., 2000). The enzyme primary sequence contains two potential N-

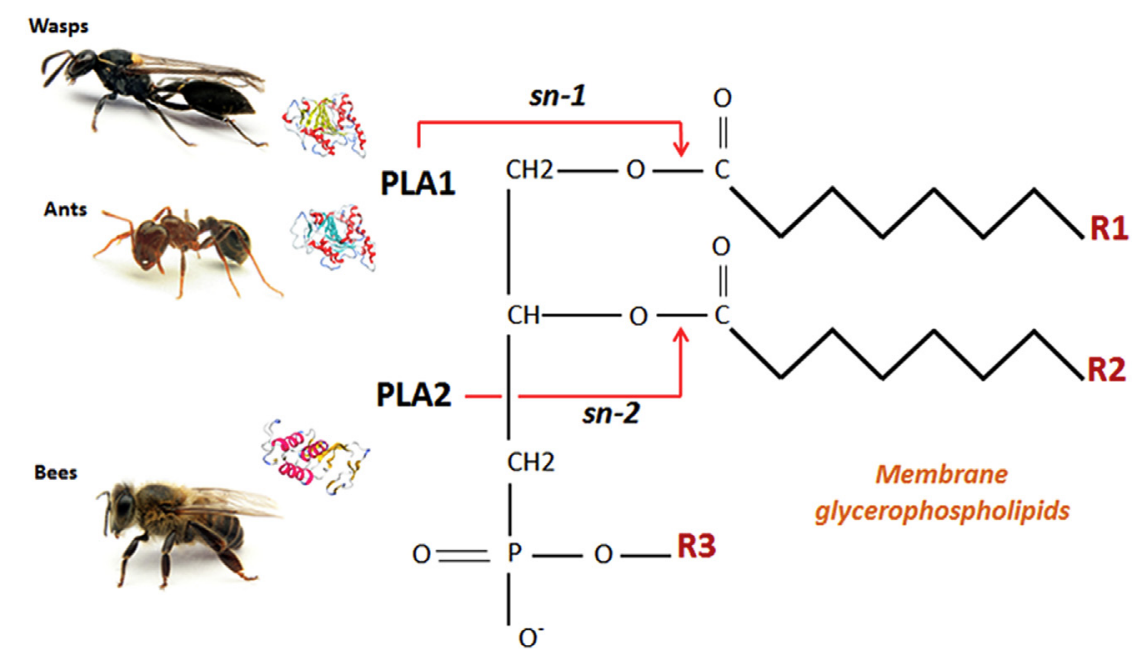

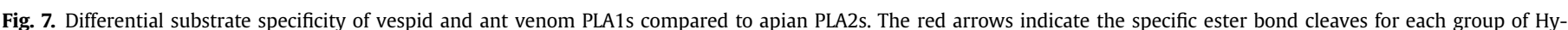

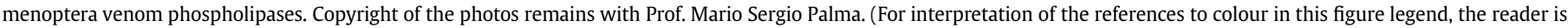
referred to the Web version of this article.)

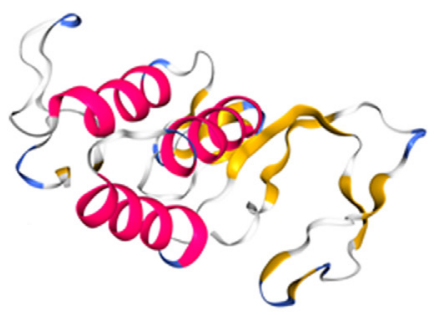

A

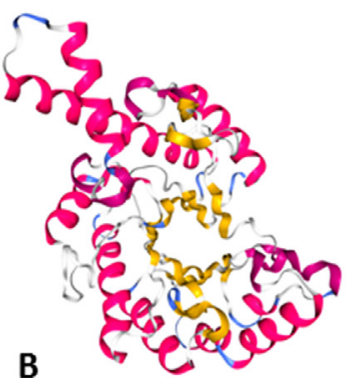

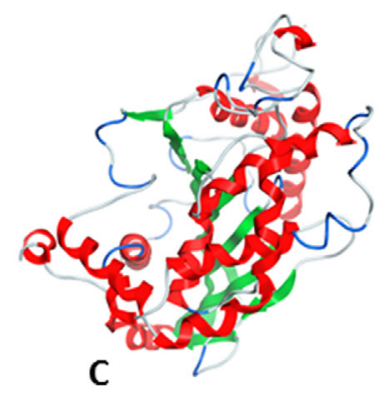

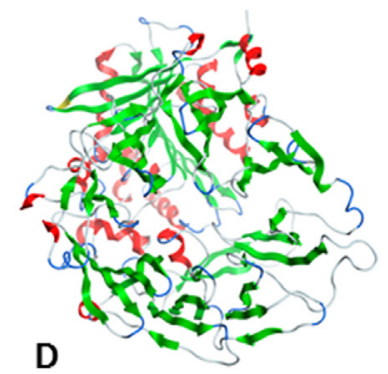

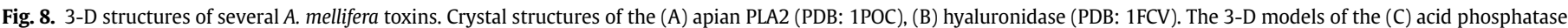

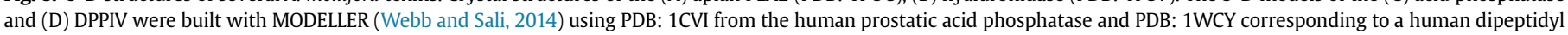
peptidase IV (DPPIV), respectively. 
glycosylation sites from which only one (Asn263) is modified. Asn 236 carries the $\alpha-1-3$ fucosylated N-glycan (Hemmer et al., 2004) typical from insect cross-reactive carbohydrate determinants (CCD) (Blank et al., 2011a,b). The occurrence of this type of glycosylation is a major problem for proper diagnosis of allergic patients. The detection of clinical irrelevant cross-reactive specific $\operatorname{IgE}(\mathrm{s} \operatorname{IgE}$ ) which recognize CCDs often results in misidentification of the culprit venom (Spillner et al., 2014). The 3-D structure of the enzyme solved by X-crystallography showed an overall folding that resembles the common $(\alpha / \beta)_{8}$ TIM barrel identified in mammalian hyaluronidases (Marković-Housley et al., 2000). In the case of the apid hyaluronidase a minor change was noted as the barrel is composed of seven strands, as shown in Fig. 8B.

Based on the amino acid sequence and three dimensional structure the enzyme was included in family 56 of glycosyl hydrolases (Bordon et al., 2015). Similar to venom hyaluronidases from spiders, scorpions, and snakes, Api $\mathrm{m} 2$ is involved in HBV venom components diffusion from the sting site during the envenoming process. The enzyme cleaves hyaluronan, a high molecular weight non-sulfated linear glycosaminoglycan highly abundant in extracellular matrix which is found in connective tissue (dos Santos et al., 2012a,b). By degrading hyaluronan, hyaluronidase activity increases the absorption rates and penetration of the venom toxins thus enhancing their pathophysiological functions in the victim (Ferrer et al., 2013). Hyaluronidase activity in the venom of the spider Loxosceles intermedia was suggested to be responsible for the spreading on the venom from the local point of inoculation and to increase in vivo the levels of the necrosis caused by an spider dermonecrotic toxin (LiRecDT1) (Ferrer et al., 2013). Similarly, venom hyaluronidase from the indian cobra (Naja Naja) indirectly potentiates the activity of other venom components such as a phospholipolytic myotoxin and the hemorrhagic complex-I toxin (Girish et al., 2004).

Primary sequence of Api m 2 shows different levels of identity with hyaluronidase from snakes ( $30,1 \%)$, spiders $(33,5 \%)$, scorpions $(34,9 \%)$, paper wasps $(50,2 \%)$ and yellow jackets $(52,8 \%)$. Crossreactivity with vespid hyaluronidases such as Ves $\mathrm{v} 2$ appears to be based on the presence of $\alpha-1-3$ fucose epitopes as no peptidebased cross-reactivity occurred between CCDs-depleted molecules (Seismann et al., 2010a). Unlike Ves v 2, apid hyaluronidase is a clinically relevant allergen as up to $50 \%$ of patients with a history of allergic reactions to HBV showed sIgE to Api m 2 (Köhler et al., 2014).

\subsubsection{Acid phosphatase}

Acid phosphatase (Api m 3) was described as a predominant allergenic protein in early studies of HBV composition (Hoffman et al., 1977). Api m 3 is a $49 \mathrm{kDa}$ enzyme with two N-glycosylation sites which accounts for $1-2 \%$ of the bee venom dry weight (Jakob et al., 2017). The application of an -in silico-approach to scan bee genome using previously available data for Api $\mathrm{m} 3$ peptides resulted in cloning, molecular characterization and heterologous expression of the allergen (Grunwald et al., 2006). Multiple alignment of the deduced amino acid sequence obtained for Api m 3 showed the occurrence of several motifs common to previously described high-molecular weight acid phosphatases. The 3-D model of Api m 3 was built with MODELLER (Webb and Sali, 2014) using PDB: 1CVI from the human prostatic acid phosphatase, and is shown in Fig. 8C.

Considering the low sensitivity often associated to the use of Api $\mathrm{m} 1$ in molecular diagnosis, Api $\mathrm{m} 3$ have emerged as a valuable tool for detection of HBV sensitizations. Previous analysis showed that up to $50 \%$ of sera from patients allergic to HBV displayed sIgE to this allergen (Köhler et al., 2014). Furthermore, in a group of patients
( $\mathrm{n}=28$ ) unequivocally diagnosed with the HBV allergy but with Api m 1 negative sera, $8(28,6 \%)$ contains sIgE to Api $m$ 3. This data supports the importance of this toxin as an allergenic protein during the envenoming process. Hymenoptera venom acid phosphatases have been described as a potent elicitor of histamine released from basophils of sensitized humans, which also caused swelling after intradermal injection into the skin of allergic patients (Hoffman, 2006). Unfortunately, the pathophysiological role related to the enzymatic activity of this protein after the venom inoculation remains largely unexplored.

\subsubsection{Dipeptidyl peptidase IV}

Dipeptidyl peptidase IV (DPPIV) from HBV (Api m 5) was described in the high molecular weight fraction of the crude venom, using tandem mass spectrometry-based sequencing (Blank et al., 2010). In this study, the DPPIV from yellow jacket venom (YJV) (Ves v 3) was also identified. Api m 5 and Ves v 3 are $\sim 100 \mathrm{kDa}$ enzymes with six predicted N-glycosylation sites which were the first components from the high molecular weight fraction of insect venoms identified as relevant allergens. Both proteins have CCDs modifying their primary structures (Hemmer et al., 2004) and share a significant sequence similarity (55\%). These structural features could potentially represent the molecular basis for the incidence of carbohydrate and peptidic-based cross-reactivity during differential diagnosis of HBV and YJV allergic patients. This is particularly important considering that nearly $60 \%$ of $\mathrm{HBV}$-sensitized patients have sIgE to Api m 5 (Blank et al., 2010; Köhler et al., 2014).

Api $\mathrm{m} 5$ and Ves $\mathrm{v} 3$ are similar to previously described human CD26 (Mentlein, 1999), and a snake venom DPPIVs (32\%) (Aird, 2008). The human DPPIV (CD26) is a highly glycosylated serine exopeptidase included in the S9B protein family that cleaves $\mathrm{N}$ terminal Xaa-Pro or Xaa-Ala dipeptides of polypeptides such as chemokines, neuropeptides and peptidic hormones (Matteucci and Giampietro, 2009). The 3-D model of DPPIV (Api m 5) was built with MODELLER (Webb and Sali, 2014) using PDB: 1WCY corresponding to a human dipeptidyl peptidase IV (DPPIV), and is shown in Fig. 8D.

In addition to HBV and YJV and PWV (Schiener et al., 2018), DPPIVs are widely distributed in snakes (Aird, 2008). In this group of venomous animals, DPPIV has been reported as a venom component in several ophidian taxa, from different families, including Elapidae and Viperidae. The biological role of insect DPPIVs in the envenoming process remains unexplored. Based on the sequence identity with CD26 and the in vitro analysis of the enzymatic activity, Blank et al. (2010) proposed that Api m 5 and Ves v 3 could be involved in the conversion of pro-toxins in their active forms after venom inoculation (Blank et al., 2010). The in vitro conversion of promelittin into its active form by DPPIVs enzymes was reported in an early study of HBV components (Kreil et al., 1980).

\subsubsection{Vitellogenins}

The application of an approach similar to that used for identification of Api $\mathrm{m} 5$ and Ves $v$ 3, also resulted in the description of novel vitellogenins from HBV (Api m 12) and YJV (Ves v 6) (Blank et al., 2013b). Both toxins are $200 \mathrm{kDa}$, low abundant venom proteins and represent the only vitellogenin allergens reported in insect venoms. The primary sequence of Api m 12 contains 1770 amino acids and includes 3 putative $\mathrm{N}$-glycosylation sites of which only one is likely to be glycosylated. In contrast, Ves v 6 is a 1756 amino acid toxin with 4 putative $\mathrm{N}$-glycosylation which were suggested to be modified. Both allergens share $40 \%$ of sequence identity and unlike DPPVs, are CCD-free molecules. As the authors mentioned, although a plethora of data related to this group of molecules in bees is available, the role of vitellogenin in insect 
venom is unknown. However, similar to other allergens, their presence in HBV and JYV suggest additional pathophysiological functions for this group of insect venom toxins (Blank et al., 2013b).

\subsubsection{Non allergenic toxins}

In classical proteomic studies using 2D-gel electrophoresis of the venom components, the presence of low abundant compounds is masked by high abundant proteins such as PLA2. The application of novel approaches such as shotgun proteomics circumvents this problem allowing the detection of rare compounds from a complex mix of molecules. In addition to the well characterized allergens, the analysis of HBV using a combinatorial peptide ligand library sample pretreatment followed by shotgun LC-FT-ICR MS analysis resulted in the identification of an apian platelet-derived growth factor (Van Vaerenbergh et al., 2014). As the author mentioned, this toxin could act as the previously described vascular endothelial growth factor (VEFG)-like protein from snake venom which increases vascular permeability facilitating the diffusion of other venom compounds. Overall, 17 new novel apian toxins including esterases, serine proteases, carbohydrate-degrading enzymes, growth factors and C-type lectins were identified in the study. In an in depth proteomic analysis of $B$. terrestris, 52 venom compounds never described in bumblebees were identified (Van Vaerenbergh et al., 2015). Among the toxins, multiple serine proteases including five (1-5) previously described in HBV (Van Vaerenbergh et al., 2014), were detected.

\subsection{Wasp venom allergens}

Unlike HBV, in which 12 different types of allergenic toxins (Api m 1-12) have been described (Jakob et al., 2017), only a few groups of venom allergens (5) have been identified in vespids (Table 4). To date, venoms from species typical of the Northern Hemisphere including yellow jackets, European and American paper wasps as well as bald-faced hornets represent the most studied in wasps. However, significant efforts have been made during the last decade to identify and characterize the allergenic toxins from species of the Southern Hemisphere such as South America paper wasps (e.g. P. paulista) (dos Santos et al., 2010; Perez-Riverol et al., 2017). Further systemic analysis of wasp venoms using in-depth approaches are required to increase the list of identified and characterized allergens from this group of clinically relevant Hymenoptera. This represents a critical prerequisite for the improvement of specific molecular diagnosis and above all for a better understanding of the symptoms experienced by the victim during the envenoming process (Spillner et al., 2014).

To date, three groups of allergenic toxins have been extensively characterized in wasp venoms: phospholipase A1 (PLA1), hyaluronidase and antigen 5 (Jakob et al., 2017; Perez-Riverol et al., 2017). In addition to these molecules, other insect venom toxins such as DPPIV (Ves v 3) and vitellogenins (Ves v 6) from $V$. vulgaris were described as clinically relevant allergens (Blank et al., 2010, 2013b). Phospholipase A1 and antigen 5 are predominant in wasps accounting for up to $6-14 \%$ and $5-10 \%$ of the venom d.w, respectively. Unlike, hyaluronidases, DPPIV and vitellogenins which are common to bees and wasps, HBV lacks allergenic PLA1 and antigen 5. Thus, with Api m 1, PLA1s (Ves v 1, Pol d 1) and antigen 5 (Ves v 5, Pol d 5) are extensively used in allergy diagnosis for HBV differentiation and wasp sensitization (Monsalve et al., 2012; Müller et al., 2012; Selb, 2015; Vos et al., 2013).

\subsubsection{Phospholipases A1}

PLA1s are common to venoms of most clinically relevant social wasps currently studied (Jakob et al., 2017). Typically, wasp PLA1s are $\sim 34 \mathrm{kDa}$, non-glycosylated, and consequently CCDs-lacking allergens with no sequence identity with HBV PLA2s. Insect venom PLA1s are members of the pancreatic lipase gene family with cleaves ester bonds of 1,2-diacyl-3-sn glycerophospholipids at the position sn-1 (Santos et al., 2007).The PLA1 activity is involved in disruption of biological membranes (Hou et al., 2016), hemolysis (Santos et al., 2007), inflammation (Jim and Wittkowski, 2003) and activates platelet aggregation leading to thrombosis (Yang et al., 2008). It has been suggested that the severe hemolysis (Hou et al., 2016), myocardial dysfunction (Santos et al., 2007) and aortic thrombosis (Lee and $\mathrm{Wu}, 2004$ ) experienced by the victims after massive attack of wasps are related to PLA1s.

Primary sequences from venom wasp PLA1s currently described shows different identity values (King et al., 1996). Similarly, despite sharing the $\alpha / \beta$ fold common to many lipases, the 3-D from several wasp venoms PLA1s partially differs. The tertiary structure of vespid venom PLA1 was elucidated recently by using X-ray crystallography (Hou et al., 2016). The tightly packed $\beta$-sheet described in the model of several wasp's PLA1 is surrounded by four $\alpha$-helices in P. paulista (Poly p 1) (Santos et al., 2007), six in V. affinis (Ves a 1) (Sukprasert et al., 2013) and ten in V. basalis (Hou et al., 2016). The 3-D model of phospholipase A1 from $V$. vulgaris venom was built with MODELLER (Webb and Sali, 2014) using the PDB: 4QNN of the venom PLA1 Vespa basalis, and is shown in Fig. 9C.

Recently, high levels of peptide-based cross-reactivity among PLA1 from different South American and European paper wasps, were detected (Perez-Riverol et al., 2018a). No cross-reactivity occurred between PLA1s from PWV and YJV. The experimental data discussed in the study provides several insights regarding the presence of common continuous and discontinuous IgE epitopes in the venom PLA1s from the species analyzed.

As noted, PLA1s represent valuable markers for an unequivocal diagnosis of wasp venom allergy (Müller et al., 2012). Consequently, several efforts have been made to clone and produce these toxins as recombinant proteins (Borodina et al., 2011; Monsalve et al., 2012; Perez-Riverol et al., 2016; Seismann et al., 2010b). Ves v 1 has been extensively used to differentiate true double positivity to HBV and JYV from irrelevant cross-reactivity (Müller et al., 2012; Seismann et al., 2010a). Likewise, a recombinant form of $P$. dominula venom PLA1 (Pol d 1) has been applied to differentiate PWV from YJV sensitizations (Monsalve et al., 2012). A recombinant form of Poly p 1 is currently under evaluation for development of CRD of allergy to the venom of the South American paper wasp, Polybia paulista (Perez-Riverol et al., 2016, 2018a).

\subsubsection{Vespid hyaluronidases}

As mentioned, hyaluronidases are widely distributed in venomous animals. Similar to vespid PLA1s this group of toxins has been identified nearly in all venoms from clinically relevant Hymenoptera currently studied (An et al., 2012; Bordon et al., 2015; dos Santos et al., 2012a,b; King et al., 1996), highlighting their critical role in the envenoming process. Vespid hyaluronidases are glycosylated, CCD-harboring proteins with molecular mass ranging from 33-45 kDa (Jakob et al., 2017). As noted, the primary structures of insect venom hyaluronidase show significant values of identity that are higher among vespids. The multiple alignment of Poly p 2 amino acid sequences showed a 95.5\% identity with Pol a 2, 78,8\% (Dol m 2), 75, 3\% (Ves v 2) (dos Santos-Pinto et al., 2012a). These pronounced levels of identity and the presence of CCDs in the structure of these toxins often results in the occurrence of crossreactivity, thus hampering their use in molecular diagnosis (Jin et al., 2010).

The 3-D structure of the hyaluronidase (Fig. 9A) from $V$. vulgaris (Ves v 2) determined by X-ray crystallography revealed a central core $(\alpha / \beta)_{7}$ barrel further stabilized by two disulfide bonds (Skov 
Table 4

Biochemical and functional features of the best characterized proteinaceous toxins from social Hymenoptera venoms.

\begin{tabular}{|c|c|c|c|}
\hline Toxins & $\mathrm{MW} / \% \mathrm{DW}^{\mathrm{a}}$ & $\begin{array}{l}\text { Accession number } \\
\text { Uniprot/PDB }\end{array}$ & Described or suggested role in envenoming process \\
\hline
\end{tabular}

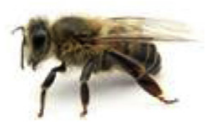

bees

Phospholipase A2

Hyaluronidase $\quad 45 \mathrm{KDa} / 2$

Acid phosphatase $49 \mathrm{KDa} / 1-2$

DPPIV

Vitellogenin

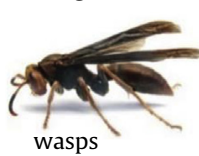

Phospholipase A1

$34 \mathrm{KDa} / 6-14$

$34 \mathrm{KDa} /$ unknown

$\begin{array}{ll}\text { Hyaluronidase } & 45 \mathrm{kDa} / 1-3 \\ & 35 \mathrm{kDa} / / \text { unknown } \\ & 42 \mathrm{kDa} / / \text { unknown } \\ & 38 \mathrm{kDa} / \text { unknown } \\ & 45 \mathrm{kDa} / \text { unknown } \\ & 100 / \text { unknown }\end{array}$

Antigen $5 \quad 23 \mathrm{kDa} / 5-10$

23/unknown

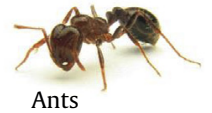

Phospholipase A1

Sol i 2

Antigen 5

Sol i 4

a Venom gland dry weight.

b Non-available.
P00630-PA2_APIME/1POC (Honeybee) P82971- PA2_BOMTE/n.a ${ }^{\mathrm{b}}$ (Bumble bees)

Q08169- HUGA_APIME/1FCV (Honeybee)

Q5BLY5-ACPH1_APIME/n.a

B2D0J4-VDPP4_APIME n.a

O18330-VIT_APIME/n.a
Cell membrane disruption, pore formation, mast cell degranulation/Hypersensitive reactions. HBV: Api m 1, Api c 1, Api d 1; BBV: Bom t 1, Bom p 1.

Spreading factor. Increases tissue/vascular permeability and facilitates toxin diffusion/Hypersensitive reactions (Api m 2).

Unknown enzymatic activity related pathophysiological role/Hypersensitive reactions (Api m 3)/Mast cells and basophils degranulation.

Activation of venom with polypeptides N-terminal Xaa

-Pro or Xaa-Ala/Hypersensitive reactions (Api m 5)

Unknown/Hypersensitive reaction (Api m 12)
P49369-PA1_VESVU/unavailable (JYV) P0CH87-PA1_VESCR/4QNN (Hornet) P53357 PA12_DOLMA/n.a (Bald-faced hornet) Q6Q250-PA13_POLDO/n.a (European paper wasp) Q9U6W0-PA1_POLAN/n.a (American paper wasp) A2VBC4-PA1_POLPI/n.a (South American paper wasp) P49370-HUGAA_VESVU/2ATM (YJV) P86875-HUGA_VESMG/n.a (Hornet) P49371-HUGA_DOLMA/n.a (bald-faced hornet) Q9U6V9-HUGA_POLAN/n.a (American paper wasp) P86687-HUGA_POLPI/n.a (South American paper wasp) B1A4F7_VDDP4_VESVU/n.a (YJV)

\section{Q05110-VA5_VESVU/1QNX (YJV)}

P86870-VA5_VESMG/n.a (Hornet) P10736-VA52_DOLMAn.a (bald-faced hornet) P81656-VA5_POLDO/n.a (European paper wasp) Q05109-VA5_POLAN/n.a (American paper wasp) P86686 VA5_POLPI/n.a (South American paper wasp)
Cell membrane disruption, pore formation/ Hypersensitive reactions. YJV: Ves v 1, Ves m 1, Ves s 1; Hornet: Vesp c 1, Vesp ma 1, Vesp m 1; Bald-faced hornet: Dol m 1; European paper wasp: Pol d 1, Pol a 1; American paper wasp: Pol a 1, Pol e 1; South America paper wasp: Poly p 1.

Similar to HBV hyaluronidase/Hypersensitive reactions. YJV: Ves v 2, Ves $m$ 2; Hornet: Vesp ma 2; Bald-faced hornet: Dol m 2; American paper wasp: Pol a 2; South American paper wasp: Poly p 1.

Similar to HBV DPPIV/Hypersensitive reactions. YJV: Ves $v 3$

Unknown/Hypersensitive reactions. YJV: Ves v 5, Ves v 5, Ves f 5, Ves g 5, Ves $m$ 5, Ves p 5, Ves s 5, Ves v 5; Hornet: Vesp c 5, Vesp ma 5, Vesp m 5; Bald-faced hornet: Dol $m$ 5, Dol a 5; European paper wasp: Pol d 5, Pol g 5; American paper wasp: Pol a 5, Pol e 5, Pol f 5, Pol m 5; South American paper wasp: Poly p 5, Poly s 5.
Q68KK0-PA1_SOLIN/n.a (Fire ant)

P35775-VA2_SOLIN/2YGU (Fire ant)

P35778 -VA3_SOLIN/2VZN (Fire ant)
Similar to wasp phospholipase A1/Hypersensitive reactions. Fire ant: Sol i 1

Putative pheromone ligand/Hypersensitive reactions. Fire ant: Sol i 2

Similar to wasp phospholipase A1/Hypersensitive reactions. Fire ant: Sol i 3, Sol r 3, Sol s 3 Sol; Asian needle ant: Pac 3

Unknown/Hypersensitive reactions. Fire ant: Sol i 4

P35777-VA4_SOLIN/unavailable (Fire ant) 


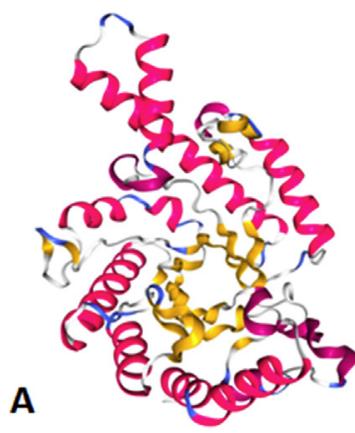

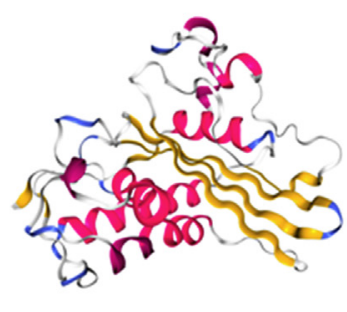

B

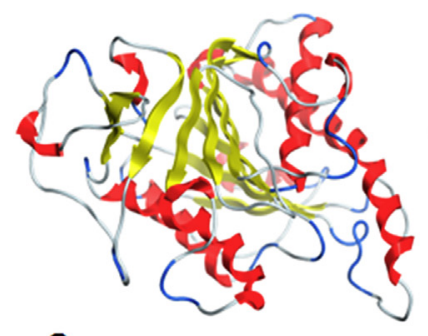

C

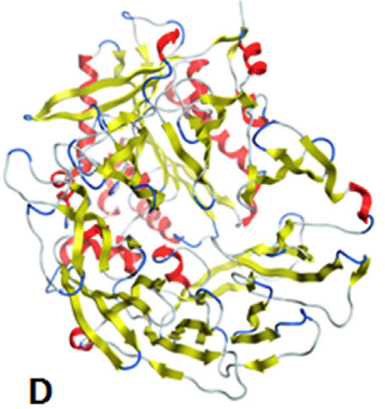

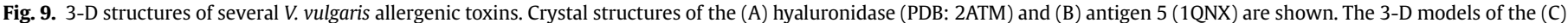

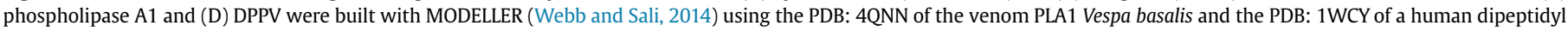
Peptidase IV (DPPIV), respectively.

structure (Fig. 9B) of Ves v 5, was solved by X-ray crystallography and revealed a unique fold for insect venom allergens consisting in an $\alpha-\beta-\alpha$ sandwich (Henriksen et al., 2001). Typically, insect venom antigen 5 are not glycosylated, CCD-lacking proteins that share high levels of primary sequence and 3-D structural identity among different species (Schiener et al., 2017). These similarities represent the molecular basis for peptide-based cross-reactivity occurrence during molecular diagnosis of sensitizations to Vespinae and Polistinae venoms (Caruso et al., 2007; Severino et al., 2010).

Up to 20 vespid antigen 5 s have been included in the official list of Hymenoptera venom allergens (www.allergen.org). Some members of these groups such as Ves v 5, Pol d 5, Pol a 5, Dol m 5 and Poly p 5 have been cloned and produced as recombinant proteins in different cellular systems (Bazon et al., 2017; Monsalve et al., 1999; Schiener et al., 2017; Vinzón et al., 2010). In general, the heterologous forms of the allergen proved to retain the allergenicity of their native counterparts and have been successfully used for improved CRD of insect venom allergy (Monsalve et al., 2012; Selb, 2015; Vos et al., 2013). This is particularly important for differential diagnosis of YJV and PWV sensitizations which remains a difficult task for clinicians due to the incidence of peptidebased cross-reactivity (Schiener et al., 2017).

A recently published study reported the B-cell linear epitopes mapping of the antigen 5 from $P$. paulista venom (Poly p 5) (dos Santos-Pinto et al., 2015). Nine epitopes immunoreactive to human IgG were identified in the analysis. One of them (peptide 7WAKTKE) was also recognized by human IgE antibodies. Interestingly, a multiple alignment of Poly p 5 with several annotated vespid venom antigen 5 reveals that peptide 7 is highly conserved in the primary structures of these toxins (data not shown). This linear B-cells epitope was proposed to be settled at a loop on the Poly p 5 surface (dos Santos-Pinto et al., 2015) and could represent a common determinant of cross-reactivity among these groups of allergenic toxins in vespid venoms.

\subsubsection{Vespid dipeptydylpeptidase IV}

As noted, DPPIVs from vespid venoms were initially identified in V. vulgaris (Ves v 3) using data obtained from its HBV counterpart, Api $\mathrm{m} 5$ (Blank et al., 2010). Ves v 3 is a clinically relevant allergen as up to $57 \%$ (20/35) of patients with a history of allergic reaction to YJV showed detectable sIgE to this allergen. Another study which aimed to evaluate the clinical value of novel HBV and JYV venom allergens, reported similar levels $(62,4 \%)$ of sensitization to Ves v 3 , highlighting the important role of vespid DPPIV as allergenic toxins in the envenoming process. The 3-D model of DPPIV from $V$. vulgaris venom was built with MODELLER (Webb and Sali, 2014) using the PDB: 1WCY of a human DPPIV, and is shown in Fig. 9D.

Recently, the DPPIV from $P$. dominula venom (Pol d 3) was identified, sequenced and produced as a heterologous protein (Schiener et al., 2018). The nucleotide sequence of the mature allergen encodes a $\sim 86,2 \mathrm{kDa}$ protein of 751 amino acids. As the authors mentioned, the discrepancy between the in silico calculated and the apparent molecular mass ( $100 \mathrm{kDa}$ ) is due to carbohydrate modifications. The primary sequence of Pol d 3 contains four potential N-glycosylation sites. Interestingly, unlike Api $\mathrm{m} 5$ and Ves $\mathrm{v}$ 3 , none of the posttranslational modifications in Pol d 3 correspond to insect CCDs as allergens from Polistinae lack this type of glycosylation in their structures (Blank et al., 2013a; Perez-Riverol et al., 2018b). The primary sequence of Pol d 3 shares a pronounced identity with Api $m 5$ (54, 0\%) and Ves v 3 (76, 6\%). Moreover, Pol d 3 cross-reacted with Api $\mathrm{m} 5$ and Ves $\mathrm{v} 3$, thus suggesting the presence of conserved clinically relevant epitopes among these insect venom toxins.

\subsection{Ant venom allergens}

Fire ant venoms are known to cause several pathophysiological symptoms including local erythema, hemolysis, paralysis inflammation and in a few cases life threatening hypersensitive reactions (Touchard et al., 2016a). However, despite being one of the most diverse organisms on earth with $\sim 25,000$ species estimated and more than 13,000 species currently identified (Bolton, 2014), data related to toxinology of ant venoms remains scarce (dos SantosPinto et al., 2012b). The small amounts of venom produced by each individual hampers the venomic analysis and consequently has limited the available biological data regarding ant venom composition.

Similar to other insects, most studies about proteinaceous toxins in ant venoms are related to allergens (Hoffman et al., 2005; Jeong et al., 2016; Padavattan et al., 2008; Wiese et al., 2007). Partially, this is due to the fact that about $50 \%$ of ant venom proteinaceous components are allergenic proteins (Bouzid et al., 2013). Nevertheless, the use of -omics- approaches combined with the application of novel bioinformatics tools has started to shed light on the diversity of ant venom proteome and particularly on the proteinaceous toxin arsenal (Aili et al., 2017; Bouzid et al., 2013; dos Santos-Pinto et al., 2012b; Torres et al., 2014). Some of the new compounds identified in these studies are similar to potent toxins described in Hymenoptera, snakes as well as other venomous animals (dos Santos-Pinto et al., 2012b).

Due to their clinical relevance, venoms from Genera Solenopsis, Myrmecia, Pachycondyla represent the most thoroughly studied among ants (Hoffman, 2010). Interestingly, rather than proteins, all the venom allergens currently identified from Myrmecia, the major cause of ant-related anaphylaxis in Australia, are peptides (Myr p 1Myr p 3) (Jakob et al., 2017; Wiese et al., 2007). 


\subsubsection{Phospholipases $A 1 / A 2$}

The PLA1 from the fire ant S. invicta (Sol i 1 ) is the only molecule from this group of enzymes officially recognized as a major ant venom allergen (Hoffman et al., 2005). The mature toxin is a 34 , $1 \mathrm{kDa}$ protein which contains 309 amino acids and three potential sites for N-glycosylation. The analysis of the primary sequence revealed that, similar to Ves $\mathrm{v} 1$ and Poly $\mathrm{p} 1$, Sol i 1 belongs to the GX class, lipoprotein lipase superfamily, pancreatic lipases (ab20.3) homologous family and RP2 sub-group of phospholipase (Santos et al., 2007). Furthermore, multiple alignment of the primary sequence with vespid PLA1s showed low levels of identity (35-40\%). Recently, an immunological analysis showed that no peptide-based cross-reactivity occurred with PLA1 from $P$. paulista (Perez-Riverol et al., 2018a). Interestingly, Sol i 1 is the only insect venom PLA1 which carries CCDs (Hoffman et al., 2005). As a consequence, the toxin has been shown to cause extensive carbohydrate-caused cross-reactivity with HBV and YJV (Hoffman et al., 1988).

Ant venomic analysis conducted recently has rendered confronting results regarding the presence of phospholipase A1-like proteins. A study on the transcriptome of the venom gland from Dinoponera quadriceps (predatory giant ant) unraveled the presence of Sol i 1-like sequences (Torres et al., 2014). Along with the so called lethal-like proteins, venom phospholipases accounted for the largest number of contigs. Notably, and as the author mentioned, Sol i 1-like toxins represented one of the predominant encoded proteins found in the venom gland of this ant. As expected, a proteome profiling of the S. invicta Buren also resulted in the detection of fragment matching Sol i 1 sequences (dos SantosPinto et al., 2012b), In contrast, no PLA1-related sequences were found in an analysis of the T. bicarinatum venom gland neither in the proteome profiling of the South American bullet ant Paraponera clavata (Aili et al., 2017). The 3-D model of phospholipase A1 (Sol i 1) was built with MODELLER (Webb and Sali, 2014) using the PDB: 4QNN of the venom PLA1 Vespa basalis, and is shown in Fig. 10A.

Phospholipase A2 has been identified as a common ant venom component Aili et al., 2017; dos Santos-Pinto et al., 2012b; Torres et al., 2014). Unlike Sol i 1, phospholipase A2 from ant venom are non-allergenic toxins that mediate toxic reactions in the victim (Touchard et al., 2016a). Two of the spots obtained in the venom proteome profiling of $S$. invicta corresponded to PLA2-like sequences (dos Santos-Pinto et al., 2012b). PLA2 is also highly abundant in the venom of $P$. clavata (Aili et al., 2017). Several isoforms of the enzyme were detected after 2-D gel-mediated separation of the venom proteinaceous components followed by mass-spectrometry sequencing. As mentioned about other insect toxins discussed here, the production of these isoforms could represent a strategy for evasion of the victim immune system (dos Santos et al., 2011). Finally, PLA2-like sequences were also detected in the transcriptome of the predatory giant ant (Torres et al., 2014). Similar to Api m 1 and other venomous animals, ant venom PLA2s have been suggested to cause membrane disruption, cytotoxicity, hemolysis and potential neurotoxicity (Touchard et al., 2016a).

\subsubsection{Ant venom antigen 5}

Antigen 5 is a predominant allergen also found in S. invicta (Sol i 3) and P. chinensis (Pac c 3) (Jeong et al., 2016; Padavattan et al., 2008). The mature Sol i 3 (23,9 kDa) consists of 212 amino acids and contains three putative N-glycosylation sites (Padavattan et al., 2008). None of these residues are modified in native Sol i 3 and consequently, the allergen is devoid of CCDs (Schiener et al., 2017). The 3-D structure (Fig. 10B) also resolved by X-ray crystallography showed the $\alpha-\beta-\alpha$ sandwich fold, previously reported for other insect venom antigen 5 such as Ves v 5 (Henriksen et al., 2001). The primary sequence of Sol i 3 showed low identity (45\%) with Ves v 5. Furthermore, it was proposed that major differences in the overall structures of these molecules occurred in the solvent-exposed loop. The limited identity and conservation of the surface charges and topology resulted in either low or lack of cross-reactivity between these insect allergenic toxins (Hoffman et al., 1988; Padavattan et al., 2008; Schiener et al., 2017).

An immunologic characterization of the Asian needle ant venom resulted in the identification of an antigen 5-like protein (Pac c 3 ) as a major allergen (Lee et al., 2009). After 2-D electrophoresis of the venom, the sera from allergic patients were used to detect IgE immunoreactive proteins which were further subjected to N-terminal sequencing and ESI-MS/MS. Pac c 3 (23 KDa) consists of 206 amino acids with no $\mathrm{N}$-glycosylation sites in the primary sequence. In multiple alignments, Pac c 3 showed $54 \%$ and $50 \%$ of identity with Sol i 3 and Ves v 3, respectively. The protein is recognized by sIgE antibodies in the sera of $85,7 \%$ of allergic patients highlighting its role as a prevalent allergen from $P$. chinensis venom. Similar rates of sensitization were detected using a recombinant form of the protein recently obtained in P. pastoris cells (Jeong et al., 2016). Interestingly, several Sol i 3-like sequences have also been detected in venomic analysis of $D$. quadriceps (Torres et al., 2014), P. clavata (Aili et al., 2017) and T. bicarinatum (Bouzid et al., 2013) also suggesting a critical role for these groups of toxins in the envenoming process.

In addition to Sol i 1 and Sol i 3, two proteins (Sol i 2 and Sol i 4) of unknown biological functions have been identified as major allergen in S. invicta venom (Lockwood et al., 2012). These are low molecular weight toxins ( $14 \mathrm{kDa})$ with partial identity $(35 \%)$ in their primary sequences. Soli 2 and -4 have been suggested to be unique to ant venoms (Touchard et al., 2016a). The 3-D structure (Fig. 10C) of Sol i 2 (14 kDa) was solved by X-ray crystallography and showed an overall fold consisting of five helices that enclose a central hydrophobic cavity (Borer et al., 2012). Structural alignment showed limited identity with a Drosophila pheromone ligand (LUSH). However, further analyses are required in order to unravel
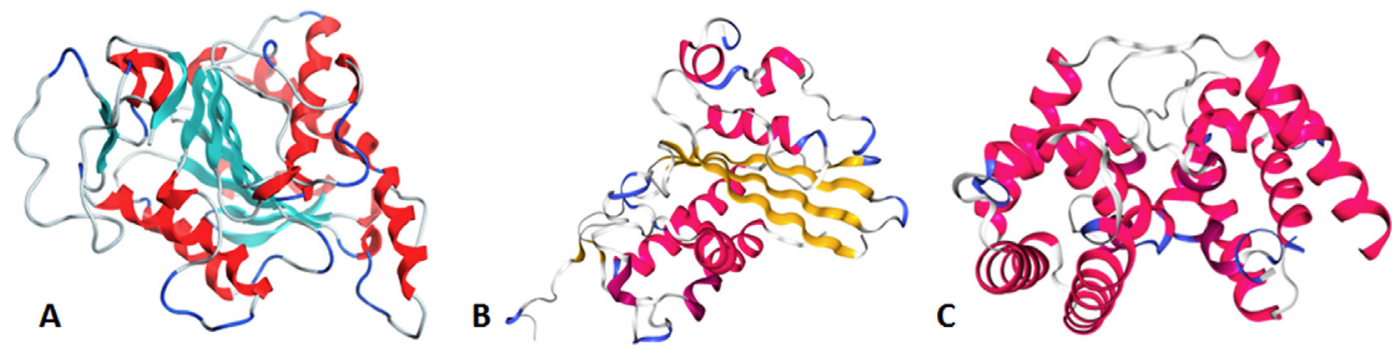

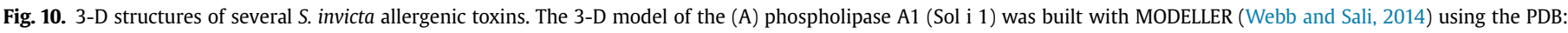
4QNN of the venom PLA1 Vespa basalis. Crystal structures of the (B) antigen 5 (Sol i 3) (PDB: 2VZN) and (C) Sol i 2 (PDB: 2YGU) are shown. 
the biological role of these molecules in ant venoms. Sol i 2 homologues were predicted to occur also in the transcriptome of D. quadriceps (Torres et al., 2014).

\subsubsection{Non allergenic toxins}

Several non-allergenic proteins with predicted toxic activity have been identified in ant venoms. The proteomic profiling of S. invicta (dos Santos-Pinto et al., 2012a,b) resulted in the detection of a myotoxin 2-like protein similar to those previously reported in snake venoms and are known to cause myonecrosis in the victims (Gallacci and Cavalcante, 2010). Moreover, four putative neurotoxins were identified in the analysis of fire ant venom proteome including an U5-ctenitoxin-Pk1a, a Scolopendra toxin, an alphatoxin Tc48a and a PsTX-60-like toxin. The alpha-toxin Tc48a are putative blockers with $\mathrm{Na}^{+}$-channel activity in vertebrates (Batista et al., 2002). Meanwhile U5-ctenitoxin-Pk1a have been suggested to cause spastic paralysis and death in mice (Richardson et al., 2006).

The biochemical and functional characteristics of the most thoroughly studied proteinaceous components of Hymenoptera venoms are summarized in Table 4.

\section{Concluding remarks}

Current available data shows that Hymenoptera venoms can present a great diversity of peptides and proteins, most of them with potential pharmacological and biotechnological application. However, these venoms remain partially explored as low abundant bioactive compounds have been difficult to identify, isolate and further characterize using structural and functional analysis. Until recently, the detection of venom toxins in social Hymenoptera was significantly hampered by the low amount of samples that can be obtained from each one and the technical limitations used for the venomic analyses. Nonetheless, the application of novel approaches that allow in depth analysis of venom peptidome and proteome has significantly uncovered hundreds of previously hidden toxins from social Hymenoptera venoms. The data resulting from these analyses revealed that, in addition to common features such as the presence of short, linear polycationic peptides, which usually acts in natural membranes- and homologue allergens, insect venoms contain differential and specialized molecular compositions evolved to improve ecological success. This remarkable complexity and diversity makes social Hymenoptera venoms a promising source of bioactive molecules that can be explored as novel pharmaceutical products such as antimicrobial, neuroactive and anticancer drugs. Furthermore, additional efforts to explore these venoms will likely result in the discovery of more bioactive toxins which may become useful tools for the rational design of novel biotechnological products, and will provide new insight on the molecular evolution in Hymenoptera venoms.

\section{Ethical statement}

This contribution is a review and does not warrant an ethical statement.

\section{Conflict of interest}

The authors declare that there are no conflicts of interest.

\section{Acknowledgments}

This work was supported by grants from FAPESP (Proc. 2016/ 16212-5), CNPq (Proc. 301656/2013-4) and INCT Program/ii-CNPq/ MCT. M.S.P. is a researcher from the National Research Council of
Brazil-CNPq. A.P.R. is a Post-Doc Research fellow from FAPESP (Proc. 2017/22405-3) at São Paulo State University - UNESP, Rio Claro, Brazil, J.R.A.S.P. is a Post-Doc Research fellow from CNPq (Proc. 150699/2017-4) at São Paulo State University - UNESP, Rio Claro, Brazil and A.M.L. is a researcher from Center for Genetic Engineering and Biotechnology, System Biology Department, Havana, Cuba.

\section{Transparency document}

Transparency document related to this article can be found online at https://doi.org/10.1016/j.toxicon.2018.04.029.

\section{References}

Aili, S.R., Touchard, A., Escoubas, P., Padula, M.P., Orivel, J., Dejean, A., Nicholson, G.M., 2014. Diversity of peptide toxins from stinging ant venoms. Toxicon 92, 166-178.

Aili, S.R., Touchard, A., Petitclerc, F., Dejean, A., Orivel, J., Padula, M.P., Escoubas, P., Nicholson, G.M., 2017. Combined peptidomic and proteomic analysis of electrically stimulated and manually dissected venom from the South American bullet ant Paraponera clavata. J. Proteome Res. 16, 1339-1351.

Aird, S.D., 2008. Snake venom dipeptidyl peptidase IV: taxonomic distribution and quantitative variation. Comp. Biochem. Physiol. B Biochem. Mol. Biol. 150, 222-228.

Alvarez-Fischer, D., Noelker, C., Vulinović, F., Grünewald, A., Chevarin, C., Klein, C., Oertel, W.H., Hirsch, E.C., Michel, P.P., Hartmann, A., 2013. Bee venom and its component apamin as neuroprotective agents in a Parkinson disease mouse model. PLoS One 8, e61700.

An, S., Chen, L., Wei, J.F., Yang, X., Ma, D., Xu, X., Xu, X., He, S., Lu, J., Lai, R., 2012. Purification and characterization of two new allergens from the venom of Vespa magnifica. PLoS ONE 7, 5-12.

Antonicelli, L., Bilò, M.B., Bonifazi, F., 2002. Epidemiology of hymenoptera allergy. Curr. Opin. allergy Clin. Immunol. 2, 341-346.

Arcuri, H.A., Gomes, P.C., de Souza, B.M., Dias, N.B., Brigatte, P., Stabeli, R.G., Palma, M.S., 2016. Paulistine - the functional duality of a wasp venom peptide toxin. Toxins 8, 61.

Argiolas, A., Herring, P., Pisano, J.J., 1985. Amino acid sequence of bumblebee MCD peptide: a new mast cell degranulating peptide from the venom of the bumblebee Megabombus pennsylvanicus. Peptides 6, 431-436.

Argiolas, A., Pisano, J.J., 1985. Bombolitins, a new class of mast cell degranulating peptides from the venom of the bumblebee Megabombus pennsylvanicus. J. Biol. Chem. 260, 1437-1444.

Arseniev, A.S., Pluzhnikov, K.A., Nolde, D.E., Sobol, A.G., Torgov, M.Y., Sukhanov, S.V., Grishin, E.V., 1994. Toxic principle of selva ant venom is a pore-forming protein transformer. FEBS Lett. 347, 112-116.

Baek, Y.H., Huh, J.E., Lee, J.D., Park, D.S., 2006. Antinociceptive effect and the mechanism of bee venom acupuncture (Apipuncture) on inflammatory pain in the rat model of collagen-induced arthritis: mediation by $\alpha 2$-Adrenoceptors. Brain Res. 1073, 305-310.

Banks, B.E.C., Dempsey, C.E., Vernon, C.A., Warner, J.A., Yamey, J., 1990. Anti-inflammatory activity of bee venom peptide 401 (mast cell degranulating peptide) and compound 48/80 results from mast cell degranulation in vivo. Br. J. Pharmacol. 99, 350-354.

Banks, B.E.C., Shipolini, R.A., 1986. Chemistry and pharmacology of honey-bee venom. Venoms Hymenoptera Biochem. Pharmacol. Behav. aspects 329-416.

Baptista-Saidemberg, N.B., Saidemberg, D.M., de Souza, B.M., César-Tognoli, L.M.M., Ferreira, V.M.R., Mendes, M.A., dos Santos Cabrera, M.P., Neto, J.R., Palma, M.S., 2010. Protonectin (1-6): a novel chemotactic peptide from the venom of the social wasp Agelaia pallipes pallipes. Toxicon 56, 880-889.

Baptista-Saidemberg, N.B., Saidemberg, D.M., Palma, M.S., 2011. Profiling the peptidome of the venom from the social wasp Agelaia pallipes pallipes. J. Proteom. $74,2123-2137$.

Barbault, F., Landon, C., Guenneugues, M., Meyer, J.-P., Schott, V., Dimarcq, J.-L., Vovelle, F., 2003. Solution structure of Alo-3: a new knottin-type antifungal peptide from the insect Acrocinus longimanus. Biochemistry 42, 14434-14442.

Barkan, N., Bayazit, M., Ozel Demiralp, D., 2017. Proteomic characterization of the venom of five Bombus (thoracobombus) species. Toxins 9, 362.

Batista, C.V.F., Zamudio, F.Z., Lucas, S., Fox, J.W., Frau, A., Prestipino, G., Possani, L.D., 2002. Scorpion toxins from Tityus cambridgei that affect Na+-channels. Toxicon 40, 557-562.

Bazon, M.L., Perez-Riverol, A., dos Santos-Pinto, J.R.A., Palma, M.S., Zollner, Ricardo de Lima, Brochetto-braga, M.R., 2017. Heterologous expression, purification and immunoreactivity of the antigen 5 from Polybia paulista wasp venom. Toxins 9, $1-14$.

Benmoussa, K., Authier, H., Prat, M., AlaEddine, M., Lefèvre, L., Rahabi, M.C., Bernad, J., Aubouy, A., Bonnafé, E., Leprince, J., 2017. P17, an original host defense peptide from ant venom, promotes antifungal activities of macrophages through the induction of C-type Lectin Receptors dependent on LTB4-mediated PPAR $\gamma$ activation. Front. Immunol. 8. 
Bhoola, K.D., Figueroa, C.D., Worthy, K., 1992. Bioregulation of kinins: kallikreins, kininogens, and kininases. Pharmacol. Rev, 44, 1-80.

Bilò, M.B., 2011. Anaphylaxis caused by Hymenoptera stings: from epidemiology to treatment. Allergy Eur. J. Allergy Clin. Immunol. 66, 35-37.

Blank, S., Bantleon, F.I., McIntyre, M., Ollert, M., Spillner, E., 2012. The major royal jelly proteins 8 and 9 (Api m 11) are glycosylated components of Apis mellifera venom with allergenic potential beyond carbohydrate-based reactivity. Clin. Exp. Allergy 42, 976-985.

Blank, S., Michel, Y., Seismann, H., Plum, M., Greunke, K., Grunwald, T., Bredehorst, R., Ollert, M., Braren, I., Spillner, E., 2011a. Evaluation of different glycoforms of honeybee venom major allergen phospholipase A2 (Api m 1) produced in insect cells. Protein Peptide Lett. 18, 415-422.

Blank, S., Neu, C., Hasche, D., Bantleon, F.I., Jakob, T., Spillner, E., 2013a. Polistes species venom is devoid of carbohydrate-based cross-reactivity and allows interference-free diagnostics. J. Allergy Clin. Immunol. 131, 1239.

Blank, S., Seismann, H., Bockisch, B., Braren, I., Cifuentes, L., McIntyre, M., Rühl, D., Ring, J., Bredehorst, R., Ollert, M.W., Grunwald, T., Spillner, E., 2010. Identification, recombinant expression, and characterization of the $100 \mathrm{kDa}$ high molecular weight Hymenoptera venom allergens Api m 5 and Ves v. 3. J. Immunol. 184, 5403-5413 (Baltimore, Md.: 1950).

Blank, S., Seismann, H., Mcintyre, M., Ollert, M., Wolf, S., Bantleon, F.I., Spillner, E., 2013b. Vitellogenins are new high molecular weight components and allergens ( Api m 12 and ves v. 6 ) of Apis mellifera and Vespula vulgaris venom. PLOS ONE 8.

Blank, S., Seismann, H., Michel, Y., McIntyre, M., Cifuentes, L., Braren, I., Grunwald, T., Darsow, U., Ring, J., Bredehorst, R., Ollert, M., Spillner, E., 2011b. Api m 10, a genuine A. mellifera venom allergen, is clinically relevant but underrepresented in therapeutic extracts. Allergy Eur. J. Allergy Clin. Immunol. 66, 1322-1329.

Bloch, G., Cohen, M., 2014. The expression and phylogenetics of the Inhibitor Cysteine Knot peptide OCLP1 in the honey bee Apis mellifera. J. Insect Physiol. 65, 1-8.

Bolton, B., 2014. An Online Catalog of the Ants of the World.

Bordon, K.C.F., Wiezel, G.A., Amorim, F.G., Arantes, E.C., 2015. Arthropod venom Hyaluronidases: biochemical properties and potential applications in medicine and biotechnology. J. Venom. Anim. Toxins Incl. Trop. Dis. 21, 43.

Borer, A.S., Wassmann, P., Schmidt, M., Hoffman, D.R., Zhou, J.J., Wright, C., Schirmer, T., Marković-Housley, Z., 2012. Crystal structure of Sol i 2: a major allergen from fire ant venom. J. Mol. Biol. 415, 635-648.

Borodina, I., Jensen, B.M., Wagner, T., Hachem, M.A., Søndergaard, I., Lars, K., 2011. Expression of enzymatically inactive wasp venom phospholipase A1 in Pichia pastoris. PLoS ONE 6.

Bouzid, W., Klopp, C., Verdenaud, M., Ducancel, F., Vétillard, A., 2013. Profiling the venom gland transcriptome of Tetramorium bicarinatum (Hymenoptera: formicidae): the first transcriptome analysis of an ant species. Toxicon 70, 70-81.

Cajal, Y., Jain, M.K., 1997. Synergism between mellitin and phospholipase A2 from bee venom: apparent activation by intervesicle exchange of phospholipids. Biochemistry 36, 3882-3893.

Calvete, J.J., Juarez, P., Sanz, L., 2007. Snake venomics: strategy and applications. J. Mass Spectrom. 42, 1405-1414.

Calvete, J.J., Lomonte, B., 2015. A bright future for integrative venomics. Toxicon 107, $159-162$.

Calvete, J.J., Sanz, L., Pla, D., Lomonte, B., Gutiérrez, J.M., 2014. Omics meets biology: application to the design and preclinical assessment of antivenoms. Toxins 6, 3388-3405.

Caruso, B., Bonadonna, P., Severino, M.G., Manfredi, M., Dama, A., Schiappoli, M., Rizzotti, P., Senna, G., Passalacqua, G., 2007. Evaluation of the IgE cross-reactions among vespid venoms. A possible approach for the choice of immunotherapy. Allergy 62, 561-564.

Chahdi, A., Sorokin, A., Dunn, M.J., Landry, Y., 2004. The Rac/Cdc42 guanine nucleotide exchange factor $\beta 1$ Pix enhances mastoparan-activated G i-dependent pathway in mast cells. Biochem. Biophys. Res. Commun. 317, 384-389.

Chen, H.-S., Lei, J., He, X., Wang, Y., Wen, W.-W., Wei, X.-Z., Graven-Nielsen, T., You, H.-J., Arendt-Nielsen, L., 2006. Pivotal involvement of neurogenic mechanism in subcutaneous bee venom-induced inflammation and allodynia in unanesthetized conscious rats. Exp. Neurol. 200, 386-391.

Chen, J., Guan, S.M., Sun, W., Fu, H., 2016. Melittin, the major pain-producing substance of bee venom. Neurosci. Bull. https://doi.org/10.1007/s12264-016-0024y.

Chen, J., Lariviere, W.R., 2010. The nociceptive and anti-nociceptive effects of bee venom injection and therapy: a double-edged sword. Prog. Neurobiol. 92, $151-183$.

Chen, L.-Y., Cheng, C.-W., Lin, J.-J., Chen, W.-Y., 2007. Exploring the effect of cholesterol in lipid bilayer membrane on the melittin penetration mechanism. Anal. Biochem. 367, 49-55.

Choi, J.H., Jang, A.Y., Lin, S., Lim, S., Kim, D., Park, K., Han, S., Yeo, J., Seo, H.S., 2015. Melittin, a honeybee venom-derived antimicrobial peptide, may target methicillin-resistant Staphylococcus aureus. Mol. Med. Rep. 12, 6483-6490.

Choo, Y.M., Lee, K.S., Yoon, H.J., Je, Y.H., Lee, S.W., Sohn, H.D., Jin, B.R., 2010. Molecular cloning and antimicrobial activity of bombolitin, a component of bumblebee Bombus ignitus venom. Comp. Biochem. Physiol. B Biochem. Mol. Biol. 156, 168-173.

Cologna, C.T., Cardoso, J., dos, S., Jourdan, E., Degueldre, M., Upert, G., Gilles, N., Uetanabaro, A.P.T. Costa Neto, E.M., Thonart, P., de Pauw, E., Quinton, L., 2013. Peptidomic comparison and characterization of the major components of the venom of the giant ant Dinoponera quadriceps collected in four different areas of
Brazil. J. Proteom. 94, 413-422.

Costa, H., 1997. Biochemical characterization of the venom of the social wasp Agelaia pallipes pallipes (Hymenoptera-Vespidae). J. Venom. Animals Toxins 3, 50

Craik, D.J., Daly, N.L., Waine, C., 2001. The cystine knot motif in toxins and implications for drug design. Toxicon 39, 43-60.

Davies, N.W., Wiese, M.D., Brown, S.G.A., 2004. Characterisation of major peptides in "jack jumper"ant venom by mass spectrometry. Toxicon 43, 173-183.

Davis, J., Jones, A., Lewis, R.J., 2009. Remarkable inter- and intra-species complexity of conotoxins revealed by LC/MS. Peptides 30, 1222-1227.

de Graaf, D.C., Aerts, M., Danneels, E., Devreese, B., 2009. Bee, wasp and ant venomics pave the way for a component-resolved diagnosis of sting allergy. J. Proteom. 72, 145-154.

De Oliveira, M.R., Palma, M.S., 1998. Polybitoxins: a group of phospholipases A2 from the venom of the neotropical social wasp paulistinha (Polybia paulista) Toxicon 36, 189-199.

De Souza, B.M., Mendes, M.A., Santos, L.D., Marques, M.R., C_esar, L.M.M. Almeida, R.N.A., Pagnocca, F.C., Konno, K., Palma, M.S., 2005. Structural and functional characterization of two novel peptide toxins isolated from the venom of the social wasp Polybia paulista. Peptides 26, 2157-2164.

de Souza, B.M., da Silva, A.V.R., Resende, V.M.F., Arcuri, H.A., dos Santos Cabrera, M.P., Ruggiero Neto, J., Palma, M.S., 2009. Characterization of two nove polyfunctional mastoparan peptides from the venom of the social wasp Polybia paulista. Peptides 30, 1387-1395.

de Souza, B.M., dos Santos Cabrera, M.P., Neto, J.R., Palma, M.S., 2011. Investigating the effect of different positioning of lysine residues along the peptide chain of mastoparans for their secondary structures and biological activities. Amino Acids 40, 77-90.

de Souza, B.M., Marques, M.R., Tomazela, D.M., Eberlin, M.N., Mendes, M.A. Palma, M.S., 2004. Mass spectrometric characterization of two novel inflammatory peptides from the venom of the social wasp Polybia paulista. Rapid Commun. Mass Spectrom. RCM 18, 1095-1102.

de Souza, B.M., Palma, M.S., 2008. Monitoring the positioning of short polycationic peptides in model lipid bilayers by combining hydrogen/deuterium exchange and electrospray ionization mass spectrometry. Biochim. Biophys. Acta BBA Biomembr. 1778, 2797-2805.

De Souza, B.M., Palma, M.S., 2009. Peptides from Hymenoptera Venoms: Biochemistry, Pharmacology and Potential Applications in Health and Biotechnology. Animal Toxins: the State of Art. Perspectives on Health and Biotechnology. UFMG Press, Belo Horizonte, Brazil, pp. 273-297.

Dekan, Z., Heady, S.J., Scanlon, M., Baldo, B.A., Lee, T.-H., Aguilar, M.-I., Deuis, J.R. Vetter, I., Elliott, A.G., Amado, M., 2017. $\Delta$-Myrtoxin-Mp1a Is a Helical Heterodimer from the Venom of the Jack Jumper Ant with Antimicrobial, Membrane Disrupting and Nociceptive Activities. Angewandte Chemie.

Delazari dos Santos, L., dos Santos Pinto, A., Roberto, J., Ribeiro da Silva Menegasso, A., Menezes Saidemberg, D., Garcia, C., Maria, A., Sergio Palma, M. 2012. Proteomic profiling of the molecular targets of interactions of the mastoparan peptide Protopolybia MP-III at the level of endosomal membranes from rat mast cells. Proteomics 12, 2682-2693.

Dennis, E.A., Cao, J., Hsu, Y.-H., Magrioti, V., Kokotos, G., 2011. Phospholipase A2 enzymes: physical structure, biological function, disease implication, chemical inhibition, and therapeutic intervention. Chem. Rev. 111, 6130-6185.

Dias, N.B., De Souza, B.M., Gomes, P.C., Brigatte, P., Palma, M.S., 2015. Peptidome profiling of venom from the social wasp Polybia paulista. Toxicon 107, 290-303.

Dohtsu, K., Okumura, K., Hagiwara, K., Palma, M.S., Nakajima, T., 1993. Isolation and sequence analysis of peptides from the venom of Protonectarina sylveirae (Hymenoptera-Vespidae). Nat. Toxins 1, 271-276.

Donovan, G.R., Baldo, B.A., 1997. Pilosulin 2 from Ant Venom, Cloning and Expression of a cDNA Encoding it and its Antihypertensive Properties. PCT International Application, p. 27.

dos Santos-Pinto, J.R.A., Delazari Dos Santos, L., Arcuri, H.A., Ribeiro Da Silva Menegasso, A., Pêgo, P.N., Santos, K.S., Castro, F.M., Kalil, J.E., De-Simone, S.G. Palma, M.S., 2015. B-cell linear epitopes mapping of antigen-5 allergen from Polybia paulista wasp venom. J. Allergy Clin. Immunol. 135, 264-267.

dos Santos-Pinto, J.R.A., dos Santos, L.D., Andrade Arcuri, H., Castro, F.M., Kalil, J.E., Palma, M.S., 2014. Using proteomic strategies for sequencing and posttranslational modifications assignment of antigen-5, a major allergen from the venom of the social wasp Polybia paulista. J. Proteome Res. 13, 855-865.

dos Santos, L.D., da Silva Menegasso, A.R. dos Santos Pinto, J.R.A., Santos, K.S. Castro, F.M., Kalil, J.E., Palma, M.S., 2011. Proteomic characterization of the multiple forms of the PLAs from the venom of the social wasp Polybia paulista. Protein Peptide Lett. 11, 1403-1412.

dos Santos, L.D., Santos, K.S., dos Santos Pinto, J.R.A., Dias, N.B., Souza, B.M. De, Dos Santos, M.F., Perales, J., Domont, G.B., Castro, F.M., Kalil, J.E., Palma, M.S., 2010. Profiling the proteome of the venom from the social wasp Polybia paulista: clue to understand the envenoming mechanism. J. Proteome Res. 9, 3867-3877.

dos Santos Cabrera, M.P., Arcisio-Miranda, M., da Costa, L.C., de Souza, B.M. Costa, S.T.B., Palma, M.S., Neto, J.R., Procopio, J., 2009. Interactions of mast cell degranulating peptides with model membranes: a comparative biophysical study. Arch. Biochem. Biophys. 486, 1-11.

Dos Santos Cabrera, M.P., Costa, S.T.B., De Souza, B.M., Palma, M.S., Ruggiero, J.R., Ruggiero Neto, J., 2008. Selectivity in the mechanism of action of antimicrobial mastoparan peptide Polybia-MP1. Eur. Biophys. J. 37, 879-891.

dos Santos-Pinto, J.R.A., Delazari Dos Santos, L., Andrade Arcuri, H., Baptista Dias, N., Sergio Palma, M., 2012a. Proteomic characterization of the hyaluronidase (E.C. 
3.2.1.35) from the venom of the social wasp Polybia paulista. Protein Peptide Lett. 19, 625-635.

dos Santos-Pinto, J.R.A., Fox, E.G.P., Saidemberg, D.M., Santos, L.D., Da Silva Menegasso, A.R., Costa-Manso, E., MacHado, E.A., Bueno, O.C., Palma, M.S. 2012b. Proteomic view of the venom from the fire ant Solenopsis invicta buren. J. Proteome Res. 11, 4643-4653.

Dotimas, E.M., Hamid, K.R., Hider, R.C., Ragnarsson, U., 1987. Isolation and structure analysis of bee venom mast cell degranulating peptide. Biochim. Biophys. Acta BBA Protein Struct. Mol. Enzym. 911, 285-293.

Escoubas, P., Sollod, B.L., King, G.F., 2008a. Venom landscapes: mining the complexity of spider venoms via a combined cDNA and mass spectrometric approach. Toxicon 47, 650-663.

Escoubas, P., Quinton, L., Nicholson, G.M., 2008b. Venomics: unravelling the complexity of animal venoms with mass spectrometry. J. Mass Spectrom. 43, 279-295.

Favreau, P., Menin, L., Michalet, S., Perret, F., Cheneval, O., Stöcklin, M., Bulet, P., Stöcklin, R., 2006. Mass spectrometry strategies for venom mapping and peptide sequencing from crude venoms: case applications with single arthropod specimen. Toxicon 47, 676-687.

Felix, J.P., Liu, J., Schmalhofer, W.A., Bailey, T., Bednarek, M.A., Kinkel, S., Weinglass, A.B., Kohler, M., Kaczorowski, G.J., Priest, B.T., 2006. Characterization of Kir1. 1 channels with the use of a radiolabeled derivative of tertiapin. Biochemistry 45, 10129-10139.

Ferrer, V.P., de Mari, T.L., Gremski, L.H., Trevisan Silva, D., da Silveira, R.B., Gremski, W., Chaim, O.M., Senff-Ribeiro, A., Nader, H.B., Veiga, S.S., 2013. A novel hyaluronidase from brown spider (Loxosceles intermedia) venom (Dietrich's Hyaluronidase): from cloning to functional characterization. PLoS Neglected Trop. Dis. 7, 1-12.

Fitzgerald, K.T., Flood, A.A., 2006. Hymenoptera stings. Clin. Tech. Small Anim. Pract. 21, 194-204.

Fratini, F., Cilia, G., Turchi, B., Felicioli, A., 2017. Insects, arachnids and centipedes venom: a powerful weapon against bacteria. A literature review. Toxicon 130, 91-103.

Frick, M., Fischer, J., Helbling, A., Ruëff, F., Wieczorek, D., Ollert, M., Pftüzner, W., Müller, S., Huss-Marp, J., Dorn, B., Biedermann, T., Lidholm, J., Ruecker, G., Bantleon, F., Miehe, M., Spillner, E., Jakob, T., 2016. Predominant Api m 10 sensitization as risk factor for treatment failure in honey bee venom immunotherapy. J. Allergy Clin. Immunol. 138, 1663-1671 e9.

Gajski, G., Garaj-Vrhovac, V., 2013. Melittin: a lytic peptide with anticancer properties. Environ. Toxicol. Pharmacol. 36, 697-705.

Gajski, G., Garaj-Vrhovac, V., 2009. Radioprotective effects of honeybee venom (Apis mellifera) against 915-mhz microwave radiation-induced DNA damage in wistar rat lymphocytes: in vitro study. Int. J. Toxicol. 28, 88-98.

Gallacci, M., Cavalcante, W.L.G., 2010. Understanding the in vitro neuromuscular activity of snake venom Lys49 phospholipase A2 homologues. Toxicon 55,1-11.

Gati, C.D.C., Mortari, M.R., Schwartz, E.F., 2012. Towards therapeutic applications of arthropod venom. J. Toxicol. 2012.

Gauldie, J., Hanson, J.M., Rumjanek, F.D., Shipolini, R.A., Vernon, C.A., 1976. The peptide components of bee venom. FEBS J. 61, 369-376.

Gauldie, J., Hanson, J.M., Shipolini, R.A., Vernon, C.A., 1978. The structures of some peptides from bee venom. FEBS J. 83, 405-410.

Georgieva, D., Greunke, K., Betzel, C., 2010. Three-dimensional model of the honeybee venom allergen Api m 7: structural and functional insights. Mol. Biosyst. 6, 1056-1060.

Gilly, W.F., Richmond, T.A., Duda, T.F., Elliger, C., Lebaric, Z., Schulz, J., Bingham, J.P. Sweedler, J.V., 2011. A diverse family of novel peptide toxins from an unusual cone snail, Conus californicus. J. Exp. Biol. 214, 147-161.

Girish, K.S., Shashidharamurthy, R., Nagaraju, S., Gowda, T.V., Kemparaju, K., 2004 Isolation and characterization of hyaluronidase a "spreading factor" from Indian cobra (Naja naja) venom. Biochimie 86, 193-202.

Gobbo, M., Biondi, L., Filira, F., Rocchi, R., Piek, T.O.M., 1995. Cyclic analogues of wasp kinins from Vespa analis and Vespa tropica. Chem. Biol. Drug Des, 45, 282-289.

Gobbo, M., Biondi, L., Filira, F., Scolaro, B., Rocchi, R., Piek, T., 1992. Synthesis and biological activity of the mono-and di-galactosyl-vespulakinin 1 analogues. Chem. Biol. Drug Des. 40, 54-61.

Golden, D., 2007. Insect sting anaphylaxis. Immunol. Allergy Clin. N. Am. 27, $261-272$.

Golden, D.B.K., 2017. Insect allergy. In: Middleton's Allergy Essentials. Elsevier, pp. 377-393.

Gomes, P.C., De Souza, B.M., Dias, N.B., Brigatte, P., Mourelle, D., Arcuri, H.A., Dos Santos Cabrera, M.P., Stabeli, R.G., Neto, J.R., Palma, M.S., 2014. Structure-function relationships of the peptide Paulistine: a novel toxin from the venom of the social wasp Polybia paulista. Biochim. Biophys. Acta Gen. Subj. 1840, 170-183.

Grunwald, T., Bockisch, B., Spillner, E., Ring, J., Bredehorst, R., Ollert, M.W., 2006. Molecular cloning and expression in insect cells of honeybee venom allergen acid phosphatase (Api m 3). J. Allergy Clin. Immunol. 117, 848-854.

Guzman, J., Téné, N., Touchard, A., Castillo, D., Belkhelfa, H., Haddioui-Hbabi, L., Treilhou, M., Sauvain, M., 2017. Anti-helicobacter pylori properties of the antvenom peptide bicarinalin. Toxins (Basel) 10 (1). https://doi.org/10.3390/ toxins10010021 pii: E21.

Habermann, E., 1984. Apamin. Pharmacol. Ther. 25, 255-270.

Habermann, E., 1972. Bee and wasp venoms. Science 177, 314-322.

Hao, J., Liu, M.-G., Yu, Y.-Q., Cao, F.-L., Li, Z., Lu, Z.-M., Chen, J., 2008. Roles of peripheral mitogen-activated protein kinases in melittin-induced nociception and hyperalgesia. Neuroscience 152, 1067-1075.
Hartmann, A., Müllner, J., Meier, N., Hesekamp, H., Van Meerbeeck, P., Habert, M.-O., Kas, A., Tanguy, M.-L., Mazmanian, M., Oya, H., 2016. Bee venom for the treatment of Parkinson disease-a randomized controlled clinical trial. PloS One 11, e0158235.

Hemmer, W., Focke, M., Kolarich, D., Dalik, I., Götz, M., Jarisch, R., 2004. Identification by immunoblot of venom glycoproteins displaying immunoglobulin Ebinding N-glycans as cross-reactive allergens in honeybee and yellow jacket venom. Clin. Exp. Allergy 34, 460-469.

Hendrich, A.B., Mozrzymas, J.W., Konopinska, D., Scuka, M., 2002. The effect of poneratoxin on neuromuscular transmission in the rat diaphragm. Cell. Mol. Biol. Lett. 7, 195-202.

Henriksen, A., King, T.P., Mirza, O., Monsalve, R.I., Meno, K., Ipsen, H., Larsen, J.N., Gajhede, M., Spangfort, M.D. 2001. Major venom allergen of yellow jackets, Ves v. 5: structural characterization of a pathogenesis-related protein superfamily. Proteins Struct. Funct. Genet. 45, 438-448.

Herzig, V., King, G.F., 2015. The cystine knot is responsible for the exceptional stability of the insecticidal spider toxin $\omega$-hexatoxin-Hv1a. Toxins 7, 4366-4380.

Hirai, Y., Yasuhara, T., Yoshida, H., Nakajima, T., Fujino, M., Kitada, C., 1979. Chem. Pharm. Bull. 27, 1942.

Hoffman, D., Shipman, W., Babin, D., 1977. Allergens in bee venom II. Two new high molecular weight allergenic specificities. J. Allergy Clin. Immunol. 59, 147-153.

Hoffman, D.R., 2010. Ant venoms. Curr. Opin. Allergy Clin. Immunol. 10, 342-346.

Hoffman, D.R., 2006. Hymenoptera venom allergens. Clin. Rev. Allergy Immunol. 30, 109-128.

Hoffman, D.R., 1977. Allergens in bee venom. III. Identification of allergen B of bee venom as an acid phosphatase. J. Allergy Clin. Immunol. 59, 364-366.

Hoffman, D.R., Dove, D.E., Moffitt, J.E., Stafford, C.T., 1988. Allergens in Hymenoptera venom. XXI. Cross-reactivity and multiple reactivity between fire ant venom and bee and wasp venoms. J. Allergy Clin. Immunol. 82, 828-834.

Hoffman, D.R., Sakell, R.H., Schmidt, M., 2005. Sol i 1, the phospholipase allergen of imported fire ant venom. J. Allergy Clin. Immunol. 115, 611-616.

Hoffman, R., Ph, D., Shipman, H., Diego, S., 1976. Allergens in Bee Venom, vol. 58.

Hori, Y., Demura, M., Iwadate, M., Ulrich, A.S., Niidome, T., Aoyagi, H., Asakura, T. 2001. Interaction of mastoparan with membranes studied by $1 \mathrm{H}-\mathrm{NMR}$ spectroscopy in detergent micelles and by solid-state 2H-NMR and 15N-NMR spectroscopy in oriented lipid bilayers. FEBS J. 268, 302-309.

Hou, M.H., Chuang, C.Y., Ko, T.P., Hu, N.J., Chou, C.C., Shih, Y.P., Ho, C.L., Wang, A.H.J., 2016. Crystal structure of vespid phospholipase A1 reveals insights into the mechanism for cause of membrane dysfunction. Insect Biochem. Mol. Biol. 68, 79-88.

Hu, H., Chen, D., Li, Y., Zhang, X., 2006. Effect of polypeptides in bee venom on growth inhibition and apoptosis induction of the human hepatoma cell line SMMC-7721 in-vitro and Balb/c nude mice in-vivo. J. Pharm. Pharmacol. 58, $83-89$.

Hugues, M., Romey, G., Duval, D., Vincent, J.P., Lazdunski, M., 1982. Apamin as a selective blocker of the calciumdependent potassium channel in neuroblastoma cells: voltage-clamp and biochemical characterization of the toxin receptor. Proc. Natl. Acad. Sci. U. S. A. 79, 1308-1312.

Huh, J.-E., Baek, Y.-H., Lee, M.-H., Choi, D.-Y., Park, D.-S., Lee, J.-D., 2010. Bee venom inhibits tumor angiogenesis and metastasis by inhibiting tyrosine phosphorylation of VEGFR-2 in LLC-tumor-bearing mice. Cancer Lett. 292, 98-110.

Inagaki, H., Akagi, M., Imai, H.T., Taylor, R.W., Kubo, T., 2004. Molecular cloning and biological characterization of novel antimicrobial peptides, pilosulin 3 and pilosulin 4, from a species of the Australian ant genus myrmecia. Arch. Biochem. Biophys. 428, 170-178.

Inagaki, H., Masuko, K., Kudo, T., 2008. SKTXs: peptides identified from the ant Strumigenys kumadori that block sodium channels. In: Proceedings of the 8thAsia-Pacific Congress on Animal, Plant and Microbial Toxins, Hanoi, Vietnam, pp. 2-6.

Issam, A.-A., Zimmermann, S., Reichling, J., Wink, M., 2015. Pharmacological synergism of bee venom and melittin with antibiotics and plant secondary metabolites against multi-drug resistant microbial pathogens. Phytomedicine 22, $245-255$.

Jakob, T., Müller, U., Helbling, A., Spillner, E., 2017. Component resolved diagnostics for hymenoptera venom allergy. Curr. Opin. Allergy Clin. Immunol. 17 (5), 363-372.

Jasani, B., Kreil, G., Mackler, B.F., Stanworth, D.R., 1979. Further studies on the structural requirements for polypeptide-mediated histamine release from rat mast cells. Biochem. J. 181, 623-632.

Jeong, K.Y., Yi, M.H., Son, M., Lyu, D., Lee, J.H., Yong, T.S., Park, J.W., 2016. IgE reactivity of recombinant pac c 3 from the Asian needle ant (Pachycondyla chinensis). Int. Arch. Allergy Immunol. 169, 93-100.

Jia, C., Qi, W., He, Z., Qiao, B., 2006. Sequencing peptides by electrospray ion-trap mass spectrometry: a useful tool in synthesis of Axinastatin 3. Cent. Eur. J. Chem. 4, 620-631.

Jim, S.Y., Wittkowski, K.M., 2003. Inflammatory role of two venom components of yellow jackets (Vespula vulgaris): a mast cell degranulating peptide mastoparan and phospholipase A1. Int. Arch. Allergy Immunol. 131, 25-32.

Jiménez-Vargas, J.M., Possani, L.D., Luna-Ramírez, K., 2017. Arthropod toxins acting on neuronal potassium channels. Neuropharmacology 127, 139-160.

Jin, C., Focke, M., Léonard, R., Jarisch, R., Altmann, F., Hemmer, W., 2010. Reassessing the role of hyaluronidase in yellow jacket venom allergy. J. Allergy Clin. Immunol. 125, 184-190.

Jin, W., Lu, Z., 1999. Synthesis of a stable form of tertiapin: a high-affinity inhibitor 
for inward-rectifier K+ channels. Biochemistry 38, 14286-14293.

Jin, W., Lu, Z., 1998. A novel high-affinity inhibitor for inward-rectifier K+ channels. Biochemistry 37, 13291-13299.

Johnson, S.R., Copello, J.A., Evans, M.S., Suarez, A.V., 2010. A biochemical characterization of the major peptides from the Venom of the giant Neotropical hunting ant Dinoponera australis. Toxicon 55, 702-710.

Johnson, S.R., Rikli, H.G., Schmidt, J.O., Evans, M.S., 2017. A reexamination of poneratoxin from the venom of the bullet ant Paraponera clavata. Peptides 98, $51-62$.

Kabsch, W., Sander, C., 1983. Dictionary of protein secondary structure: pattern recognition of hydrogen-bonded and geometrical features. Biopolymers 22 (12), 2577-2637.

Kanjhan, R., Coulson, E.J., Adams, D.J., Bellingham, M.C., 2005. Tertiapin-Q blocks recombinant and native large conductance $\mathrm{K}+$ channels in a use-dependent manner. J. Pharmacol. Exp. Ther. 314, 1353-1361.

Kazuma, K., Masuko, K., Konno, K., Inagaki, H., 2017. Combined venom gland transcriptomic and venom peptidomic analysis of the predatory ant Odontomachus monticola. Toxins 9, 323.

Kim, H., Lee, G., Park, S., Chung, H.-S., Lee, H., Kim, J.-Y., Nam, S., Kim, S.K., Bae, H., 2013. Bee venom mitigates cisplatin-induced nephrotoxicity by regulating CD4. Evid. Based Compl. Altern. Med. 2013.

King, G.F., Gentz, M.C., Escoubas, P., Nicholson, G.M., 2008. A rational nomenclature for naming peptide toxins from spiders and other venomous animals. Toxicon 52, 264-276.

King, G.F., Hardy, M.C., 2013. Spider-venom peptides: structure, pharmacology, and potential for control of insect pests. Annu. Rev. Entomol. 58, 475-496.

King, T.P., Lu, G., Gonzalez, M., Qian, N., Soldatova, L., 1996. Yellow jacket venom allergens, hyaluronidase and phospholipase: sequence similarity and antigenic cross-reactivity with their hornet and wasp homologs and possible implications for clinical allergy. J. Allergy Clin. Immunol. 98, 588-600.

King, T.P., Sobotka, A.K., Kochoumian, L., Lichtenstein, L.M., 1976. Allergens of honey bee venom. Arch. Biochem. Biophys. 172, 661-671. https://doi.org/10.1016/ 0003-9861(76)90121-1.

Kitamura, H., Yokoyama, M., Akita, H., Matsushita, K., Kurachi, Y., Yamada, M., 2000. Tertiapin potently and selectively blocks muscarinic $\mathrm{K}+$ channels in rabbit cardiac myocytes. J. Pharmacol. Exp. Ther. 293, 196-205.

Koburova, K., Mikhaĭlova, S., Shkenderov, S., 1984. Antipyretic effect of a polypeptide from bee venom-adolapin. Eksp. Meditsina i Morfol. 23, 143-148.

Koburova, K.L., Michailova, S.G., Shkenderov, S.V., 1985. Further investigation on the antiinflammatory properties of adolapin-bee venom polypeptide. Acta Physiol. Pharmacol. Bulg. 11, 50-55.

Köhler, J., Blank, S., Müller, S., Bantleon, F., Frick, M., Huss-Marp, J., Lidholm, J., Spillner, E., Jakob, T., 2014. Component resolution reveals additional major allergens in patients with honeybee venom allergy. J. Allergy Clin. Immunol. 133. 1383-1389.

Konno, K., Palma, M.S., Hitara, I.Y., Juliano, M.A., Juliano, L., Yasuhara, T., 2002. Identification of bradykinins in solitary wasp venoms. Toxicon 40, 309-312.

Korošec, P., Valenta, R., Mittermann, I., Čelesnik, N., Eržen, R., Zidarn, M., Košnik, M., 2011. Low sensitivity of commercially available rApi $m 1$ for diagnosis of honeybee venom allergy. J. Allergy Clin. Immunol. 128, 671-673. https://doi.org/ 10.1016/j.jaci.2011.03.012.

Kreil, G., Mollay, C., Kaschnitz, R., Haiml, L., Vilas, U., 1980. Prepromellitin: specific cleavage of the pre and propeptide in vitro. Ann. N. Y. Acad. Sci. 343, 338-346.

Krishnakumari, V., Nagaraj, R., 1997. Antimicrobial and hemolytic activities of crabrolin, a 13-residue peptide from the venom of the European hornet, Vespa crabro, and its analogs. Chem. Biol. Drug Des. 50, 88-93.

Kuhn-Nentwig, L., 2003. Antimicrobial and cytolytic peptides of venomous arthropods. Cell. Mol. Life Sci. CMLS 60, 2651-2668.

Kwon, Y.B., Lee, H.J., Han, H.J., Mar, W.C., Kang, S.K., Yoon, O.B., Beitz, A.J., Lee, J.H., 2002. The water-soluble fraction of bee venom produces antinociceptive and anti-inflammatory effects on rheumatoid arthritis in rats. Life Sci. 71, 191-204.

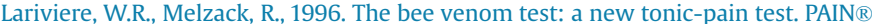
66, 271-277.

Lazdunski, M., 1983. Apamin, a neurotoxin specific for one class of Ca2+-dependent $\mathrm{K}+$ channels. Cell Calcium 4, 421-428.

Lee, E.K., Jeong, K.Y., Lyu, D.P., Lee, Y.W., Sohn, J.H., Lim, K.J., Hong, C.S., Park, J.W. 2009. Characterization of the major allergens of Pachycondyla chinensis in ant sting anaphylaxis patients. Clin. Exp. Allergy 39, 602-607.

Lee, G. Bae, H., 2016a. Anti-inflammatory applications of melittin, a major component of bee venom: detailed mechanism of action and adverse effects. Molecules 21, 616

Lee, G., Bae, H., 2016b. Bee venom phospholipase A2: yesterday's enemy becomes today's friend. Toxins 8 .

Lee, N., Wu, A., 2004. Thrombosis and cerebral infarction after massive wasp. J. Am. Med. 116, 567-569.

Lee, S.H., Baek, J.H., Yoon, K.A., 2016a. Differential properties of venom peptides and proteins in solitary vs. social hunting wasps. Toxins 8, 1-29.

Lee, S.H., Baek, J.H., Yoon, K.A., 2016b. Differential properties of venom peptides and proteins in solitary vs. Social hunting wasps. Toxins 8.

Leite, N.B., Aufderhorst-Roberts, A., Palma, M.S., Connell, S.D., Neto, J.R., Beales, P.A., 2015. PE and PS lipids synergistically enhance membrane poration by a peptide with anticancer properties. Biophys. J. 109, 936-947. https://doi.org/10.1016/ j.bpj.2015.07.033.

Levin, S.G., Shamsutdinova, A.A., Godukhin, O.V., 2010. Apamin, a selective blocker of SKCa channels, inhibits posthypoxic hyperexcitability but does not affect rapid hypoxic preconditioning in hippocampal CA1 pyramidal neurons in vitro. Neurosci. Lett. 484, 35-38.

Li, K.-C., Chen, J., 2004. Altered pain-related behaviors and spinal neuronal responses produced by sc injection of melittin in rats. Neuroscience 126 753-762.

Li, L., Chen, K., Xiang, Y., Yoshimura, T., Su, S., Zhu, J., Bian, X. -w., Wang, J.M., 2015. New development in studies of formyl-peptide receptors: critical roles in host defense. J. Leukoc. Biol. 99, 1-11.

Liu, S., Yu, M. He, Y., Xiao, L., Wang, F., Song, C., Sun, S., Ling, C., Xu, Z., 2008. Melittin prevents liver cancer cell metastasis through inhibition of the Rac1-dependent pathway. Hepatology 47, 1964-1973.

Lockwood, S.A., HaghiPour-Peasley, J., Hoffman, D.R., Deslippe, R.J., 2012. Identification, expression, and immuno-reactivity of Sol i 2 \& Sol i 4 venom proteins of queen red imported fire ants, Solenopsis invicta Buren (Hymenoptera: formicidae). Toxicon 60, 752-759. https://doi.org/10.1016/j.toxicon.2012.05.011.

Lu, Z.-M., Xie, F., Fu, H., Liu, M.-G., Cao, F.-L., Hao, J., Chen, J., 2008. Roles of peripheral P2X and P2Y receptors in the development of melittin-induced nociception and hypersensitivity. Neurochem. Res. 33, 2085-2091.

Marković-Housley, Z., Miglierini, G., Soldatova, L., Rizkallah, P.J., Müller, U., Schirmer, T., 2000. Crystal structure of hyaluronidase, a major allergen of bee venom. Structure 8, 1025-1035. https://doi.org/10.1016/S0969-2126(00)00511 6.

Matsuzaki, K., Yoneyama, S., Miyajima, K., 1997. Pore formation and translocation of melittin. Biophys. J. 73, 831-838.

Matteucci, E., Giampietro, O., 2009. Dipeptidyl peptidase-4 (CD26): knowing the function before inhibiting the enzyme. Curr. Med. Chem. 16, 2943-2951. https://doi.org/10.2174/092986709788803114.

Mendes, M.A., De Souza, B.M., Marques, M.R., Palma, M.S., 2004. Structural and biological characterization of two novel peptides from the venom of the neotropical social wasp Agelaia pallipes pallipes. Toxicon 44, 67-74.

Mendes, M.A., De Souza, B.M., Palma, M.S., 2005. Structural and biological characterization of three novel mastoparan peptides from the venom of the neotropical social wasp Protopolybia exigua (Saussure). Toxicon 45, 101-106. https://doi.org/10.1016/j.toxicon.2004.09.015.

Meng, Y., Yang, X.X., Zhang, J.L., Yu, D.Q., 2012. A novel peptide from Apis mellifer and solid-phase synthesis of its analogue. Chin. Chem. Lett. 23, 1161-1164.

Mentlein, R., 1999. Dipeptidyl-peptidase IV (CD26)-role in the inactivation of reg ulatory peptides. Regul. Pept. 85, 9-24. https://doi.org/10.1016/S0167-0115(99) 00089-0.

Michel, Y., McIntyre, M., Ginglinger, H., Ollert, M., Cifuentes, L., Blank, S., Spillner, E. 2012. The putative serine protease inhibitor Api m 6 from Apis mellifera venom: recombinant and structural evaluation. J. Invest. Allergol. Clin. Immunol. 22, 476-484.

Miles, G.P., Samuel, M.A., Jones, A.M., Ellis, B.E., 2004. Mastoparan rapidly activates plant MAP kinase signaling independent of heterotrimeric G proteins. Plant physiol. 134, 1332-1336.

Monoi, N., Usui, M., Takahashi, S., Ito, H., Kumakura, K., Kasai, H., 2004. Tetrapeptides on $\mathrm{N}$-and $\mathrm{C}$-terminal regions of mastoparan inhibit catecholamine release from chromaffin cells by blocking nicotinic acetylcholine receptor. Cell. Mol. Neurobiol. 24, 37-50.

Monsalve, R.I., Lu, G., King T.P. 1999. Expressions of recombinant venom allergen, antigen 5 of yellowjacket (Vespula vulgaris) and paper wasp (Polistes annularis), in bacteria or yeast. Protein Expr. Purif. 16, 410-416. https://doi.org/10.1006 prep.1999.1082.

Monsalve, R.I., Vega, A., Marqués, L., Miranda, A., Fernández, J., Soriano, V., Cruz, S. Domínguez-Noche, C., Sánchez-Morillas, L., Armisen-Gil, M., Guspí, R. Barber, D., 2012. Component-resolved diagnosis of vespid venom-allergic individuals: phospholipases and antigen $5 \mathrm{~s}$ are necessary to identify Vespula or Polistes sensitization. Allergy Eur. J. Allergy Clin. Immunol. 67, 528-536. https://doi.org/10.1111/j.1398-9995.2011.02781.x.

Moon, D.-O., Park, S.-Y., Heo, M.-S., Kim, K.-C., Park, C., Ko, W.S., Choi, Y.H., Kim, G.-Y. 2006. Key regulators in bee venom-induced apoptosis are Bcl-2 and caspase-3 in human leukemic U937 cells through downregulation of ERK and Akt. Int. Immunopharmacol. 6, 1796-1807.

Moreno, M., Giralt, E., 2015. Three valuable peptides from bee and wasp venoms for therapeutic and biotechnological use: melittin, apamin and mastoparan. Toxins 7, 1126-1150. https://doi.org/10.3390/toxins7041126.

Mourelle, D., Brigatte, P., Bringanti, L.D.B., De Souza, B.M., Arcuri, H.A., Gomes, P.C., Baptista-Saidemberg, N.B., Neto, J.R., Palma, M.S., 2014. Hyperalgesic and edematogenic effects of Secapin-2, a peptide isolated from Africanized honeybee (Apis mellifera) venom. Peptides 59, 42-52.

Müller, U., Schmid-Grendelmeier, P., Hausmann, O., Helbling, A., 2012. IgE to recombinant allergens Api m 1, Ves v. 1, and Ves v 5 distinguish double sensitization from cross-reaction in venom allergy. Allergy Eur. J. Allergy Clin. Immunol. 67, 1069-1073. https://doi.org/10.1111/j.1398-9995.2012.02847.x.

Müller, U.R., 2011. Hymenoptera venom proteins and peptides for diagnosis and treatment of venom allergic patients. Inflamm. Allergy Drug Targets 10, 420-428. https://doi.org/10.2174/187152811797200704.

Murata, K., Shinada, T., Ohfune, Y., Hisada, M., Yasuda, A., Naoki, H., Nakajima, T. 2009. Novel mastoparan and protonectin analogs isolated from a solitary wasp, Orancistrocerus drewseni drewseni. Amino Acids 37, 389-394.

Nakajima, T., 1986. Pharmacological biochemistry of vespid venoms. Venoms Hymenoptera 309-327.

Nicolas, J., Lin, Y., Lambeau, G., Ghomashchi, F., Lazdunski, M., Gelb, M.H., 1997. Localization of structural elements of bee venom phospholipase a 2 involved in 
N-type receptor binding and neurotoxicity. J. Biol. Chem. 272, 7173-7181. https://doi.org/10.1074/jbc.272.11.7173.

Nolde, D.E., Sobol, A.G., Pluzhnikov, K.A., Grishin, E.V., Arseniev, A.S., 1995. Threedimensional structure of ectatomin from Ectatomma tuberculatum ant venom. J. Biomol. NMR 5, 1-13.

Ollert, M., Blank, S., 2015. Anaphylaxis to insect venom allergens : role of molecular diagnostics. Curr. Allergy Asthma Rep. 15 https://doi.org/10.1007/s11882-0150527-z.

Orivel, J., Redeker, V., Le Caer, J.-P., Krier, F., Revol-Junelles, A.-M., Longeon, A., Chaffotte, A., Dejean, A., Rossier, J., 2001. Ponericins, new antibacterial and insecticidal peptides from the venom of the ant Pachycondyla goeldii. J. Biol. Chem. 276, 17823-17829.

Oropeza, A.R., Bindslev-Jensen, C., Broesby-Olsen, S., Kristensen, T., Møller, M.B. Vestergaard, H., Kjaer, H.F., Halken, S., Lassen, A., Mortz, C.G., 2017. Patterns of anaphylaxis after diagnostic work-up: a follow-up study of 226 patients with suspected anaphylaxis. Allergy 0,1-9. https://doi.org/10.1111/all.13207.

Oršolić, N., Šver, L., Verstovšek, S., Terzić, S., Bašić, I., 2003. Inhibition of mammary carcinoma cell proliferation in vitro and tumor growth in vivo by bee venom. Toxicon 41, 861-870.

Padavattan, S., Schmidt, M., Hoffman, D.R., Marković-Housley, Z., 2008. Crystal structure of the major allergen from fire ant venom, Sol i 3. J. Mol. Biol. 383, 178-185. https://doi.org/10.1016/j.jmb.2008.08.023.

Palma, M.S., 2013. Hymenoptera venom peptides. In: Kastin, Abba (Ed.), Handbook of Biologically Active Peptides. Academic press/Elsevier, San Diego, pp. 416-422.

Pan, J., Hink, W.F., 2000. Isolation and characterization of myrmexins, six isoforms of venom proteins with anti-inflammatory activity from the tropical ant Pseudomyrmex triplarinus. Toxicon 38, 1403-1413.

Park, J.-H., Lee, W.-R., Kim, H.-S., Han, S.-M., Chang, Y.-C., Park, K.-K., 2014. Protective effects of melittin on tumor necrosis factor- $\alpha$ induced hepatic damage through suppression of apoptotic pathway and nuclear factor-kappa B activation. Exp. Biol. Med. 239, 1705-1714.

Peggion, E., Mammi, S., Schievano, E., 1997. Conformation and interactions of bioactive peptides from insect venoms: the bombolitins. Biopolymers 43 419-431.

Peiren, N., Vanrobaeys, F., De Graaf, D.C., Devreese, B., Van Beeumen, J., Jacobs, F.J., 2005. The protein composition of honeybee venom reconsidered by a proteomic approach. Biochim. Biophys. Acta Proteins Proteom. 1752, 1-5. https:// doi.org/10.1016/j.bbapap.2005.07.017.

Perez-Riverol, A., Campos Pereira, F.D., Musacchio Lasa, A., Romani Fernandes, L.G., dos Santos-Pinto, J.R.A., Justo-Jacomini, D.L., Oliveira de Azevedo, G. Bazon, M.L., Palma, M.S., Zollner, R. de L., Brochetto-Braga, M.R., 2016. Molecular cloning, expression and IgE-immunoreactivity of phospholipase A1, a major allergen from Polybia paulista (Hymenoptera: vespidae) venom. Toxicon 124, 44-52. https://doi.org/10.1016/j.toxicon.2016.11.006.

Perez-Riverol, A., dos Santos-Pinto, J.R.A., Lasa, A.M., Palma, M.S., BrochettoBraga, M.R., 2017. Wasp venomic: unravelling the toxins arsenal of Polybia paulista venom and its potential pharmaceutical applications. J. Proteom. 161, 88-103. https://doi.org/10.1016/j.jprot.2017.04.016.

Perez-Riverol, A., Fernandes, L.G.R., Musacchio Lasa, A., dos Santos-Pinto, J.R.A. Moitinho Abram, D., Izuka Moraes, G.H., Jabs, F., Miehe, M., Seismman, H. Palma, M.S., de Lima Zollner, R., Spillner, E., Brochetto-Braga, M.R., 2018a. Phospholipase A1-based cross-reactivity among venoms of clinically relevant Hymenoptera from Neotropical and temperate regions. Mol. Immunol. 93, 87-93. https://doi.org/10.1016/j.molimm.2017.11.007.

Perez-Riverol, A., Justo-Jacomini, D.L., de Lima Zollner, R., Brochetto-Braga, M.R., 2015. Facing Hymenoptera venom allergy: from natural to recombinant allergens. Toxins 7, 2551-2570. https://doi.org/10.3390/toxins7072551.

Perez-Riverol, A., Miehe, M., Jabs, F., Seismann, H., Fernandes, L.G.R., de Lima Zollner, R., Jakob, T., Brochetto-Braga, M.R., Spillner, E., 2018b. Venoms of Neotropical wasps lack cross-reactive carbohydrate determinants enabling reliable protein-based sIgE determination. J. Allergy Clin. Immunol. https:/ doi.org/10.1016/j.jaci.2017.12.990 (in press).

Piek, T., 1991. Neurotoxic kinins from wasp and ant venoms. Toxicon 29, 139-149.

Piek, T., Buitenhuis, A., Simonthomas, R.T., Ufkes, J.G.R., Mantel, P., 1983. Smooth muscle contracting compounds in the venom of Megascolia flavifrons (Hym: Scoliidae) with notes on the stinging behaviour. Comp. Biochem. Physiol. Part C Comp. Pharmacol. 75, 145-152.

Piek, T. Duval, A., Hue, B., Karst, H., Lapied, B., Mantel, P., Nakajima, T., Pelhate, M., Schmidt, J.O., 1991. Poneratoxin, a novel peptide neurotoxin from the venom of the ant, Paraponera clavata. Comp. Biochem. Physiol. Part C Comp. Pharmacol. 99, 487-495.

Piek, T., Hue, B., Mony, L., Nakajima, T., Pelhate, M., Yasuhara, T., 1987a. Block of synaptic transmission in insect CNS by toxins from the venom of the wasp Megascolia flavifrons (Fab.). Comp. Biochem. Physiol. Part C Comp. Pharmacol. 87, 287-295.

Piek, T., Hue, B., Pelhate, M., Mony, L., 1987b. The venom of the wasp Campsomeris sexmaculata (F.) blocks synaptic transmission in insect CNS. Comp. Biochem. Physiol. Part C Comp. Pharmacol. 87, 283-286.

Pluzhnikov, K.A., Kozlov, S.A., Vassilevski, A.A., Vorontsova, O.V., Feofanov, A.V., Grishin, E.V., 2014. Linear antimicrobial peptides from Ectatomma quadridens ant venom. Biochimie 107, 211-215.

Pluzhnikov, K.A., Nolde, D.E., Tertishnikova, S.M., Sukhanov, S.V., Sobol, A.G., Torgov, M.Y., Filippov, A.K., Arseniev, A.S., Grishin, E.V., 1994. Structural and functional-studies of toxic principle of ectatomma-tuberculatum ant venom.
Bioorg. Khimiya 20, 857-871.

Pluzhnikov, K.A., Shevchenko, L.V., Grishin, E.V., 2000. Ant polypeptide toxins. In: Animal Toxins. Springer, pp. 90-98.

Pluzhnikov, K., Nosyreva, E., Shevchenko, L., Kokoz, Y., Schmalz, D., Hucho, F., Grishin, E., 1999. Analysis of ectatomin action on cell membranes. FEBS J. 262, 501-506.

Przybilla, B., Ruëff, F., 2010. Hymenoptera venom allergy, 2010, 114-129. https:// doi.org/10.1111/j.1610-0387.2009.07125.x.

Puri, N., Roche, P.A., 2008. Mast cells possess distinct secretory granule subsets whose exocytosis is regulated by different SNARE isoforms. Proc. Natl. Acad. Sci. 105, 2580-2585.

Rady, I., Siddiqui, I.A., Rady, M., Mukhtar, H., 2017. Melittin, a major peptide component of bee venom, and its conjugates in cancer therapy. Cancer Lett. https://doi.org/10.1016/j.canlet.2017.05.010.

Raghuraman, H., Chattopadhyay, A., 2007. Melittin: a membrane-active peptide with diverse functions. Biosci. Rep. 27, 189-223.

Ramu, Y., Xu, Y., Lu, Z., 2008. Engineered specific and high-affinity inhibitor for a subtype of inward-rectifier K+ channels. Proc. Natl. Acad. Sci. 105, 10774-10778.

Ribeiro, S.P., Mendes, M.A., Santos, L.D., Dos, Souza, B.M., De, Marques, M.R., Azevedo, W.F. De, Palma, M.S., 2004. Structural and functional characterization of N-terminally blocked peptides isolated from the venom of the social wasp Polybia paulista. Peptides 25, 2069-2078. https://doi.org/10.1016/ j.peptides.2004.08.019.

Richardson, M., Pimenta, A.M.C., Bemquerer, M.P., Santoro, M.M., Beirao, P.S.L., Lima, M.E., Figueiredo, S.G., Bloch, C., Vasconcelos, E.A.R., Campos, F.A.P., Gomes, P.C., Cordeiro, M.N., 2006. Comparison of the partial proteomes of the venoms of Brazilian spiders of the genus Phoneutria. Comp. Biochem. Physiol. C Toxicol. Pharmacol. 142, 173-187. https://doi.org/10.1016/j.cbpc.2005.09.010.

Rifflet, A., Gavalda, S., Téné, N., Orivel, J., Leprince, J., Guilhaudis, L., Génin, E., Vétillard, A., Treilhou, M., 2012. Identification and characterization of a novel antimicrobial peptide from the venom of the ant Tetramorium bicarinatum. Peptides 38, 363-370.

Rodríguez, A.A., Salceda, E. Garateix, A.G., Zaharenko, A.J. Peigneur, S., López, O. Pons, T., Richardson, M., Díaz, M., Hernández, Y., 2014. A novel sea anemone peptide that inhibits acid-sensing ion channels. Peptides 53, 3-12.

Romero-Curiel, A., López-Carpinteyro, D., Gamboa, C., Zamudio, S., Flores, G., 2011. Apamin induces plastic changes in hippocampal neurons in senile Sprague-Dawley rats. Synapse 65, 1062-1072.

Rungsa, P., Incamnoi, P., Sukprasert, S., Uawonggul, N., Klaynongsruang, S., Daduang, J., Patramanon, R., Roytrakul, S., Daduang, S., 2016. Cloning, structural modelling and characterization of VesT2s, a wasp venom hyaluronidase (HAase) from Vespa tropica. J. Venom. Anim. toxins Incl. Trop. Dis. 22, 28. https://doi.org/ 10.1186/s40409-016-0084-5.

Santos, L.D., Santos, K.S., de Souza, B.M., Arcuri, H.A., Cunha-Neto, E., Castro, F.M., Kalil, J.E., Palma, M.S., 2007. Purification, sequencing and structural characterization of the phospholipase A1 from the venom of the social wasp Polybia paulista (Hymenoptera, Vespidae). Toxicon 50, 923-937. https://doi.org/ 10.1016/j.toxicon.2007.06.027.

Schachter, M., Thain, E.M., 1954. Chemical and pharmacological properties of the potent, slow contracting substance (kinin) in wasp venom. Br. J. Pharmacol. 9, 352-359.

Schiener, M., Eberlein, B., Moreno-Aguilar, C., Pietsch, G., Serrano, P., McIntyre, M., Schwarze, L., Russkamp, D., Biedermann, T., Spillner, E., Darsow, U., Ollert, M., Schmidt-Weber, C.B., Blank, S., 2017. Application of recombinant antigen 5 allergens from seven allergy-relevant Hymenoptera species in diagnostics. Allergy Eur. J. Allergy Clin. Immunol. 72, 98-108. https://doi.org/10.1111/ all.13000.

Schiener, M., Hilger, C., Eberlein, B., Pascal, M., Kuehn, A., Revets, D., Planchon, S., Pietsch, G., Serrano, P., Moreno-Aguilar, C., de la Roca, F., Biedermann, T., Darsow, U., Schmidt-Weber, C.B., Ollert, M., Blank, S., 2018. The high molecular weight dipeptidyl peptidase IV Pol d 3 is a major allergen of Polistes dominula venom. Sci. Rep. https://doi.org/10.1038/s41598-018-19666-7 (in press).

Schievano, E., Mammi, S., Monticelli, L., Ciardella, M., Peggion, E., 2003. Conformational studies of a bombolitin III-derived peptide mimicking the four-helix bundle structural motif of proteins. J. Am. Chem. Soc. 125, 15314-15323.

Schmidt, C.A., Shattuck, S.O., 2014. The higher classification of the ant subfamily Ponerinae (Hymenoptera: formicidae), with a review of ponerine ecology and behavior. Zootaxa 3817, 1-242.

Scott, D.L., Otwinowski, Z., Gelb, M.H., Sigler, P.B., 1990. Crystal structure of beevenom phospholipase $\mathrm{A} 2$ in a complex with a transition-state analogue. Science 250, 1563-1566.

Seismann, H., Blank, S., Braren, I., Greunke, K., Cifuentes, L., Grunwald, T., Bredehorst, R., Ollert, M., Spillner, E., 2010a. Dissecting cross-reactivity in Hymenoptera venom allergy by circumvention of $\alpha-1,3$-core fucosylation. Mol. Immunol. 47, 799-808, https://doi.org/10.1016/j.molimm.2009.10.005.

Seismann, H., Blank, S., Cifuentes, L., Braren, I., Bredehorst, R., Grunwald, T., Ollert, M., Spillner, E., 2010b. Recombinant phospholipase A1 (Ves v. 1) from yellow jacket venom for improved diagnosis of Hymenoptera venom hypersensitivity. Clin. Mol. Allergy 8, 7. https://doi.org/10.1186/1476-7961-8-7.

Selb, J., 2015. Improved recombinant Api m 1- and Ves v. 5-based IgE testing to dissect bee and yellow jacket allergy and their correlation with the severity of the sting reaction. Exp. Allergy 621-630. https://doi.org/10.1111/cea.12639.

Severino, M.G., Caruso, B., Bonadonna, P., Labardi, D., Macchia, D., Campi, P., Passalacqua, G., 2010. Cross reactivity between european hornet and yellow 
jacket venoms. Eur. Ann. Allergy Clin. Immunol. 42, 141-145.

Shen, L.-R., Ding, M.-H., Zhang, L.-W., Zhang, W.-G., Liu, L., Li, D., 2010. Expression of a bee venom phospholipase A2 from Apis cerana cerana in the baculovirusinsect cell. J. Zhejiang Univ. Sci. B 11, 342-349. https://doi.org/10.1631/ jzus.B0900254.

Shipolini, R.A., Doonan, S., Vernon, C.A., 1974. The disulphide bridges of phospholipase A2 from bee venom. Eur. J. Biochem. FEBS 483, 477-483.

Shkenderov, S., Koburova, K., 1982. Adolapin-a newly isolated analgetic and antiinflammatory polypeptide from bee venom. Toxicon 20, 317-321.

Skov, L.K., Seppälä, U., Coen, J.J.F., Crickmore, N., King, T.P., Monsalve, R., Kastrup, J.S., Spangfort, M.D., Gajhede, M., 2006. Structure of recombinant Ves v. 2 at $2.0 \AA$ resolution: structural analysis of an allergenic hyaluronidase from wasp venom. Acta Crystallogr. Sect. D. Biol. Crystallogr. 62, 595-604.

Smith, R., Separovic, F., Milne, T.J., Whittaker, A., Bennett, F.M., Cornell, B.A., Makriyannis, A., 1994. Structure and orientation of the pore-forming peptide melittin, in lipid bilayers. J. Mol. Biol. 241, 456-466.

Spillner, E., Blank, S., Jakob, T., 2014. Hymenoptera allergens: from venom to "venome." Front. Immunol. 5, 1-7. https://doi.org/10.3389/fimmu.2014.00077.

Sukprasert, S., Rungsa, P., Uawonggul, N., Incamnoi, P., Thammasirirak, S., Daduang, J., Daduang, S., 2013. Purification and structural characterisation of phospholipase A1 (Vespapase, Ves a 1) from Thai banded tiger wasp (Vespa affinis) venom. Toxicon 61, 151-164. https://doi.org/10.1016/ j.toxicon.2012.10.024.

Szolajska, E., Poznanski, J., Ferber, M.L., Michalik, J., Gout, E., Fender, P., Bailly, I., Dublet, B., Chroboczek, J., 2004. Poneratoxin, a neurotoxin from ant venom. FEBS J. 271, 2127-2136.

Téné, N., Bonnafé, E., Berger, F., Rifflet, A., Guilhaudis, L., Ségalas-Milazzo, I., Pipy, B., Coste, A., Leprince, J., Treilhou, M., 2016. Biochemical and biophysical combined study of bicarinalin, an ant venom antimicrobial peptide. Peptides 79, 103-113.

Todokoro, Y. Yumen, I., Fukushima, K., Kang, S.-W., Park, J.-S., Kohno, T. Wakamatsu, K., Akutsu, H., Fujiwara, T., 2006. Structure of tightly membranebound mastoparan-X, a G-protein-activating peptide, determined by solidstate NMR. Biophys. J. 91, 1368-1379.

Tonk, M., Vilcinskas, A., Rahnamaeian, M., 2016a. Insect antimicrobial peptides: potential tools for the prevention of skin cancer. Appl. Microbiol. Biotechnol. 100, 7397-7405.

Tonk, M., Vilcinskas, A., Rahnamaeian, M., 2016b. Insect antimicrobial peptides: potential tools for the prevention of skin cancer. Appl. Microbiol. Biotechnol. 100, 7397-7405. https://doi.org/10.1007/s00253-016-7718-y.

Torres, A.F.C., Huang, C., Chong, C.M., Leung, S.W., Prieto-da-Silva, Á.R.B., Havt, A., Quinet, Y.P., Martins, A.M.C., Lee, S.M.Y., Rádis-Baptista, G., 2014. Transcriptome analysis in venom gland of the predatory giant ant dinoponera quadriceps: insights into the polypeptide toxin arsenal of hymenopterans. PLoS ONE 9. https://doi.org/10.1371/journal.pone.0087556.

Touchard, A., Aili, S.R., Fox, E.G.P., Escoubas, P., Orivel, J., Nicholson, G.M., Dejean, A., 2016a. The biochemical toxin arsenal from ant venoms. Toxins $8,1-28$. https:// doi.org/10.3390/toxins8010030.

Touchard, A., Brust, A., Cardoso, F.C., Chin, Y.K.Y., Herzig, V., Jin, A.H., Dejean, A., Alewood, P.F., King, G.F., Orivel, J., Escoubas, P., 2016b. Isolation and characterization of a structurally unique $\beta$-hairpin venom peptide from the predatory ant Anochetus emarginatus. Biochim. Biophys. Acta Gen. Subj. 1860, 2553-2562. https://doi.org/10.1016/j.bbagen.2016.07.027.

Touchard, A., Dauvois, M., Arguel, M.J., Petitclerc, F., Leblanc, M., Dejean, A., Orivel, J.Ô., Nicholson, G.M., Escoubas, P., 2014a. Elucidation of the unexplored biodiversity of ant venom peptidomes via MALDI-TOF mass spectrometry and its application for chemotaxonomy. J. Proteom. 105, 217-231. https://doi.org/ 10.1016/j.jprot.2014.01.009.

Touchard, A., Koh, J.M.S., Aili, S.R., Dejean, A., Nicholson, G.M., Orivel, J., Escoubas, P., 2015. The complexity and structural diversity of ant venom peptidomes is revealed by mass spectrometry profiling. Rapid Commun. Mass Spectrom. 29, 385-396. https://doi.org/10.1002/rcm.7116.

Touchard, A., Labrière, N., Roux, O., Petitclerc, F., Orivel, J., Escoubas, P., Koh, J.M.S. Nicholson, G.M., Dejean, A., 2014b. Venom toxicity and composition in three Pseudomyrmex ant species having different nesting modes. Toxicon 88, 67-76. https://doi.org/10.1016/j.toxicon.2014.05.022.

Van Vaerenbergh, M., Debyser, G., Devreese, B., de Graaf, D.C., 2014. Exploring the hidden honeybee (Apis mellifera) venom proteome by integrating a combinatorial peptide ligand library approach with FTMS. J. Proteom. 99, 169-178. https://doi.org/10.1016/j.jprot.2013.04.039.

Van Vaerenbergh, M., Debyser, G., Smagghe, G., Devreese, B., De Graaf, D.C., 2015. Unraveling the venom proteome of the bumblebee (Bombus terrestris) by integrating a combinatorial peptide ligand library approach with FT-ICR MS Toxicon 102, 81-88. https://doi.org/10.1016/j.toxicon.2013.10.002.

Varanda, E.A., Monti, R., Tavares, D.C., 1999. Inhibitory effect of propolis and bee venom on the mutagenicity of some direct-and indirect-acting mutagens. Teratog. Carcinog. Mutagen. 19, 403-413.

Vick, J.A., Shipman, W.H., Brooks Jr., R., 1974. Beta adrenergic and anti-arrhythmic effects of cardiopep, a newly isolated substance from whole bee venom. Toxicon 12, 139-142.

Vinzón, S.E., Pirpignani, M.L., Nowicki, C., De Jimènez Bonino, M.B., 2010. Molecular cloning and expression in Pichia pastoris of a hypoallergenic antigen 5. Protein Expr. Purif. 73, 23-30. https://doi.org/10.1016/j.pep.2010.03.029.

Vlasak, R., Kreil, G., 1984. Nucleotide sequence of cloned cDNAs coding for preprosecapin, a major product of queen-bee venom glands. Eur. J. Biochem. 145, 279-282.

Vos, B., Köhler, J., Müller, S., Stretz, E., Ruëff, F., Jakob, T., 2013. Spiking venom with rVes v. 5 improves sensitivity of IgE detection in patients with allergy to Vespula venom. J. Allergy Clin. Immunol. 131, 1225-1227. https://doi.org/10.1016/ j.jaci.2012.07.041.

Wanandy, T., Gueven, N., Davies, N.W., Brown, S.G.A., Wiese, M.D., 2015. Pilosulins: a review of the structure and mode of action of venom peptides from an Australian ant Myrmecia pilosula. Toxicon 98, 54-61. https://doi.org/10.1016/ j.toxicon.2015.02.013.

Wang, K., Yan, J., Zhang, B., Song, J., Jia, P., Wang, R., 2009. Novel mode of action of polybia-MPI, a novel antimicrobial peptide, in multi-drug resistant leukemic cells. Cancer Lett. 278, 65-72.

Wang, K., Zhang, B., Zhang, W., Yan, J., Li, J., Wang, R., 2008. Antitumor effects, cell selectivity and structure-activity relationship of a novel antimicrobial peptide

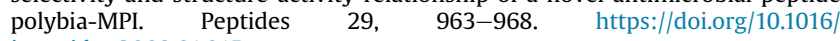
j.peptides.2008.01.015.

Webb, B., Sali, A., 2014. Protein structure modeling with MODELLER. In: Protein Structure Prediction. Springer, pp. 1-15.

Wemmer, D., Kallembach, N.R., 1982. Assignments and structure of apamin and related peptides in bee venom. Biochemistry 22, 1901-1906.

Wiese, M.D., Brown, S.G.A., Chataway, T.K., Davies, N.W., Milne, R.W., Aulfrey, S.J., Heddle, R.J., 2007. Myrmecia pilosula (Jack Jumper) ant venom: identification of allergens and revised nomenclature. Allergy Eur. J. Allergy Clin. Immunol. 62, 437-443. https://doi.org/10.1111/j.1398-9995.2007.01320.x.

Wu, Q.X., King, M.A., Donovan, G.R., Alewood, D., Alewood, P., Sawyer, W.H., Baldo, B.A., 1998. Cytotoxicity of pilosulin 1, a peptide from the venom of the jumper ant Myrmecia pilosula. Biochim. Biophys. Acta BBA Gen. Subj. 1425, 74-80.

Xin, Y., Choo, Y.M., Hu, Z., Lee, K.S., Yoon, H.J., Cui, Z., Sohn, H.D., Jin, B.R., 2009 Molecular cloning and characterization of a venom phospholipase A2 from the bumblebee Bombus ignitus. Comp. Biochem. Physiol. B Biochem. Mol. Biol. 154 195-202. https://doi.org/10.1016/j.cbpb.2009.06.003.

Xu, X., Nelson, J.W., 1993. Solution structure of tertiapin determined using nuclear magnetic resonance and distance geometry. Proteins Struct. Funct. Bioinforma. 17, 124-137.

Yang, H., Xu, X., Ma, D., Zhang, K., Lai, R., 2008. A phospholipase A1 platelet activator from the wasp venom of Vespa magnifica (Smith). Toxicon 51, 289-296. https:// doi.org/10.1016/j.toxicon.2007.10.003.

Yasuhara, T., Mantel, P., Nakajima, T., Piek, T., 1987. Two kinins isolated from an extract of the venom reservoirs of the solitary wasp Megascolia flavifrons. Toxicon 25, 527-535.

Yoon, H., Kim, M.J., Yoon, I., Li, D.X., Bae, H., Kim, S.K., 2015. Nicotinic acetylcholine receptors mediate the suppressive effect of an injection of diluted bee venom into the GV3 acupoint on oxaliplatin-induced neuropathic cold allodynia in rats. Biol. Pharm. Bull. 38, 710-714.

Yu, Y.-Q., Zhao, F., Chen, J., 2009. Activation of ERK1/2 in the primary injury site is required to maintain melittin-enhanced wind-up of rat spinal wide-dynamicrange neurons. Neurosci. Lett. 459, 137-141.

Zelezetsky, I., Pag, U., Antcheva, N., Sahl, H.-G., Tossi, A., 2005. Identification and optimization of an antimicrobial peptide from the ant venom toxin pilosulin. Arch. Biochem. Biophys. 434, 358-364.

Zhou, Z., Yang, H., Xu, X., Wang, X., Lai, R., 2006. The first report of kininogen from invertebrates. Biochem. Biophys. Res. Commun. 347 (4), 1099-1102.

Zhu, S., Darbon, H., Dyason, K., Verdonck, F., Tytgat, J.A.N., 2003. Evolutionary origin of inhibitor cystine knot peptides. FASEB J. 17, 1765-1767.

Ziai, M., Russek, S., Wang, H., Beer, B., Blume, A.J., 1990. Mast cell degranulating peptide: a multi-functional neurotoxin. J. Pharm. Pharmacol. 42, 457-461. 